Linköping Studies in Science and Technology

Dissertation No. 1628

\title{
Synthesising Metal Oxide Materials and Their Composite Nanostructures for Sensing and Optoelectronic Device Applications
}

\section{Kimleang Khun}

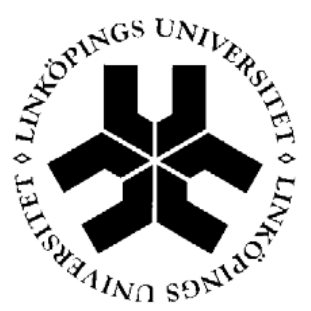

\section{Linköping University} INSTITUTE OF TECHNOLOGY

Physical Electronics and Nanotechnology Division

Department of Science and Technology (ITN)

Campus Norrköping, Linköping University

SE-60174 Norrköping Sweden 
Copyright (c) 2015 by Kimleang Khun

khun.kimleang@rupp.edu.kh

kimleang_khun@yahoo.com

Printed by LiU-Tryck, Linköping University

Linköping, Sweden, 2015

Dissertations No. 1628

ISBN: 978-91-7519-207-9

ISSN: 0345-7524 
Dedicated to:

My family and teachers 



\title{
Synthesising Metal Oxide Materials and Their Composite Nanostructures for Sensing and Optoelectronic Device Applications
}

\author{
Kimleang Khun \\ Department of Science and Technology, Linköping University, Sweden, 2015
}

\begin{abstract}
Research on nanomaterials has been revolutionized in the last few years because of the attractive properties they have in comparison to the bulk phase of similar materials. These properties are physical, chemical, catalytic and optical. Among these nanomaterials, the metal oxide nanostructures have become of particular interest to scientists for the development of different optical, biochemical and biomedical nanodevices. In the present research work using the advantageous features of nanotechnology, high performance nanodevices for optoelectronics with a wide band gap compound nanostructure and highly sensitive sensor devices have been demonstrated. The nanotechnology is used to fabricate sensitive and precise nanodevices based on nanomaterials for the application of sensing.

Among metal oxide nanostructures, $\mathrm{ZnO}, \mathrm{CuO}$ and $\mathrm{NiO}$ are attractive materials because of their unique properties; their high surface area to volume ratio, their energy band gap of $3.37 \mathrm{eV}$, $1.2 \mathrm{eV}$ and $3.7 \mathrm{eV}$, respectively, biocompatibility, high electron mobility, fast electron transfer rate and they are environmental-friendly in many applications. When used in sensor devices, nanomaterials have indicated high selectivity for possible use to detect the various analytes even in small volumes. Metal oxide nanostructures have shown to be good for optoelectronic nanodevices because of their electrical characteristics, high optical absorption and low-processing temperature.

In this thesis, the synthesis of different morphologies of metal oxide semiconductor nanostructures and their composite using the hydrothermal method are demonstrated for various applications. This thesis is divided into three parts:

In the first part of this research work, the fabrication of well-aligned $\mathrm{ZnO}$ nanorods using different concentrations of composite seed layer of inorganic and organic materials when using the hydrothermal growth method is presented. The effect of the composite seed layer on the
\end{abstract}


alignment, density and optical properties of the grown $\mathrm{ZnO}$ nanorods is investigated (paper I). Utilizing the advantage of $\mathrm{ZnO}$ nanostructure, a comparative study of $\mathrm{ZnO}$ nanorods and thin films for chemical and biosensing application was carried out. The $\mathrm{ZnO}$ nanorods and thin films were functionalized with strontium ionophore membrane, immobilized the galactose oxidase and lactate oxidase for determining the strontium ions, D-galactose and L-lactic acid, respectively (paper II).

In the second part, the effects of different urea concentrations on the morphology of $\mathrm{CuO}$ nanostructures is studied as described in paper III. Moreover, $\mathrm{CuO}$ nanoflowers were functionalized with cadmium ion ionophore for the detection of $\mathrm{Cd}$ ions, while $\mathrm{CuO}$ nanosheets were grown by the low temperature growth method and were used for the development of a nonenzymatic glucose sensor, respectively (Paper IV).

In the last part of this thesis, composite nanostructures of $\mathrm{CuO} / \mathrm{ZnO}$ and $\mathrm{NiO} / \mathrm{ZnO}$ were applied to develop dopamine sensor and fast sensitive UV photodetector, respectively. A nanohybrid of $\mathrm{CuO} / \mathrm{ZnO}$ nanostructure was used as a non-enzymatic electrode to detect dopamine by cyclic voltammetry and amperometric techniques (Paper V). In paper VI, we have demonstrated a strong UV absorption from $\mathrm{ZnO}$ nano-sheets achieved by the supramolecules-assisted growth solution using the hydrothermal method. The synthesized nanomaterial was used in the fabrication of UV photodetector based on p-NiO/ n- $\mathrm{ZnO}$ heterostructures.

Keywords: Hydrothermal method; metal oxide nanostructure; composite seed solution; wellaligned $\mathrm{ZnO}$ nanorods; composite structures; glucose and dopamine non-enzymatic sensors; heavy metals; supramolecular; UV photodetector sensor. 


\section{Acknowledgment}

This thesis is the one of the most important part in my journey of life. During this journey, I have not traveled alone; there are many people who supported and encouraged me for the successful completion of this high academic degree. Furthermore, I would like to thank all those people who made my journey successful and a memorable one. Truly, words are not enough to express my appreciation to all of them.

First, I would like to express my sincere gratitude to my supervisor, Prof. Dr. Magnus Willander, for accepting me to join his research group. Thanks for giving me freedom to develop my research ideas, for showing me different ways to solve research problems. He have been always available whenever I need his help and encouragement. I would also like to thank my cosupervisor, associate professor Omer Nour, for his positive interest, encouragement and support throughout this journey.

I would like to thank all of my co-authors, especially Dr. Zafar Hussain Ibupoto for his valuable discussions and encouragement during this research work. I am also thankful to our research administrator Ann-Christin Norén for her kind administrative help and cooperation.

I am thankful to the International Science Programme (ISP), Uppsala University, Sweden and Royal University of Phnom Penh, Cambodia for financial support throughout my Ph.D. studies.

I would like to thank all the present and previous members of the Physical Electronics and Nanotechnology Group and my entire colleagues for their cooperation and moral support.

Finally, I am deeply thankful to my family for their good wishes and support during my difficult time of Ph.D. studies. I appreciate my both sisters for their guidance and encouragements. Most importantly, my parents, it was their dream that made me successful in this journey.

Kimleang Khun

Norrköping, January 2015 



\section{List of publication included in this thesis}

\section{Paper I}

Fabrication of well-aligned $\mathrm{ZnO}$ nanorods using a composite seed layer of $\mathrm{ZnO}$ nanoparticles and chitosan polymer

K. Khun, Z.H. Ibupoto, M.S. AlSalhi, M. Atif, A.A. Ansari and M. Willander Materials 2013, 6, 4361-4374

\section{Paper II}

Comparative study of $\mathrm{ZnO}$ nanorods and thin films for chemical and biosensing applications and the development of $\mathrm{ZnO}$ nanorods based potentiometric strontium ion sensor

K. Khun, Z. H. Ibupoto, C.O. Chey, J. Lu, O. Nur and M. Willander

Applied Surface Science 2013, 268, 37-43

\section{Paper III}

Urea assisted synthesis of flower like $\mathrm{CuO}$ nanostructures and their chemical sensing application for the determination of cadmium ions

K. Khun, Z. H. Ibupoto and M. Willander

Electroanalysis 2013, 25, 1425 - 1432

\section{Paper IV}

Synthesis of novel $\mathrm{CuO}$ nanosheets and their non-enzymatic glucose sensing applications

Z.H. Ibupoto, K. Khun, V. Beni, X. Liu and M. Willander

Sensors 2013, 13, 7926-7938

\section{Paper V}

An electrochemical dopamine sensor based on the $\mathrm{ZnO} / \mathrm{CuO}$ nano-hybrid structures K. Khun, Z.H. Ibupoto, X. Liu, N. A. Mansor, A.P.F. Turner, V. Beni, and M. Willander Journal of Nanoscience and Nanotechnology 2014, 14, 6646-6652 


\section{Paper VI}

Supramolecules-assisted ZnO nanostructures growth and their UV photodetector application

K. Khun, S. Elhag, Z.H. Ibupoto, V. Khranovsky, O. Nur and M. Willander Submitted manuscript 


\section{Related papers not included in this thesis}

1. Selective zinc ion detection by functionalized $\mathrm{ZnO}$ nanorods with ionophore Z.H. Ibupoto, S.M. Usman Ali, C.O. Chey, K. Khun, O. Nur and M. Willander Journal of Applied Physics 2011, 110, 104702

2. ZnO nanorods based enzymatic biosensor for selective determination of penicillin Z.H. Ibupoto, S.M. Usman Ali, K. Khun, C.O. Chey, O. Nur and M. Willander Biosensors 2011, 1, 153-163.

3. L-ascorbic acid biosensor based on immobilized enzyme on $\mathrm{ZnO}$ nanorods Z.H. Ibupoto, S.M. Usman Ali, K. Khun and M. Willander, Journal of Biosensor Bioelectronics 2011, 2, 3

4. Selective thallium (I) ion sensor based on functionalized $\mathrm{ZnO}$ nanorods Z.H. Ibupoto, S.M. Usman Ali, K. Khun and M. Willander Journal of Nanotechnology 2012, 2012, Article ID 619062

5. Development of a disposable potentiometric antibody immobilized $\mathrm{ZnO}$ nanotubes based sensor for the detection of $\mathrm{C}$-reactive protein

Z.H. Ibupoto, N. Jamal, K. Khun and M. Willander

Sensors and Actuators B, Chemical 2012, 166, 809-814

6. Potentiometric glucose sensor based on the glucose oxidase immobilized iron ferrite magnetic particle/chitosan composite modified gold coated glass electrode K. Khun, Z.H. Ibupoto, J. Lu, M.S. AlSalhi, M. Atif, A.A. Ansari and M. Willander, Sensors and Actuators B, Chemical 2012, 173, 698-703.

7. Electrochemical L-lactic acid sensor based on immobilized $\mathrm{ZnO}$ nanorods with lactate oxidase

Z.H. Ibupoto, S.M. Usman Ali, K. Khun and M. Willander Sensors 2012, 12, 2456-2466.

8. Indirect determination of mercury ion by inhibition of a glucose biosensor based on ZnO nanorods

C. O. Chey, Z. H. Ibupoto, K. Khun, O. Nur and M. Willander Sensors 2012, 12, 15063-15077 
9. Iron ion sensor based on functionalized $\mathrm{ZnO}$ nanorods

K. Khun, Z.H. Ibupoto, S.M. Usman Ali, C.O. Chey, O. Nur and M. Willander Electroanalysis 2012, 24, 521-528

10. Development of galactose biosensor based on functionalized $\mathrm{ZnO}$ nanorods with galactose oxidase

K. Khun, Z.H. Ibupoto, O. Nur, and M. Willander Journal of Sensors 2012, 2012, Article ID 696247

11. Potentiometric creatinine biosensor based on $\mathrm{ZnO}$ nanowires

C.O. Chey, S.M. Usman Ali, Z.H. Ibupoto, K. Khun, O. Nur and M. Willander Journal of Nanoscience Letters 2012, 2, 24

12. Growth and characterization of $\mathrm{ZnO}$ nanowires for optical applications M.S. AlSalhi, M. Atif, A.A. Ansari, K. Khun, Z.H. Ibupoto and M. Willander Laser physics 2013, 23, Article ID 065602

13. A selective iodide ion sensor electrode based on functionalized $\mathrm{ZnO}$ nanotubes Z.H. Ibupoto, K. Khun and M. Willander Sensors 2013, 13, 1984-1997

14. A potentiometric immunosensor based on silver nanoparticles decorated $\mathrm{ZnO}$ nanotubes for the selective detection of d-dimer

Z.H. Ibupoto, N. Jamal, K. Khun, X. Liu and M. Willander

Sensors and Actuators B, Chemical 2013, 182, 104-111

15. Hydrothermal growth of vertically aligned $\mathrm{ZnO}$ nanorods using a biocomposite seed layer of ZnO nanoparticles

Z.H. Ibupoto, K. Khun, M. Eriksson, M. AlSalhi, M. Atif, A. Ansari and M. Willander Materials 2013, 6, 3584-3597

16. Well aligned $\mathrm{ZnO}$ nanorods growth on the gold coated glass substrate by aqueous chemical growth method using seed layer of $\mathrm{Fe}_{3} \mathrm{O}_{4}$ and $\mathrm{Co}_{3} \mathrm{O}_{4}$ nanoparticles

Z.H. Ibupoto, K. Khun, J. Lu, X. Liu, M.S. AlSalhi, M. Atif, A.A. Ansari and M. Willander

Journal of Crystal Growth 2013, 368, 39-46 
17. Hydrothermal synthesis of nanoclusters of $\mathrm{ZnS}$ comprised on nanowires

Z.H. Ibupoto, K. Khun, X. Liu, M. Willander

Nanomaterials 2013, 3, 564-571

18. Non-enzymatic glucose sensor based on the novel flower like morphology of nickel oxide

Z.H. Ibupoto, K. Khun, V. Beni and M. Willander

Soft Nanoscience Letters 2013, 3, 46-50

19. Selective lead ion sensor based on the $\mathrm{CuO}$ nanoshuttles

Z.H. Ibupoto, K. Khun, M. Willander,

Sensors Letters 2013, 11, 2049-2054

20. Development of sensitive glucose sensor using $\mathrm{CuO}$ functionalized carbon nanotubes based nanochip

M. Willander, K. Khun, X. Liu, J. Lu, W. Khalid and Z. H. Ibupoto

Chemical Sensors 2014, 4, 5

21. A potentiometric biosensor for the detection of notch 3 using functionalized $\mathrm{ZnO}$ nanorods

Z.H. Ibupoto, K. Khun, X. Liu and M. Willander

Journal of Nanoscience and Nanotechnology 2014, 14, 1-7

22. Development of a pH sensor using nanoporous nanostructures of $\mathrm{NiO}$

Z.H. Ibupoto, K. Khun, M. Willander

Journal of Nanoscience and Nanotechnology 2014, 14, 1-5

23. A selective potentiometric copper (II) ion sensor based on the functionalized ZnO nanorods

K. Khun, Z.H. Ibupoto, X. Liu, O. Nur, M. Willander, B. Danielsson

Journal of Nanoscience and Nanotechnology 2014, 14, 1-9

24. Hydrothermal growth of $\mathrm{CuO}$ nanoleaf structures using cetyltrimethylammonium bromide surfactant and their mercuric ion detection application

Z.H. Ibupoto, K. Khun, M. Willander

Journal of Nanoscience and Nanotechnology 2014, 14, 1-7 
25. Development of fast and sensitive ultraviolet photodetector using p-type $\mathrm{NiO} / \mathrm{n}$-type $\mathrm{TiO}_{2}$ heterostructures

K. Khun, Z.H. Ibupoto and M. Willander

Physica Status Solidi A 2013, 210, 2720-2724

26. The Synthesis of $\mathrm{Co}_{3} \mathrm{O}_{4}$ Nanowires; Structural Characterization and their Application as Glucose Non-enzymatic Sensor

K. Khun, Z.H. Ibupoto, X. Liu, V. Beni, M.Willander

Submitted manuscript

27. Ethylene glycose-assisted ZnO nanorods growth and their Schottky diode for UV photodetector application

K. Khun, S. Elhag, V. Khranovskyy, O. Nur and M. Willander

Manuscript

\section{Review articles}

1. ZnO based potentiometric and amperometric nanosensor

M. Willander, K. Khun and Z.H. Ibupoto

Journal of Nanoscience and Nanotechnology 2014, 14, 1-12

2. Metal oxide nanosensor using polymeric membranes, enzymes and antibodies receptors as ion and molecular recognition elements

M. Willander, Z.H. Ibupoto, K. Khun

Sensors 2014, 14, 8605-8632

\section{Invited articles}

1. UV detectors and LEDs in different metal oxide nanostructures

M. Willander, M.A. Abbasi, K. Khun, M. Hussain, Z.H. Ibupoto, and O. Nur Proceedings of SPIE 2014, 8987, 89871Y 


\section{Conference papers}

1. Fabrication and characterization of light emitting diodes based on $\mathrm{n}$-ZnO nanotubes grown by a low temperature aqueous chemical method on $\mathrm{p}-\mathrm{GaN}$

C.O. Chey, S. M. Usman Ali, Z.H. Ibupoto, C. Sann, K. Khun, K. Meak, O. Nur and M. Willander

CLV-02, Vinh City, 2011, Vietnam

2. Synthesis of $\mathrm{ZnO}$ nanorods in PBS solution, their morphological and optical characterization

K. Khun, Z.H. Ibupoto, S. Chen, W.M. Chen, I.A. Buyanova, M. Willander, CLV-03, Phnom Penh, 2013, Cambodia 



\section{List of abbreviations}

\begin{tabular}{|c|c|}
\hline Abbreviation & Word or Phrase \\
\hline AFM & Atomic Force Microscope \\
\hline $\mathrm{CuO}$ & Copper (II) Oxide \\
\hline I-V & Current Voltage \\
\hline $\mathbf{C V}$ & Cyclic Voltammetric \\
\hline EDX & Energy Dispersive X-ray \\
\hline EHT & Extra High Tension or high voltage \\
\hline FESEM & Field Emission Scanning Electron Microscope \\
\hline FTO & Fluorine Doped Tin Oxide \\
\hline FTIR & Fourier Transform Infrared Spectroscopy \\
\hline GCGS & Gold Coated Glass Substrate \\
\hline HMT & Hexamethylenetetramine \\
\hline JCPDS & Joint Committee on Powder Diffraction Standards \\
\hline Mag & Magnification \\
\hline NRs & Nanorods \\
\hline NSs & Nanostructures \\
\hline $\mathrm{NiO}$ & Nickel Oxide \\
\hline $1 D$ & One dimension \\
\hline $\mathbf{O}_{\mathbf{Z n}}$ & Oxygen anti-site \\
\hline $\mathbf{O}_{\mathbf{i}}$ & Oxygen interstitial \\
\hline $\mathbf{V}_{\mathbf{0}}$ & Oxygen vacancies \\
\hline PBS & Phosphate Buffer Solution \\
\hline PL & Photoluminescence \\
\hline PVC & Polyvinyl Chloride \\
\hline pH & Power of Hydrogen \\
\hline TEM & Transmission Electron Microscope \\
\hline TOSs & Transparent Oxide Semiconductors \\
\hline UV & Ultraviolet \\
\hline WD & Working Distance \\
\hline XRD & X-Ray Diffraction \\
\hline XPS & X-ray Photoelectron Spectroscopy \\
\hline Zno & Zinc anti-site \\
\hline $\mathbf{Z n}_{\mathbf{i}}$ & Zinc interstitial \\
\hline ZnO & Zinc Oxide \\
\hline $\mathbf{V Z n}_{\mathbf{Z n}}$ & Zinc vacancies \\
\hline
\end{tabular}




\section{List of units}

\begin{tabular}{ll}
\hline Symbol & Unit \\
\hline $\mathbf{A}$ & Ampere \\
$\mathbf{A}$ & Angstrom \\
${ }^{\circ} \mathbf{C}$ & Degree centigrade \\
$\mathbf{e V}$ & Electronvolt \\
$\mathbf{g}$ & Gram \\
$\mathbf{H z}$ & Hertz \\
$\mathbf{k e V}$ & Kiloelectronvolt \\
$\mathbf{k H z}$ & Kilohertz \\
$\mathbf{k V}$ & Kilovolt \\
$\boldsymbol{\mu} \mathbf{m}$ & Micrometer \\
$\mathbf{m b a r}$ & Millibar \\
$\mathbf{m g}$ & milligram \\
$\mathbf{m l}$ & Milliliters \\
$\mathbf{m M}$ & Millimolar \\
$\mathbf{m V}$ & Millivolt \\
$\mathbf{M}$ & Molar \\
$\mathbf{n m}$ & Nanometer \\
$\mathbf{N}$ & Newton \\
$\mathbf{\Omega}$ & Ohm \\
$\mathbf{r p m}$ & Revolutions per minute \\
$\mathbf{V}$ & Volt \\
$\mathbf{W}$ & Watt \\
\hline & \\
\hline
\end{tabular}




\section{List of figures}

Figure 2. 1: The hexagonal wurtzite structure of the $\mathrm{ZnO}$ semiconductor. ...............................8

Figure 2. 2: Schematic diagram of $1 \mathrm{D} \mathrm{ZnO}$ NSs grown on a substrate, along the c-axis............8

Figure 2. 3: Energy band diagram showing some of the defect levels in $\mathrm{ZnO}$ structures [73]....9

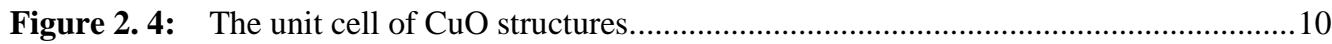

Figure 2. 5: The unit cell of a NiO structures. ........................................................................12

Figure 3. 1: Schematic diagram of gold or silver coated on a glass slide. ...............................14

Figure 3. 2: Schematic diagram of the growth of metal oxide nanostructures by the hydrothermal method. 16

Figure 3. 3: FESEM images of CuO NSs: (a) nanoflowers, and (b) nanosheets grown using the hydrothermal method [55]. 17

Figure 3. 4: FESEM images of NiO NSs: (a) nanowalls and (b) nanoflowers [108]. ..............17

Figure 3. 5: $\mathrm{XRD}$ pattern of $\mathrm{ZnO}$ nanorods grown using the hydrothermal method [109]. ......18

Figure 3. 6: FESEM top view and cross section images of $\mathrm{ZnO}$ nanorods [109]....................20

Figure 3. 7: TEM images of $\mathrm{ZnO}$ nanorods grown using the hydrothermal method [109]......21

Figure 3. 8: XPS spectra of $\mathrm{CuO}$ nanosheets grown using the hydrothermal method [110]....23

Figure 3. 9: $\quad \mathrm{PL}$ spectrum of $\mathrm{ZnO}$ nanorods at room temperatures $\left(25^{\circ} \mathrm{C}\right)$ [109]....................24

Figure 3. 10: AFM image of $\mathrm{ZnO}$ seed nanoparticle on the gold coated substrate [109]...........25

Figure 4. 1: FESEM images of the ZnO NRs grown with composite seed layer at different amounts of $\mathrm{ZnO}$ nanoparticles: (a) $0 \mathrm{mg}$, (b) $10 \mathrm{mg}$, (c) $30 \mathrm{mg}$ and (d) $50 \mathrm{mg}$ [112]

Figure 4. 2: FESEM images of the ZnO NRs grown with composite seed layer at different amounts of $\mathrm{ZnO}$ nanoparticles: (a) $70 \mathrm{mg}$ and (b) $90 \mathrm{mg}$; (c) the cross sectional image of the $\mathrm{ZnO}$ NRs growth using $90 \mathrm{mg}$ of $\mathrm{ZnO}$ nanoparticles and (d) The EDX spectra of the ZnO NRs using $70 \mathrm{mg}$ of $\mathrm{ZnO}$ nanoparticles [112] 30

Figure 4. 3: HRTEM image of the $\mathrm{ZnO}$ nanorods grown with $70 \mathrm{mg}$ of $\mathrm{ZnO}$ nanoparticle [112]

Figure 4. 4: $\mathrm{PL}$ data of the $\mathrm{ZnO}$ NRs grown with the composite seed layer using $70 \mathrm{mg}$ of $\mathrm{ZnO}$ nanoparticle and the seed layer of zinc acetate dihydrate [112] .32

Figure 4. 5: Top view FESEM image of ZnO NSs (a) NRs and (b) thin films [109]. .33 
Figure 4. 6: Schematic diagram of potentiometric measurement of immobilized ZnO nanorods and thin films based on a chemical and biosensing application. 34

Figure 4. 7: The calibration curve of the strontium ion sensor based on immobilized $\mathrm{ZnO}$ (a) nanorods and (b) thin films [109]. .34

Figure 4. 8: FESEM image of CuO nanoflowers synthesized by adding different amounts of urea in the growth solution: (a) $0.1 \mathrm{~g}$, (b) $0.4 \mathrm{~g}$, (c) $0.8 \mathrm{~g}$ and (d) $1.0 \mathrm{~g}$ [55].........36

Figure 4. 9: (a) The calibration curve of the proposed $\mathrm{Cd}^{2+}$ sensor and (b) the time response curve measured at a concentration $1.0 \times 10^{-6} \mathrm{M}$ [55]. .37

Figure 4. 10: FESEM images of $\mathrm{CuO}$ nanosheets (a) low magnification image and (b) high magnification image [110]

Figure 4. 11: (a) The full XPS spectra of $\mathrm{CuO}$ nanosheets grown using the hydrothermal method, (b) Cu 2p XPS spectra and (c) O 1s XPS spectra [110]. 39

Figure 4. 12: (a) The calibration curve of the non-enzymatic electrode based on the glucose and (b) the response time curve of the proposed glucose sensor with successive addition of glucose in $0.10 \mathrm{M} \mathrm{NaOH}$ solution [110]

Figure 4. 13: FESEM image of $\mathrm{ZnO} / \mathrm{CuO}$ nano-hybrid structures (a) top view and (b) cross sectional view [107].

Figure 4. 14: $\mathrm{XRD}$ pattern of $\mathrm{ZnO} / \mathrm{CuO}$ composite NSs grown using the hydrothermal method [107].

Figure 4. 15: (a) The current response for the fabricated dopamine sensor versus the square root of the scan rate in $2.0 \mathrm{mM}$ concentration of dopamine in PBS and (b) the CV curve at a scan rate of $10 \mathrm{mV}^{-1}$ of the fabricated sensor at different concentrations of dopamine [107]

Figure 4. 16: (a) The calibration curve of the current versus dopamine concentration by amperometric measurement at an applied potential of $0.50 \mathrm{~V}$ and (b) the interference response of the fabricated dopamine sensor for $1.0 \mathrm{mM}$ of glucose, uric acid and ascorbic acid [107].

Figure 4. 17: FESEM images of metal oxide nanostructures: (a) $\mathrm{ZnO}$ nanorods, (b) $\mathrm{ZnO}$ nanosheets, (c) $\mathrm{NiO}$ nanoflowers and (d) cross section of $\mathrm{ZnO} / \mathrm{NiO}$ nanocomposite. 
Figure 4. 18: (a) XRD pattern of $\mathrm{ZnO} / \mathrm{NiO}$ nanocomposite growth on FTO and (b) the PL spectra of ZnO nanosheets (blue solid line) and ZnO NRs (red dotted line). ........46

Figure 4. 19: Plot of $(\alpha h v)^{2}$ versus the photon energy for the ZnO NRs and nanosheets. ..........46

Figure 4. 20: (a) The I-V data obtained in the dark current (solid red line) and under UV light (dotted black line), (b) The time response of $\mathrm{ZnO} / \mathrm{NiO} \mathrm{UV}$ photodetector in conditions of on/off UV light. 47 


\section{List of tables}

Table 2. 1: Summary of the basic physical properties of $\mathrm{ZnO}$ at room temperatures [59, 74,

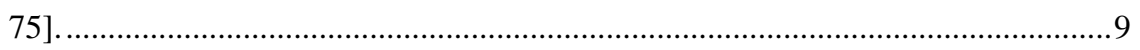

Table 2. 2: $\quad$ Summary of the basic physical properties of the CuO material [82-84]................11

Table 2. 3: Summary of the basic physical and chemical properties of the NiO material [102, 103].. 12

Table 4. 1: Summary of results for the comparative study of $\mathrm{ZnO}$ nanorods and thin films, for

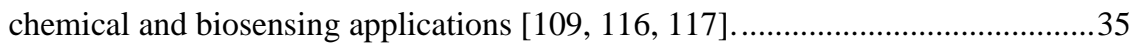




\section{Table of contents}

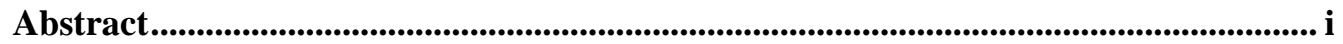

Acknowledgment........................................................................................................................... iii

List of publication included in this thesis .......................................................................... v

Related papers not included in this thesis ....................................................................... vii

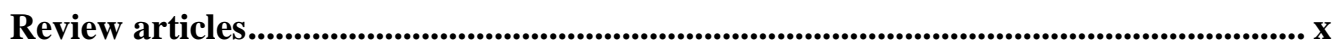

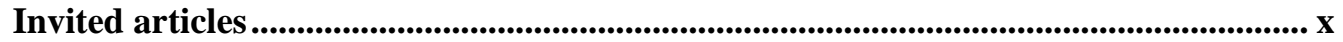

Conference papers ..................................................................................................................... xi

List of abbreviations .............................................................................................................. xiii

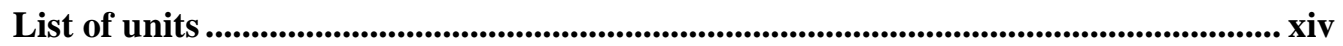

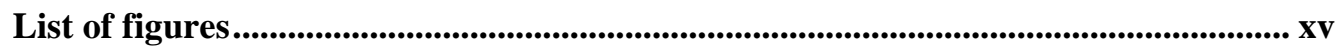

List of tables........................................................................................................................... xviii

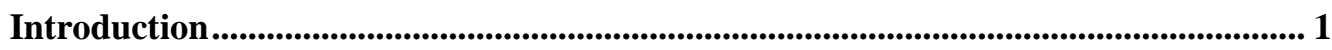

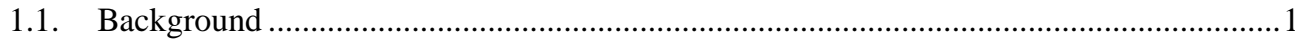

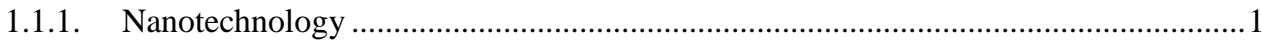

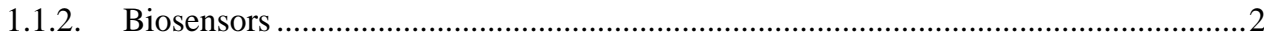

1.1.3. Metal oxide semiconductor nanostructures...............................................................

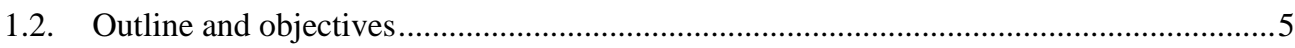

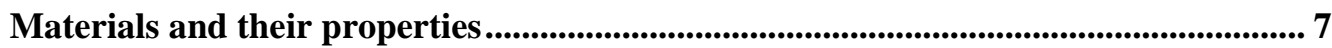

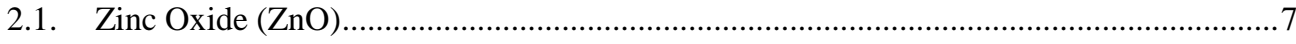

2.2. Copper (II) Oxides (CuO) ..................................................................................... 10

2.3. Nickel Oxide ( $\mathrm{NiO})$.................................................................................................11

Synthesis and characterization of metal oxide nanostructures .................................... 13

3.1. The preparation of the substrate .......................................................................................13

3.1.1. Standard substrate wet cleaning method ...................................................................13

3.1.2. The deposition of the gold or silver thin layer on glass substrates ...........................13

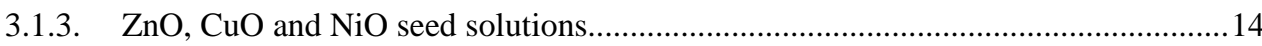

3.2. Fabrication of metal oxide nanostructures on gold coated glass substrate (GCGS) using the hydrothermal method ........................................................................................... 15

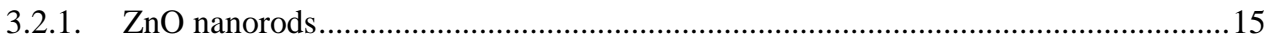


3.2.2. The synthesis of $\mathrm{CuO}$ nanoflowers and nanosheets onto GCGS ............................16

3.2.3. The fabrication of nickel oxide (NiO) nanowalls on the GCGS .............................17

3.3. The characterization tools for the study of metal oxide nanostructures..........................18

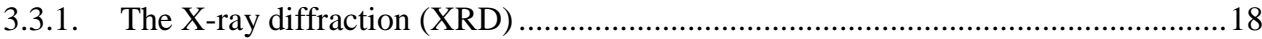

3.3.2. The field emission scanning electron microscope (FESEM) ..................................19

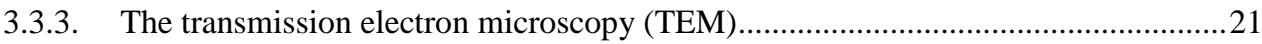

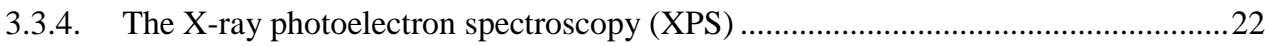

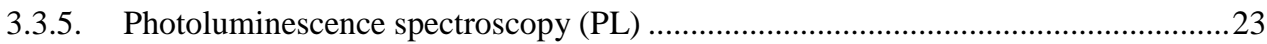

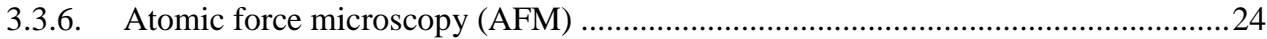

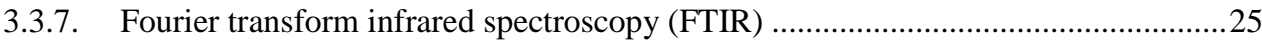

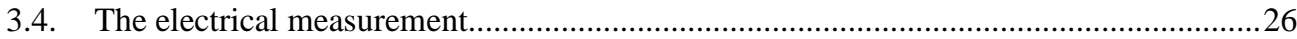

Fabrication and characterization of devices

4.1. The growth of well-aligned $\mathrm{ZnO} \mathrm{NRs}$ and thin films based on strontium ion sensing application

4.1.1. Fabrication of well-aligned $\mathrm{ZnO}$ NRs using $\mathrm{ZnO}$ nanoparticles and chitosan polymer as a composite seed layer (paper I).

4.1.2. The comparative study of $\mathrm{ZnO} \mathrm{NRs}$ and thin films, for chemical and biosensing applications and the development of a $\mathrm{ZnO}$ NRs based potentiometric strontium ion sensor (paper II)

4.2. The synthesis of novel $\mathrm{CuO}$ nanostructures and their chemical and biosensing application 35

4.2.1. Urea assisted synthesis of CuO NSs and their chemical sensing application for the determination of cadmium ions (paper III) 36

4.2.2. The growth of $\mathrm{CuO}$ nanosheets and their non-enzymatic glucose sensor application (paper IV)

4.3. The growth $\mathrm{CuO} / \mathrm{ZnO}$ and $\mathrm{NiO} / \mathrm{ZnO}$ nanocomposite and their sensor and $\mathrm{UV}$ photoreaction application

4.3.1. An electrochemical dopamine sensor based on the $\mathrm{ZnO} / \mathrm{CuO}$ nano-hybrid structures (paper V)

4.3.2. Supramolecules-assisted $\mathrm{ZnO}$ NSs grown for the fabrication of a sensitive UV photodetector (paper VI) 
Table of contents

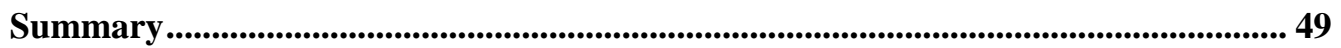

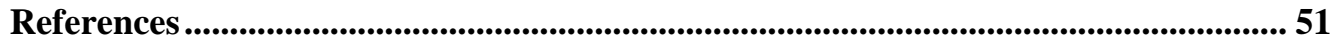





\section{Chapter 1}

\section{Introduction}

Nanomaterials are now being used for a wide variety of device applications because of their unique properties. Several nanodevices have been fabricated for different fields such as electronics, chemical sensing, biosensing and health care. Nanomaterials are expected to be useful in the near future for applications that include medicine, biotechnology and for the food industry. Nanotechnology based devices have many advantageous features but there are concerns about their effect on both human health and environment [1]. The classification and understanding of the impact of nanomaterials is very important for the development of future based industrial applications.

\subsection{Background}

\subsubsection{Nanotechnology}

Nanotechnology describes the manipulation of matter on an atomic, molecular and supramolecular level (dimension from 1 to $100 \mathrm{~nm}$ ); to achieve the fabrication of new devices with superior properties [2, 3]. The idea of nanotechnology was presented by the American Physicist Richard Feynman in his lecture “There is Plenty of Room at the Bottom” at an American Physical Society meeting in Caltech in 1959. He had suggested that it will be possible to successfully manipulate and control materials on the atomic and molecular size for electronic and mechanical systems with nanoscale components; the development of technologies into such small systems would be created from combined fields such as chemistry, biology and physics [4]. In 1974, the first term "nanotechnology" was introduced by the Japanese Scientist Norio Taniguchi at The International Conference on Production Engineering, Tokyo, from 26-29 August. He presented the process of using semiconductors, such as thin film deposition and ion beam milling characterized at a level of $1 \mathrm{~nm}$ length. He further defined "nanotechnology" as the process of separation, integration and deformation of the materials by using one atom or one molecule [5, 6]. In the 1980s, the idea of nanotechnology had been applied in the invention of instruments such as a scanning tunneling microscope (STM), developed by Gerd Binning and Heinrich Rohrer. They received the Nobel Prize in Physics in 1986 [7, 8]. It was also used in the development of the atomic force microscope (AFM), invented by Calvin Quate and Christoph 
Gerber. In 1985 the fullerenes $\left(\mathrm{C}_{60}\right)$ was investigated by Harry Kroto, Richard Smalley and Robert Curl [9, 10]. Carbon nanotubes were discovered by L. V. Radushkevich and V. M. Lukyanovich in 1952 [11]. They published a clear image of carbon nanotubes with a diameter of $50 \mathrm{~nm}$ in the Soviet Journal of Physical Chemistry, but this discovery was unnoted because of the fact that it was published in Russian language during the cold war.

The research and development of nanomaterials and the nanotechnology fields have been greatly improved by the fabrication of nanodevices and their unique properties of nanomaterials, such as:

1. The large surface area to volume ratio increases the surface reactivity around nanomaterials. This is useful for chemical and biosensing applications.

2. Increased optical emission and absorption due to electron transfer from one state to another state. This phenomenon is useful for optoelectronic nanodevices.

\subsubsection{Biosensors}

A biosensor is an analytical device, which combines a sensitive biological component such as tissue, microorganisms, enzymes, antibodies, cellular structure, nucleic acid etc. with a physicochemical detector [12]. A biosensor tool converts the signal of the interaction between the analyte and the biological element into an easily detectable signal such as light, voltage, current, mass, etc. Biotransducers are made from sensitive elements such as optical, electrochemical, piezoelectric, electronic, gravimetric and pyroelectric materials [13]. Biosensors have attractive applications in human care, food industry, controlling the environment and for genetic applications. The greatest advantage of such biosensors are in their application being user friendly, having a fast response, high sensitivity, strong selectivity, and their practical use for real sampling [14-17]. The first oxygen sensor was invented by Leland C. Clark Jr in 1956, for oxygen detection in blood, water and other liquids [14]. He is also known as the father of the chemical-/bio-sensor field [18]. In 1962, his idea was to develop the experiment of an immobilized glucose oxidase with a membrane on a Clark electrode to determine the glucose concentration with decreased oxygen concentration [15]. At the end of 1967 glucose detection based on an independent and operational enzymatic electrode was developed [16]. The first investigation of potentiometric urea detection, based on urease with an ammonium selective membrane immobilized electrode, was published in 1969 [17]. In 1970, the pH ion selective field effect transistors electrodes were demonstrated [19]. By the end of the 1980s several scientists 
were conducting experiments that focused on the biosensor field, to develop different methods for the determination of various ions and analytes [20]. Among the different biosensors, biosensors based on nanomaterials are very useful for biomolecular recombination pathogenic diagnosis and environmental monitoring applications [20-23]. The nano-size of a surface and the fast interaction with the target analytes on the surface make biosensors based on a nanomaterial able to detect analytes even in small volumes. Nanomaterials also have the ability to be inserted inside a biological cell. This property of a nanomaterial demonstrates a clear difference in ease of application, to the more bulky material used currently in biosensor applications. To have a highly sensitive biosensor with a fast response and a specific application, the choice of the material of sensor is very important. Several nanomaterials such as nanowires/nanotubes [24], gold nanoparticles [23], magnetic nanoparticles [25], carbon nanotubes [26] and quantum dots [27] have been investigated to evaluate their application as biosensors. Experiments have looked at their physical, chemical, mechanical, magnetic and optical properties for increased sensitivity, faster response and specific biomolecules recognition. Such high selectivity, fast response and sensitivity of biosensors based on these nanostructures (NSs) can be assigned to their dimensions relative to the biological or chemical analyte.

\subsubsection{Metal oxide semiconductor nanostructures}

The nanostructures of metal oxide semiconductors are attractive and important for nanosensors research because of their practical and theoretical importance in biological, environmental science and analytical chemistry applications [28-31]. The semiconducting, piezoelectric and pyroelectric properties of one dimension metal oxide NSs are very important. The most popular research areas of these nanostructures are optoelectronics [31], sensors [32], and actuators [33]. Metal oxide NSs have a high surface area to volume ratio, low toxicity, are environment-friendly, have chemical stability and biocompatibility. So metal oxide NSs also show fast electron transfer properties required to improve nanomaterials performance when used as a biomimetic membrane that will detect e.g. proteins and retain their activity [29, 31, 32]. Among these metal oxides, $\mathrm{ZnO}, \mathrm{CuO}$ and $\mathrm{NiO}$ have different and attractive morphologies as nanowires, nanorods (NRs), nanotubes, nanoleaves, nanoflowers, etc. that make them useful to fabricate nanodevices for optoelectronic and sensing applications.

In the last two decades, research on $\mathrm{ZnO}$ has been successful because of their physical and chemical properties. ZnO NSs have become increasingly popular, because of the different 
morphologies grown by various growth methods including the vapor-liquid-solid (VLS) technique [34], chemical vapor deposition (CVD) [35, 36], electrochemical deposition (ED) [37], and hydrothermal methods [38, 39]. Among these methods, the hydrothermal method has several advantages such as; they can be processed at a low temperature $\left(<100^{\circ} \mathrm{C}\right)$, cheap, environmentfriendly and give a high yield of ZnO NSs on substrates. One dimension (1D) ZnO (NRs) are highly important compared to other ZnO NSs because of the simple synthesis and the higher surface areas to volume ratio that enhance the fabrication of electronic, optoelectronic and biomedical devices [40, 41]. By using the hydrothermal methods, ZnO NRs can easily be grown on a broad range of substrates that include paper, glass, metal, and other semiconductors [42, 43]. $\mathrm{ZnO}$ has a wide direct energy band gap of $3.37 \mathrm{eV}$ at room temperature $\left(25^{\circ} \mathrm{C}\right)$, many radiative deep level defects and relatively large exciton binding energy of $60 \mathrm{meV}$, which makes $\mathrm{ZnO}$ useful for sensing and optoelectronic device applications [44, 45].

Copper (II) oxide (CuO) is known as a p-type semiconductor with narrow energy band gap of $1.2 \mathrm{eV}$ and monoclinic crystal structure. This material has also high potential in several nanodevices applications that include sensors, high critical temperature supper conductors, lithium ion batteries, field emission emitters and catalysts [46-50]. CuO NSs have shown many attractive properties such as; they can easily be grown on various substrates, prepared as different morphologies, low cost, and they are non-toxic. The researchers have been interested in the synthesis of various morphologies of $\mathrm{CuO}$ because the size and morphology of the $\mathrm{CuO}$ have a large effect on the electrochemical and catalytic nanodevices performance [51]. Several morphologies of $\mathrm{CuO}$ have been grown by the hydrothermal methods such as NRs [52], nanosheets [53], nanoflowers [54] and nanotubes [55].

Nickel oxide (NiO) is a p-type semiconductor with a wide energy band gap of $3.6 \mathrm{eV}$ to 4 $\mathrm{eV}$ and interesting properties such as magnetic, optical, catalytic and electrochemical [56, 57]. $\mathrm{NiO}$ NSs have been used in the fabrication of nanodevices such as electrochemical energystorage devices, gas sensors, dye-sensitized solar cells, and as an optical active counter-electrode tool. There are many methods for the synthesis of NiO NSs, but most of these have disadvantages except the hydrothermal method which is low cost, user friendly, easily controllable and environment-friendly. The morphologies and size of $\mathrm{NiO}$ NSs grown by the hydrothermal method are dependent on the growth parameters. Such as temperature, composition of growth solution, and growth time [58]. 


\subsection{Outline and objectives}

The outline and objective of this thesis is about the synthesis of different morphologies of metal oxide semiconductor $\mathrm{NSs}(\mathrm{ZnO}, \mathrm{CuO}$ and $\mathrm{NiO}$ ) by the hydrothermal method and their application as UV photodetectors, catalytic and chemical biosensors.

This thesis is divided into three parts:

1. The fabrication of well-aligned $\mathrm{ZnO} \mathrm{NRs}$, thin film and the synthesis of $\mathrm{CuO}$ nanoflowers and nanosheets. The morphologies and the crystal structure quality were investigated using field emission scanning electron microscope (FESEM), x-ray diffraction (XRD) and a transmission electron microscope (TEM).

2. Using $\mathrm{ZnO}, \mathrm{CuO} \mathrm{NSs}$ and their composites to fabricate chemical sensors and biosensors. We used two methods for sensing applications; potentiometric (enzymatic or ionophore type) and amperometric (non-enzymatic type) including the detection of heavy metals, dopamine and glucose.

3. The fabrication of a fast and sensitive UV photodetector using p-type $\mathrm{NiO} / \mathrm{n}$-type $\mathrm{ZnO}$ heterostructures. $\mathrm{ZnO}$ nanosheets were grown on fluorine doped tin oxide glass substrate (FTO) with supramolecular assisted solution using the hydrothermal method. This device was characterized by current-voltage (I-V) characteristics. 



\section{Chapter 2}

\section{Materials and their properties}

Among the transparent oxide semiconductors (TOSs), $\mathrm{ZnO}$ and $\mathrm{NiO}$ have a wide energy band gap and many other attractive properties. $\mathrm{CuO}$ is a narrow energy band gap semiconductor and has unique physical and chemical properties. In this chapter we describe the properties of $\mathrm{ZnO}, \mathrm{CuO}$ and $\mathrm{NiO}$ that we investigated in this research work for the fabrication of different devices.

\subsection{Zinc Oxide (ZnO)}

$\mathrm{ZnO}$ is a wide energy band gap, compound semiconductor; it is n-type native doped semiconductor material with a piezoelectric property [59]. ZnO has two main crystalline structures, hexagonal wurtzite and cubic zincblende. Of these structures, the wurtzite is the most common and is stable under ambient conditions. The image of the hexagonal wurtzite structure of $\mathrm{ZnO}$ is shown in figure 2.1. The wurtzite structure is obtained by alternate stacking along the c direction of two interpenetrating hexagonal-closed-pack (HCP-type) sub lattices. The until cell of sub lattices forms a tetrahedron structure which consists of 5 atoms; one atom belongs to oxygen and is surrounded by four $\mathrm{Zn}$ atoms and vice versa [60]. In its most common form, the hexagonal wurtzite structure of $\mathrm{ZnO}$ has two different surfaces; one is the polar plane and includes (0002), and the $(000 \overline{2})$ and the other is the nonpolar plane and includes $(11 \overline{2} 0)$ and the $(10 \overline{1} 0)$. The nonpolar surface has an equal number of $\mathrm{O}$ and $\mathrm{Zn}$ atoms. The polar surface is the most important characteristic in determining the chemical and physical properties of $\mathrm{ZnO}$; it also has a higher surface energy compared to the nonpolar surface. Due to this high surface energy of the polar plane, 1D ZnO NRs grow well along the C-direction [0001] [41], this shown in figure 2.2. The $\mathrm{ZnO}$ material has attractive electro-optical properties because of the presence of intrinsic and extrinsic point defects in the crystal structure, which are useful for optoelectronic devices. The direct wide energy band gap of approximately $3.4 \mathrm{eV}$ and the relatively high exciton-binding energy (60 $\mathrm{meV}$ ) of the $\mathrm{ZnO}$ semiconductor are useful for short wavelength optoelectronic devices and allow efficient excitonic emission at room temperature $\left(25{ }^{\circ} \mathrm{C}\right)$, respectively [61]. ZnO does not only emit in the UV region, it also emits covering the whole visible spectra which emits green, yellow and in the red region [62-64]. 


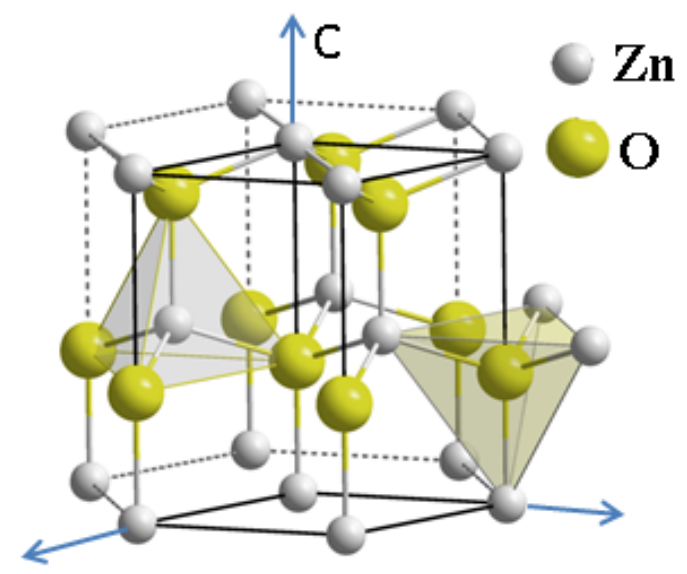

Figure 2. 1 : The hexagonal wurtzite structure of the $\mathrm{ZnO}$ semiconductor.

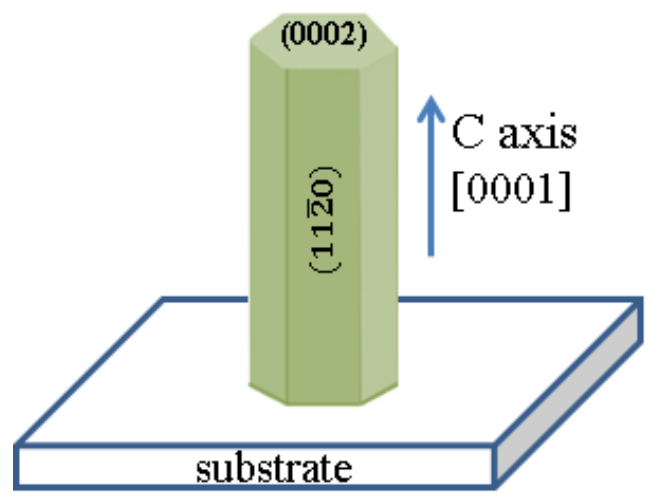

Figure 2. 2: Schematic diagram of $1 \mathrm{D} \mathrm{ZnO}$ NSs grown on a substrate, along the c-axis.

The UV spectrum is associated with near band-edge transition in $\mathrm{ZnO}$, namely, the recombination of the free excitons. The visible emission is produced because of the presence of the defect levels in $\mathrm{ZnO}$ such as Oxygen and Zinc vacancies (Vo, $\mathrm{VZn}_{\mathrm{Zn}}$ [65, 66], Oxygen and Zinc interstitial $\left(\mathrm{O}_{\mathrm{i}}, \mathrm{Zn}_{\mathrm{i}}\right)$ [67, 68], Oxygen and Zinc anti-site $\left(\mathrm{O}_{\mathrm{Zn}}\right.$ and $\left.\mathrm{Zno}_{\mathrm{O}}\right)$ [69] as shown in figure 2.3. Due to the native defects in the $\mathrm{ZnO}$ like $\mathrm{V}_{\mathrm{o}}$ and $\mathrm{Zn}_{\mathrm{o}}$ and hydrogen incorporation, the $\mathrm{ZnO}$ material will natively be n-type semiconductor. However, there are many reports about p-type doping of $\mathrm{ZnO}$ semiconductor but it is still uncontrollable and not reproducible which is a 
problem to fabricate $\mathrm{p}-\mathrm{n}$ homojunctions based on $\mathrm{ZnO}$ [70]. $\mathrm{ZnO}$ nanostructures also have other attractive physical and chemical properties that include high mobility, high electron transfer rate and high surface area to volume ratio. They are also bio-safe, bio-compatible and environmentalfriendly which make $\mathrm{ZnO}$ useful for intra/extra biosensing applications [71, 72]. Table 2.1 shows the summary of the basic physical parameters of $\mathrm{ZnO}$ semiconductor material at room temperature.

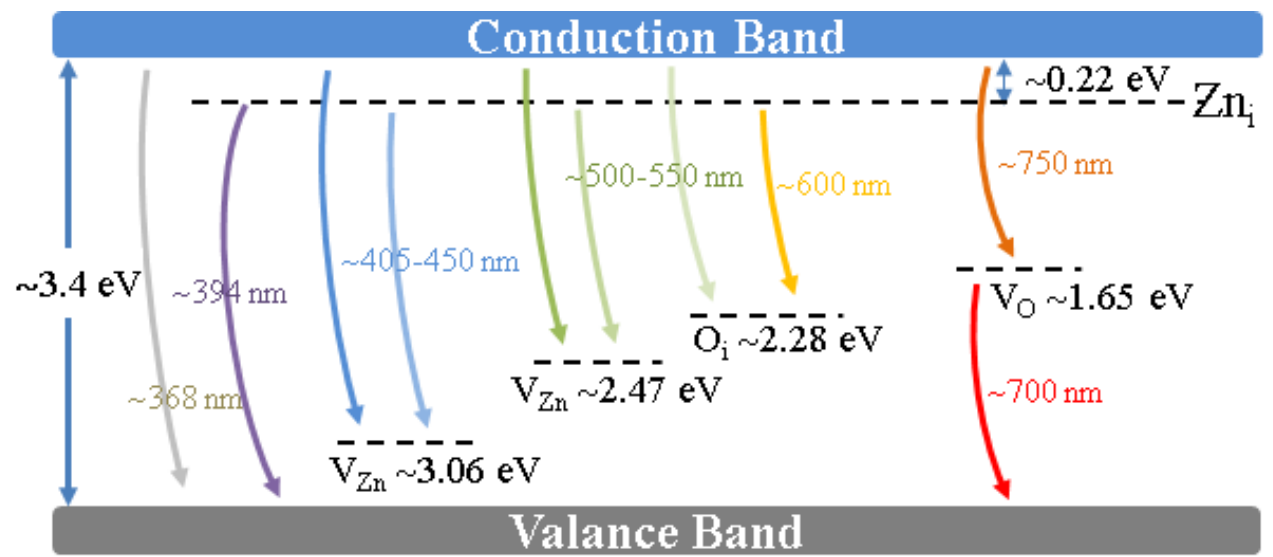

Figure 2. 3: Energy band diagram showing some of the defect levels in $\mathrm{ZnO}$ structures [73].

Table 2. 1: Summary of the basic physical properties of $\mathrm{ZnO}$ at room temperatures $[59,74,75]$.

\begin{tabular}{ll}
\hline Parameter properties & Values \\
\hline Lattice constants & $\mathrm{a}=0.325 \mathrm{~nm}, \mathrm{c}=0.527 \mathrm{~nm}$ \\
Stable crystal structure & Wurtzite \\
Density & $5.675 \mathrm{~g} / \mathrm{cm}^{3}$ \\
Molecular mass & $81.389 \mathrm{~g} / \mathrm{mol}$ \\
Melting point & $1975^{\circ} \mathrm{C}$ \\
Specific heat & $0.125 \mathrm{cal} / \mathrm{g}^{\circ} \mathrm{C}$ \\
Refractive index & 2.008 \\
Static dielectric constant & 8.656 \\
Direct energy band gap & $3.37 \mathrm{eV}$ \\
Exciton binding energy & $60 \mathrm{meV}$ \\
Electron mobility & $210 \mathrm{~cm}^{2} / \mathrm{Vs}$ \\
Effective mass of electron/hole & $0.28 \mathrm{~m}_{0} / 0.59 \mathrm{~m}_{0}$ \\
\hline
\end{tabular}




\subsection{Copper (II) Oxides (CuO)}

$\mathrm{CuO}$ is another native p-type metal oxide semiconductor with a narrow energy band gap of $1.2 \mathrm{eV}$. $\mathrm{CuO}$ belongs to the monoclinic crystal structure system with the space group $2 / \mathrm{m}$ or $\mathrm{C}_{2 \mathrm{~h}}$ as shown in figure 2.4. In a unit cell of the $\mathrm{CuO}$ structure, the copper atom is surrounded by four oxygen atoms in a square planar configuration [76]. Due to the unique physical and chemical properties of $\mathrm{CuO} \mathrm{NSs}$ and the simplicity in the synthesis of different morphologies using the hydrothermal method, $\mathrm{CuO}$ NSs can widely be used in various applications. CuO NSs have many popular advantages such as non-toxicity, cheap production and a high surface area to volume ratio, good electrochemical activity and electron transfer at low potential, which is good for bio and chemical sensing applications [77]. CuO NSs are also used for the fabrication of solar energy (cells) transformation, dry cell batteries and as an anode in lithium ion batteries [78, 79]. $\mathrm{CuO}$ NSs work effectively as high critical temperature superconductors, as field emission emitters and for magnetic storage media $[80,81]$. The summary of the basic physical properties of $\mathrm{CuO}$ material is shown in the table 2.2.

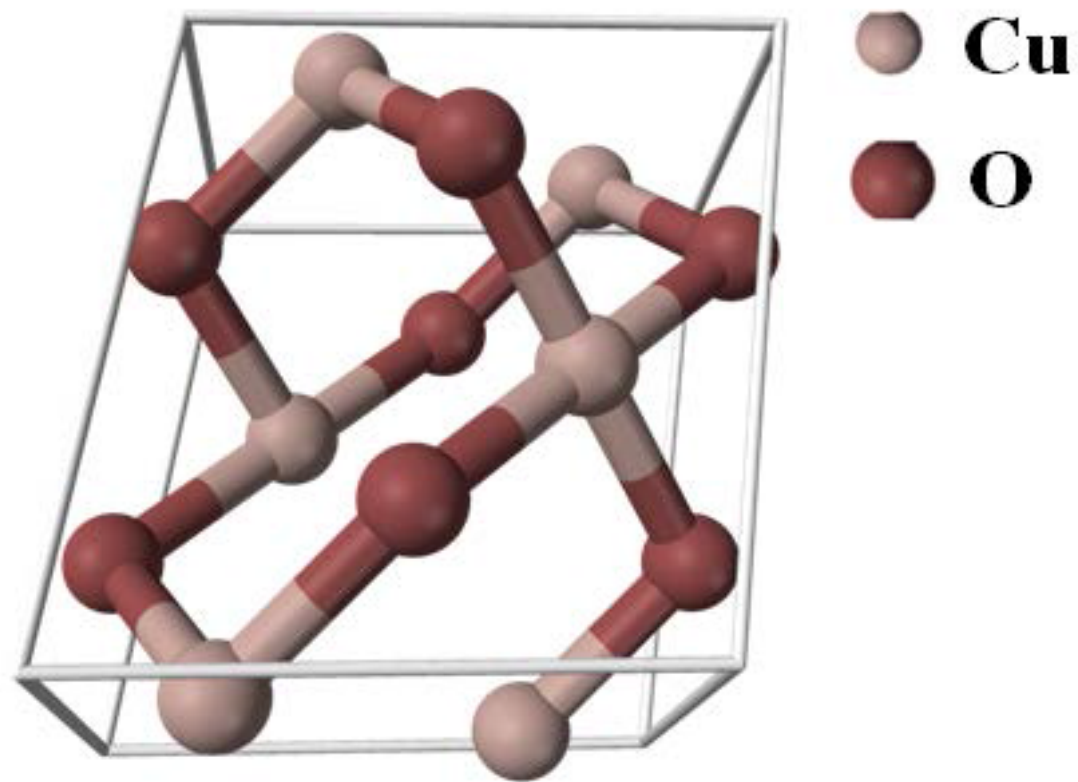

Figure 2. 4: The unit cell of $\mathrm{CuO}$ structures. 
Table 2. 2: Summary of the basic physical properties of the CuO material [82-84].

\begin{tabular}{ll}
\hline Parameter properties & Values \\
\hline Lattice constants & $\mathrm{a}=0.468 \mathrm{~nm}, \mathrm{~b}=0.342 \mathrm{~nm}, \mathrm{c}=0.513 \mathrm{~nm}$ \\
& $\alpha=90^{\circ}, \beta=99.54^{\circ}, \gamma=90^{\circ}$ \\
Crystal structure & Moniclinic \\
Space group & $\mathrm{C}_{2 \mathrm{~h}}$ \\
Molecular mass & $79.545 \mathrm{~g} / \mathrm{mol}$ \\
Density & $6.315 \mathrm{~g} / \mathrm{cm}^{3}$ \\
Boiling point & $2000^{\circ} \mathrm{C}$ \\
Melting point & $1326^{\circ} \mathrm{C}$ \\
Refractive index & 2.63 \\
Direct energy band gap & $1.2 \mathrm{eV}$ \\
Hole mobility & $0.1-10 \mathrm{~cm}^{2} / \mathrm{Vs}$ \\
\hline
\end{tabular}

\subsection{Nickel Oxide (NiO)}

$\mathrm{NiO}$ is a native p-type $3 \mathrm{~d}$ transition metal oxide semiconducting material with a wide energy band gap from $3.6 \mathrm{eV}$ to $4.0 \mathrm{eV}[85,86]$. NiO shows good electric, electro-chromic and thermoelectric properties as well as high chemical resistance [87-89]. Due to these properties, $\mathrm{NiO}$ has been used in reaction catalysis, batteries, sensors, photo-catalysts and electro-chromic devices [90-95]. The crystal structures of $\mathrm{NiO}$ material is commonly known as a cubic rock salt structure; the nickel atom is placed in a six fold octahedral coordination as shown in figure 2.5 [96]. The synthesis of NiO NSs has been achieved using several different methods such as evaporation, electrochemical deposition, chemical vapor deposition, sol-gel and hydrothermal growth [97-100]. The hydrothermal method is the best technique for growing the NiO NSs. Advantages of this method include inexpensive apparatus, low temperature operation, it is user friendly and it is substrate independent [101]. The hydrothermal method produces non-pure NiO material because of the hydroxide produced in the growth solution. The non-pure NiO NSs was annealed at $300-500{ }^{\circ} \mathrm{C}$ to produce pure $\mathrm{NiO}$ nanostructure phase [101]. Table 2.3 shows a summary of the basic properties of the $\mathrm{NiO}$ metal oxide semiconductor material. 


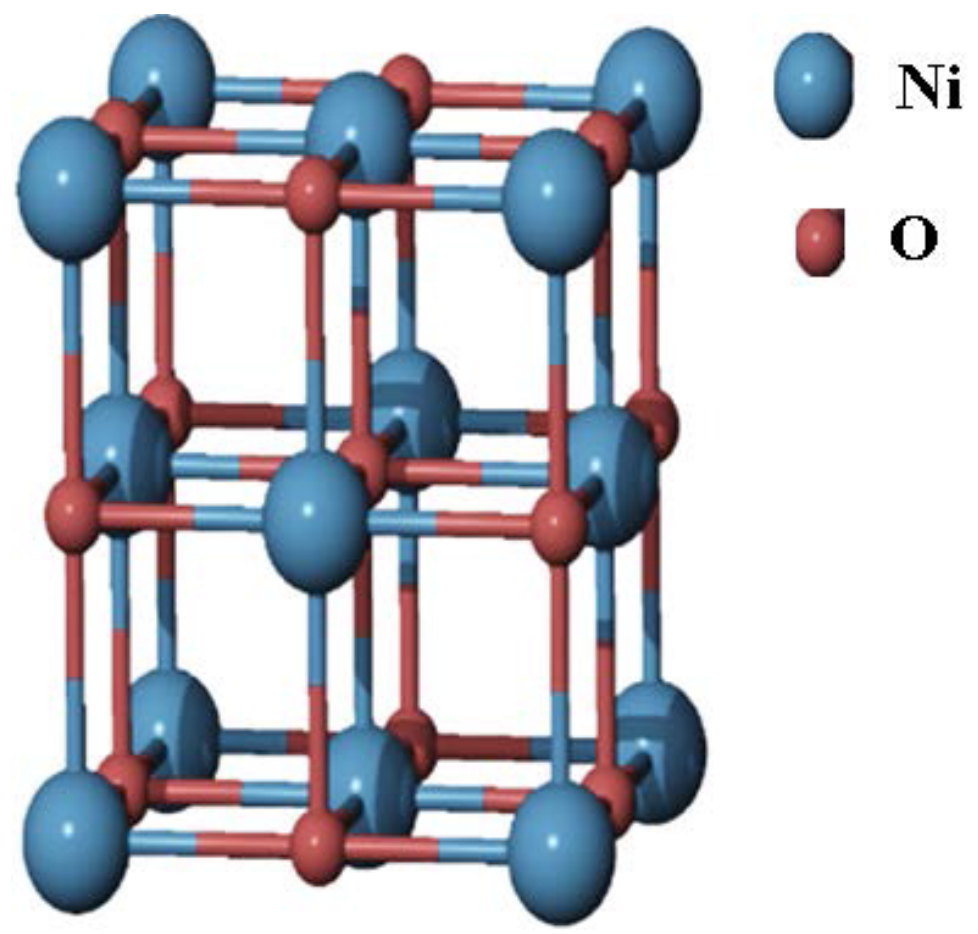

Figure 2. 5: The unit cell of a $\mathrm{NiO}$ structures.

Table 2. 3: Summary of the basic physical and chemical properties of the NiO material [102, 103].

\begin{tabular}{ll}
\hline Parameter properties & Values \\
\hline Appearance & Green crystalline solid \\
Molecular mass & $74.69 \mathrm{~g} / \mathrm{mol}$ \\
Density & $6.67 \mathrm{~g} / \mathrm{cm}$ \\
Melting point & $1995^{\circ} \mathrm{C}$ \\
Refractive index & 2.18 \\
Energy bandgap & $3.6-4.0 \mathrm{eV}$ \\
Hole mobility & $2.8 \mathrm{~cm}^{2} / \mathrm{Vs}$ \\
Electrical conductivity & $1.5 \times 10^{-3} \Omega^{-1} \cdot \mathrm{cm}^{-1}$ \\
\hline
\end{tabular}




\section{Chapter 3}

\section{Synthesis and characterization of metal oxide nanostructures}

This chapter describes the preparation and characterization of the nanostructures metal oxide semiconducting grown materials such as $\mathrm{ZnO}, \mathrm{CuO}, \mathrm{NiO}$ and their composites. The hydrothermal growth method was chosen for preparation of the above metal oxides. After preparation of the nanostructures, their morphologies, crystal quality, structure and chemical bonding were investigated. The techniques that were used for the characterization in this work are: field emission scanning electron microscope (FESEM) for the morphologies, transmission electron microscope (TEM) for studying the lattice crystal structure, X-ray diffraction (XRD) for the crystal purity characterization, X-ray photoelectron spectroscopy (XPS) for surface analyzing, Fourier transform infrared spectroscopy (FTIR) for chemical bonding and the molecular structure and photoluminescence (PL) spectroscopy for studying the optical properties of metal oxide NSs.

\subsection{The preparation of the substrate}

The substrate preparation is the most important step for the growth of metal oxide semiconducting NSs. In order to avoid contamination, impurities and dust on the substrate from grease, hands, the environment and the cutting/breaking of the substrate, carful cleaning was required. There are two ways of substrate cleaning; wet cleaning and dry cleaning. For these experiments the wet cleaning method was used, it has advantages such as low cost, easy and it is environmental-friendly.

\subsubsection{Standard substrate wet cleaning method}

The substrates were cleaned separately with acetone and isopropanol in an ultrasonic bath for 5 minutes each to remove any organic contaminant and residual particles on it. Afterward the substrate was cleaned with de-ionized water and flushed with nitrogen gas at room temperature. Finally the clean substrates were annealed in oven at $120^{\circ} \mathrm{C}$ for 10 to 15 minutes to remove water molecules from the surface of the substrate.

\subsubsection{The deposition of the gold or silver thin layer on glass substrates}

In this work, a thin layer of gold and silver were used as the contact for the electrical measurement and to grow various metal oxide semiconducting NSs on the substrate. We used 
Satis Evaporator (725) to deposit the thin gold or silver layers on the substrates. Firstly, the glass substrate was cleaned by using the standard substrate wet cleaning method. The cleaned substrate was then placed into the Satis Evaporator (725). Satis Evaporator at a pressure of $2 \times 10^{-6} \mathrm{mbar}$, was used to evaporate the metal on the glass substrate. First $10 \mathrm{~nm}$ layer of Titanium (Ti) or Chromium (Cr) was deposited on the substrate to be used as the adhesive layer, followed by the addition of a $100 \mathrm{~nm}$ layer of gold or silver. The schematic diagram of deposition of gold or silver on the glass substrate is shown in figure 3.1.

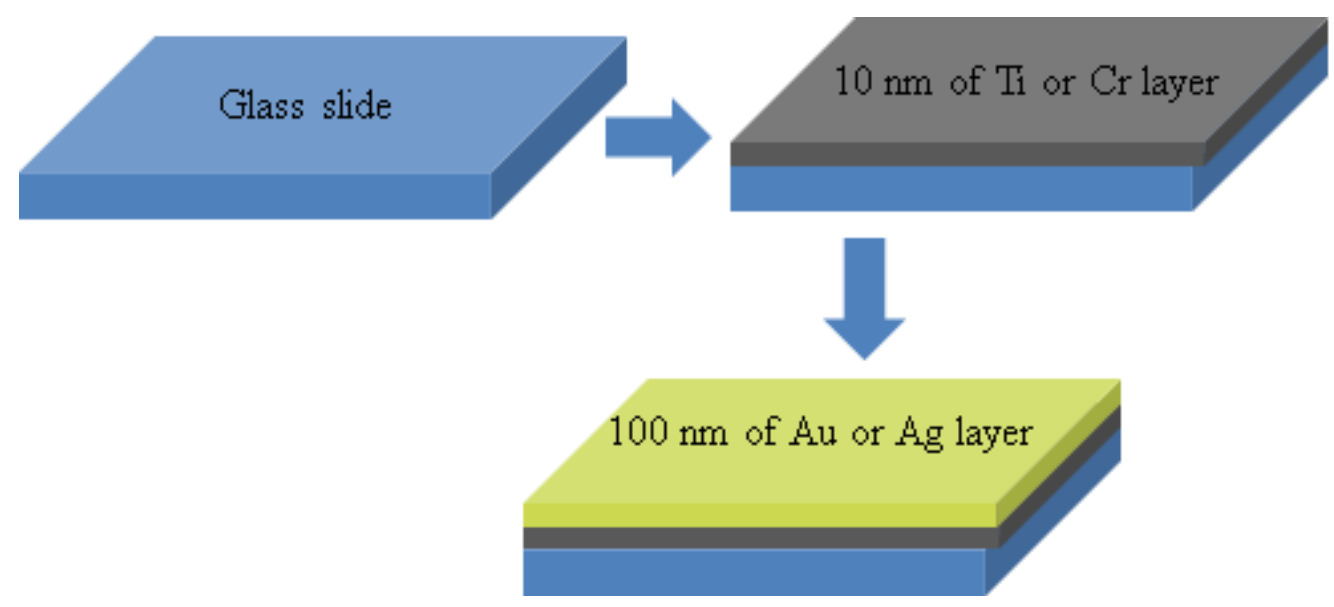

Figure 3. 1: Schematic diagram of gold or silver coated on a glass slide.

\subsection{3. $\quad \mathrm{ZnO}, \mathrm{CuO}$ and $\mathrm{NiO}$ seed solutions}

The next step for the growth of metal oxide semiconducting material NSs is the seed solution. The seed solution consists of embedding seed particles onto the substrate before the growth of the nanostructures material; this step produces nucleation sites by decreasing the thermodynamic barrier [104]. The seed particles play an important role for the metal oxide NSs growth for controlling the density, morphology and direction of growth of the metal oxide NSs. The $\mathrm{ZnO}$ seed solution was prepared with $0.01 \mathrm{M}$ zinc acetate dihydrate $\left(\mathrm{Zn}\left(\mathrm{CH}_{3} \mathrm{COO}\right)_{2} \cdot 2 \mathrm{H}_{2} \mathrm{O}\right)$ and $0.03 \mathrm{M}$ potassium hydroxide $(\mathrm{KOH})$ dissolved in $125 \mathrm{ml}$ and $65 \mathrm{ml}$ of methanol, respectively. The potassium hydroxide was added drop wise to the zinc acetate solution at constant stirring and heating at $60{ }^{\circ} \mathrm{C}$ for 2 hours. The complete seed solution has a cloudy color and contains the dispersed $\mathrm{ZnO}$ nanoparticles with a diameter of approximately 3-5 nm [105]. 
We used the same method to prepare the $\mathrm{CuO}$ and $\mathrm{NiO}$ seed solution, with $0.01 \mathrm{M}$ copper acetate monohydrate $\left(\mathrm{Cu}\left(\mathrm{CO}_{2} \mathrm{CH}_{3}\right)_{2} \cdot \mathrm{H}_{2} \mathrm{O}\right)$ and nickel acetate monohydrate $\left(\mathrm{Ni}\left(\mathrm{OCOCH}_{3}\right)_{2} \cdot 4 \mathrm{H}_{2} \mathrm{O}\right)$ in methanol, respectively. After preparation of a seed solution it was placed on the surface of the substrate using the spin coating method.

\subsection{Fabrication of metal oxide nanostructures on gold coated glass substrate (GCGS) using the hydrothermal method}

There are several techniques to grow metal oxide semiconducting $\mathrm{NSs}$ (ZnO, CuO and $\mathrm{NiO}$ ) that have been reported in the literature. Among those techniques, the hydrothermal method is the most useful technique because of its attractive advantages such as low cost, simple, and environmentally safe. $\mathrm{ZnO}$ is one of the most important metal oxide semiconducting materials and it has the richest family of nanostructures. In this work, we studied $\mathrm{ZnO} \mathrm{NRs}$, CuO nanoflowers, nanosheets, NiO nanoflowers, and their composite NSs that were grown on gold coated glass substrate and the FTO glass using the hydrothermal method [55, 106, 107].

\subsubsection{ZnO nanorods}

The growth solution for $\mathrm{ZnO} \mathrm{NRs}$ was prepared by dissolving $0.05 \mathrm{M}$ of zinc nitrate hexahydrate $\left(\mathrm{Zn}\left(\mathrm{NO}_{3}\right)_{2} \cdot 6 \mathrm{H}_{2} \mathrm{O}\right)$ and hexamethylenetetramine $\left(\mathrm{C}_{6} \mathrm{H}_{12} \mathrm{~N}_{4}\right)$ in $100 \mathrm{ml}$ of deionized water. The hydrothermal method was used to grow ZnO NRs on GCGS. First a gold substrate was cut to small sizes and cleaned by using the standard substrate cleaning method. The cleaned gold substrates were coated with $\mathrm{ZnO}$ seed solution by spin coating method for 30 seconds in one or two times at $2000 \mathrm{rpm}$; the spin coated substrate was annealed at $120{ }^{\circ} \mathrm{C}$ for 15 to 20 minutes. Finally the annealed gold substrates were placed in a Teflon holder and dipped into ZnO NRs growth solution in the oven at a temperature range of 90 to $95{ }^{\circ} \mathrm{C}$ for 5 to 7 hours. The schematic diagram of the grown metal oxide semiconducting NSs by the hydrothermal methods is shown in figure 3.2. At the end of the growth time the nanostructures samples were washed with de-ionized water to remove some salt particles from the nanostructures surface. The chemical reactions involved in the fabrication of $\mathrm{ZnO}$ NRs are shown below:

$$
\begin{array}{lll}
\left(\mathrm{CH}_{2}\right)_{6} \mathrm{~N}_{4}+6 \mathrm{H}_{2} \mathrm{O} & \rightarrow & 6 \mathrm{HCHO}+4 \mathrm{NH}_{3} \\
\mathrm{NH}_{3}+\mathrm{H}_{2} \mathrm{O} & \rightarrow & \mathrm{NH}_{4}^{+}+\mathrm{OH} \\
2 \mathrm{OH}^{-}+\mathrm{Zn}^{2+} & \rightarrow & \mathrm{Zn}(\mathrm{OH})_{2} \\
\mathrm{Zn}(\mathrm{OH})_{2} & \rightarrow & \mathrm{ZnO}(\mathrm{s})+\mathrm{H}_{2} \mathrm{O}
\end{array}
$$


During the growth time, hexamethylenetetramine plays an important role as a buffer medium and also produces ammonia as shown in eq. (1). In eq. (2) and (3), ammonia reacts with water and produces hydroxide ions; the hydroxide ions react with zinc ion and produces the zinc hydroxide. Finally, the zinc hydroxide produces ZnO NRs growth on the gold substrate. The diameter, length and density of the ZnO NRs can be controlled by the growth parameters that include the concentration of the growth solution, the temperature and the growth time.

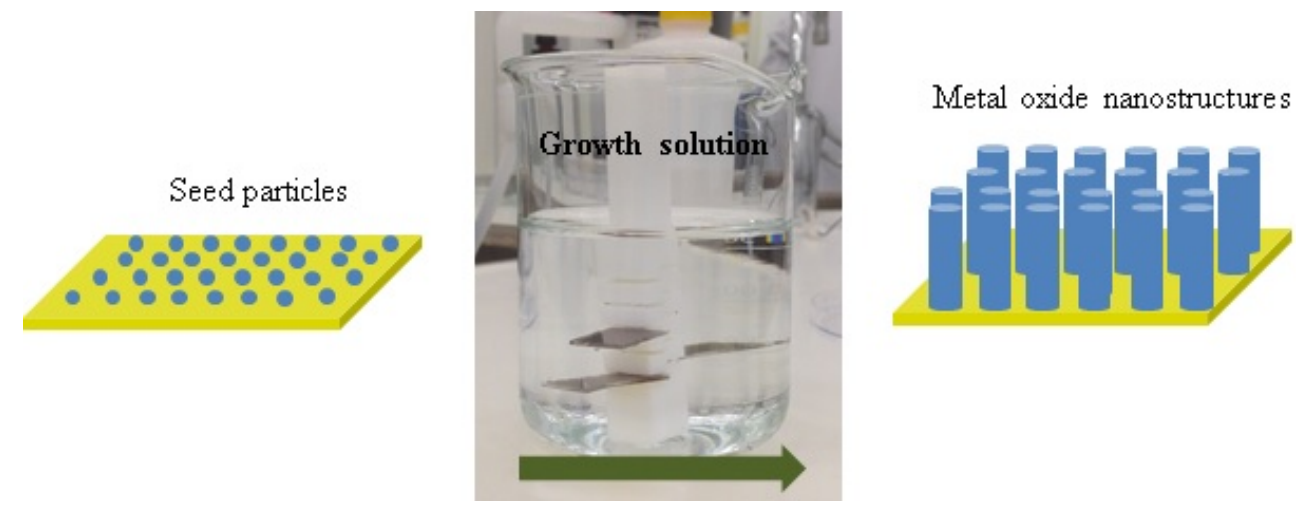

Figure 3. 2: Schematic diagram of the growth of metal oxide nanostructures by the hydrothermal method.

\subsubsection{The synthesis of $\mathrm{CuO}$ nanoflowers and nanosheets onto GCGS}

The synthesis of CuO NSs onto GCGS was done using the hydrothermal method. Cleaned gold substrates with a $\mathrm{CuO}$ seed layer was placed in the sample holder and dipped into the $\mathrm{CuO}$ growth solution of $0.025 \mathrm{M}$ of copper nitrate hemi(pentahydrate) $\left(\mathrm{Cu}\left(\mathrm{NO}_{3}\right)_{2} \cdot 2.5 \mathrm{H}_{2} \mathrm{O}\right)$ and $\mathrm{C}_{6} \mathrm{H}_{12} \mathrm{~N}_{4}$. The $\mathrm{CuO}$ nanoflowers were grown by adding urea to the growth solution so that we could investigate the effect of urea on the size of the $\mathrm{CuO}$ nanoflowers. Various amounts $0.1,0.4$, 0.5, 0.6, 0.8 and $1.0 \mathrm{~g}$ of urea were added to $100 \mathrm{ml}$ of the $\mathrm{CuO}$ growth solution. The urea was used as a template for controlling the size and density of the $\mathrm{CuO}$ nanoflowers. The $\mathrm{CuO}$ nanosheets were grown in the $\mathrm{CuO}$ growth solution at an alkaline $\mathrm{pH}$ of 11 . The $\mathrm{pH}$ of the $\mathrm{CuO}$ growth solution was changed by adding $0.1 \mathrm{M}$ of nitric acid and $25 \%$ ammonia solution. The nanostructures growth solutions were kept in the electric oven at $80-85{ }^{\circ} \mathrm{C}$ for $4-6$ hours. At the end of the growth time the $\mathrm{CuO}$ nanostructures sample was washed with de-ionized water to remove some salt particles on the nanostructures surface. The FESEM images of CuO nanoflowers and nanosheets are shown in figure 3.3. 

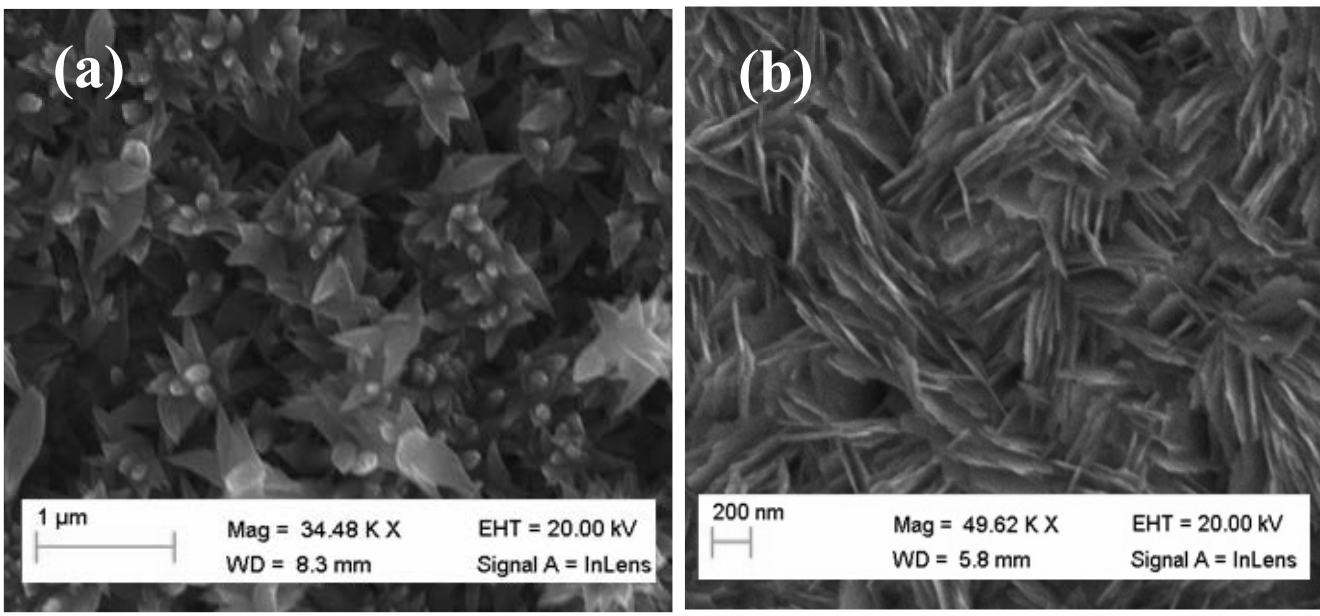

Figure 3. 3: FESEM images of CuO NSs: (a) nanoflowers, and (b) nanosheets grown using the hydrothermal method [55].
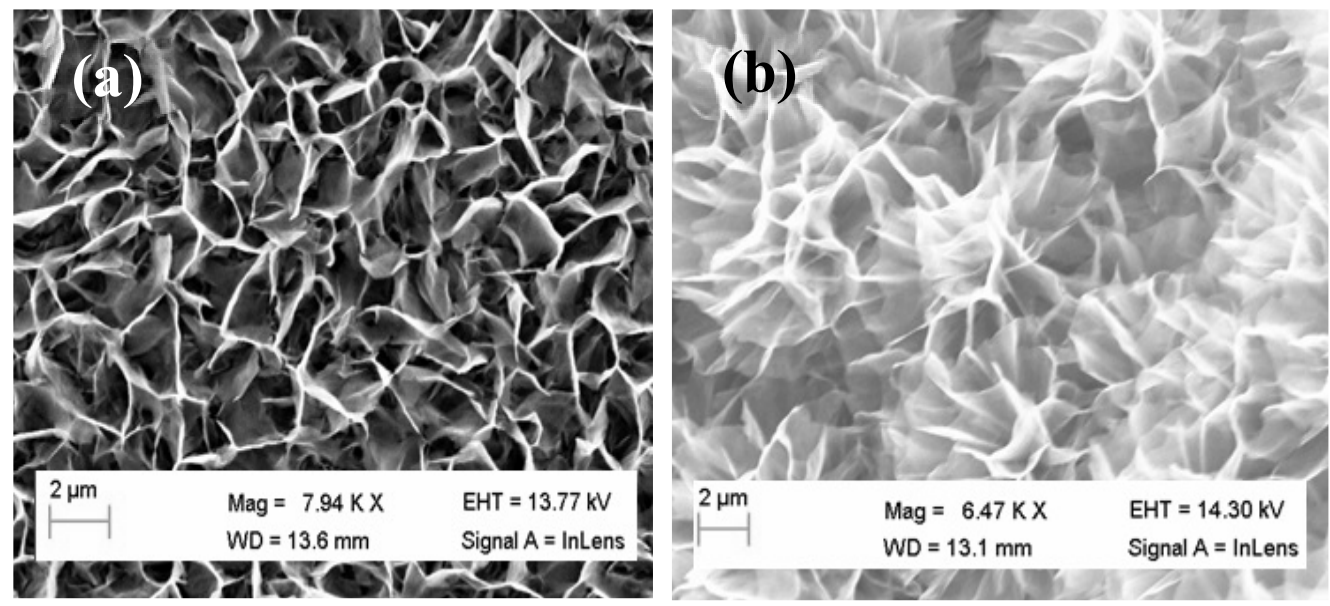

Figure 3. 4: FESEM images of NiO NSs: (a) nanowalls and (b) nanoflowers [108].

\subsubsection{The fabrication of nickel oxide (NiO) nanowalls on the GCGS}

The hydrothermal method was also used to fabricate NiO NSs on GCGS. The GCGS was deposited using $\mathrm{NiO}$ seed particles on the surface by the spin coating method at a speed of 2000 rpm for 30 seconds for one to two times. The seed particle coated gold substrate was annealed in the electric oven at $120^{\circ} \mathrm{C}$ for 15 to 20 minutes. After the completion of the annealing time, the gold substrate was fixed in the Teflon sample holder and dipped into the NiO growth solution of 
the equimolar concentration of $0.1 \mathrm{M}$ nickel nitrate hexahydrate and $\mathrm{C}_{6} \mathrm{H}_{12} \mathrm{~N}_{4}$. The growth solution was kept in the oven at $90-95{ }^{\circ} \mathrm{C}$ for 4 to 6 hours. At the end of the growth time, the sample was washed with de-ionized water, flushed with nitrogen gas and then dried at room temperature $\left(25^{\circ} \mathrm{C}\right)$. This dried sample was annealed at $450{ }^{\circ} \mathrm{C}$ for $2-4$ hours, to transfer the $\mathrm{Ni}(\mathrm{OH})_{2} \mathrm{NSs}$ into the $\mathrm{NiO} \mathrm{NSs}$ phase. The FESEM images of NiO nanowalls and nanoflowers is shown in figure 3.4 .

\subsection{The characterization tools for the study of metal oxide nanostructures}

\subsubsection{The X-ray diffraction (XRD)}

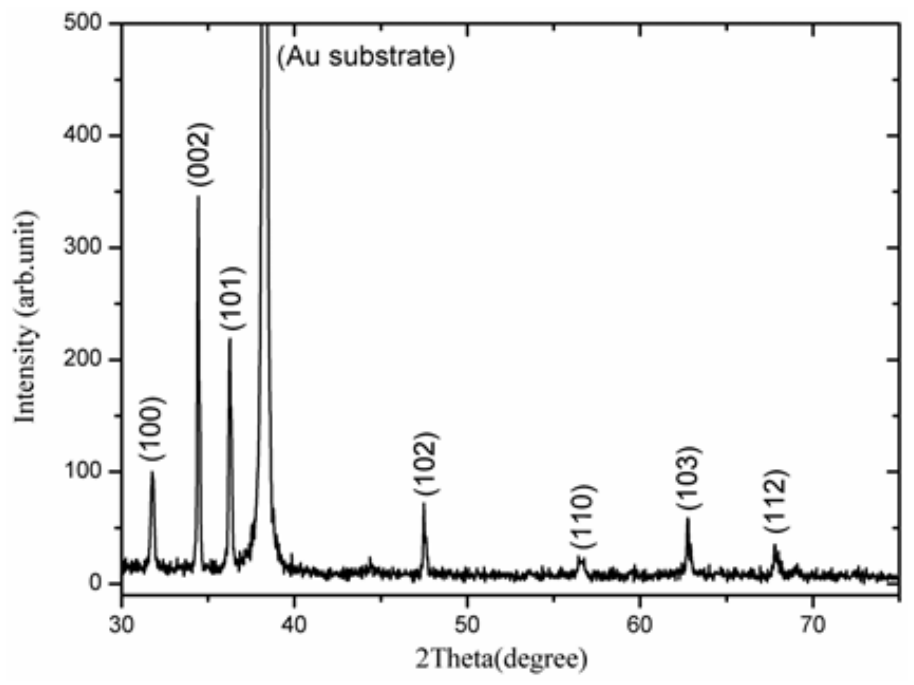

Figure 3. 5: XRD pattern of $\mathrm{ZnO}$ nanorods grown using the hydrothermal method [109].

The XRD is a useful technique to characterize the crystal quality and the composition of the synthesized material. From the XRD pattern, we can calculate the arrangement of the atoms, lattice parameters and identify crystal planes of the metal oxide semiconducting material. Also, the XRD is a powerful tool for identifying amorphous from crystalline materials. There are more information which is obtained about the prepared material using the XRD method below:

1. Lattice parameters, units cell structure and crystal plane

2. The formation mechanism of a specific material

3. The existence of different crystal phases in the prepared material

4. The ratio of crystalline and amorphous structures in the synthesized material 
5. The average crystal size can be calculated from the width of the peak in the crystal array (the particle size is inversely proportional to the peak width).

6. The structural distortion is calculated by the interplanar distance.

In this work, the XRD patterns are measured using XRD scans $(0.1 / \mathrm{sec})$ made with the Phillips PW 1729 powder differactometer and CuK $\alpha$ radiation with wavelength $(\lambda=1.5418 \AA)$. The full width at half maximum (FWHM) of the XRD peaks are calculated by pseudo-Voigt curve fitting. A typical XRD pattern of the ZnO NRs measured using the XRD model Phillip PW 1729 powder differactometer is shown in figure 3.5 .

\subsubsection{The field emission scanning electron microscope (FESEM)}

The FESEM is a powerful technique to study the surface morphology of the synthesized material. This technique produces images of materials by scanning it with a focused electron beams. The electrons interact with atoms in the material, producing a signals that contain the surface morphology and composition of the material. The FESEM can has a high resolution that is better than one nanometer due to short wavelength and high energy electron beam. The FESEM can produce different types of signals such as secondary electrons (SE), characteristic Xray, back scattered electrons (BSE), light cathodoluminescence (CL), sample current and transmitted electrons. The SE detector is the standard tool in all FESEM. The FESEM can make high-resolution images of a material surface with size less than one nanometer. Due to the very narrow electron beam, the FESEM has a large range of magnifications from 10 to more than 500,000 times compared to the magnification of the best light microscope. The BSE uses the reflection of electrons beam from the synthesized material by elastic scattering. Due to the strong intensity of the BSE related to atomic number (Z) of the material, the BSE is used in analytical FESEM with the spectra that is made from the characteristic X-ray. The BSE image can provide information about the different elements in the material. A characteristic X-ray is emitted by removing an inner shell electron from the sample using the electron beam; a higher energy electron then fills the shell and releases energy. The characteristic X-ray that is emitted can be used for identifying the composition and measuring the abundance of elements in the synthesized material. For the FESEM, a sample is normally needed to be completely dry and hard such as wood, bone or feathers because the sample chamber works at high vacuum. For a soft sample such as living cells, tissues or a soft bodied organism, chemical fixation must be used to save and stabilize their structures. 

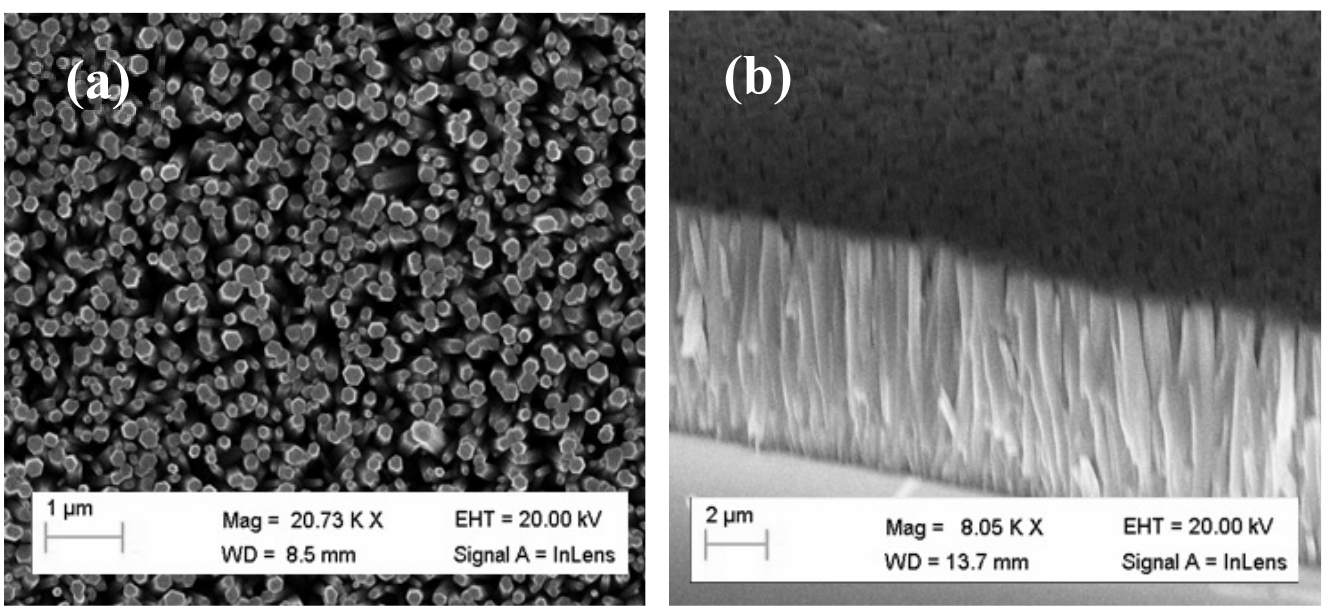

Figure 3. 6: FESEM top view and cross section images of $\mathrm{ZnO}$ nanorods [109].

An electron beam in the FESEM is thermonically emitted by a tungsten filament cathode or lanthanum hexaboride (LaB6) in an electron gun that moves towards an anode. Tungsten metal is usually used in the thermionic electron gun due to its higher melting point and lower vaporisation pressure and lower cost compared to other metals. Typically the electron beam has a high energy ranging from $200 \mathrm{eV}$ to $40 \mathrm{keV}$ which is focused by one or two magmatic condenser lenses to a very small spot size of $0.4 \mathrm{~nm}$ to $5 \mathrm{~nm}$. The electron beam moves through a pair of deflector plates in the electron column; this allows deflection of the electron beam in the horizontal and vertical direction so that it can scan a rectangular area of the sample surface. Due to the interaction of the primary electron beam with the sample surface, the electrons lose energy due to the repeated scattering and absorption in a volume of specimen which is called the interaction volume. This extends from less than $10 \AA$ to approximately $5 \mu \mathrm{m}$ under the surface. The interaction volume size depends on several parameters such as electron landing energy, the atomic number of the sample $(Z)$ and the density of the specimen on the sample. The energy exchange between the sample and the electron beam produces elastic scattering (high energy electron), inelastic scattering (secondary electron) and electromagnetic radiation which can be used to create an image of the specimen.

In this work the FESEM images of metal oxide nanostructures materials were investigated by the LEO 1550 Gemini field emission gun and JEOL JSM-6301F. Some FESEM images of the metal oxide semiconducting NSs is shown in figure 3.6. 


\subsubsection{The transmission electron microscopy (TEM)}

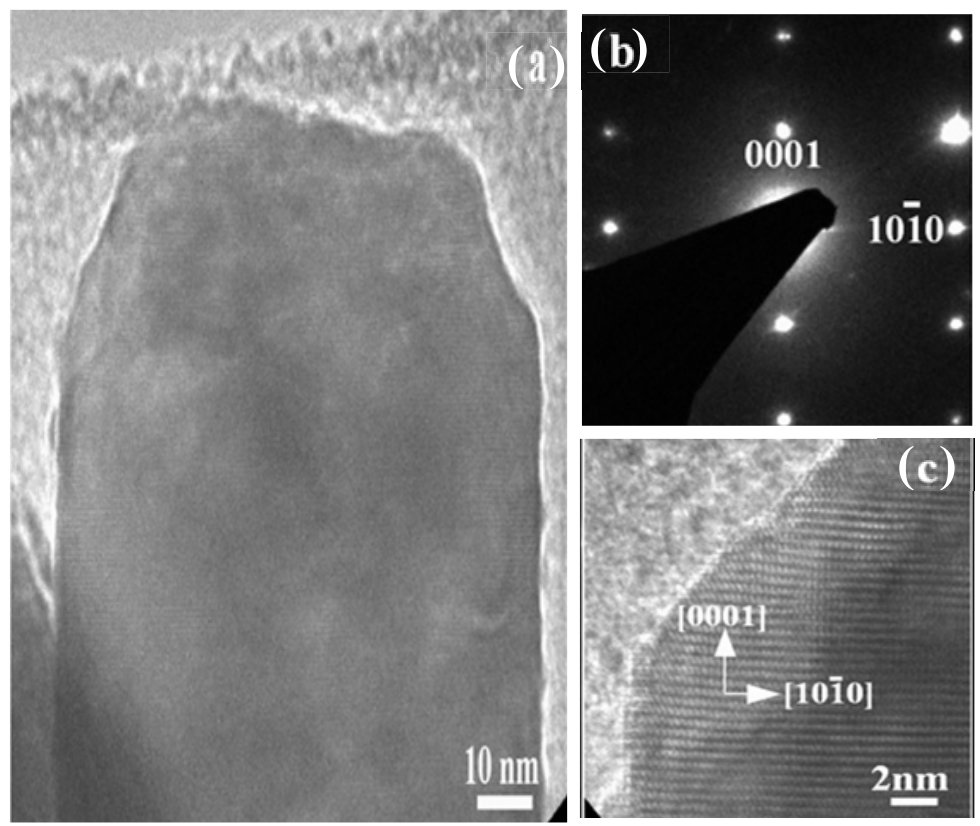

Figure 3. 7: TEM images of $\mathrm{ZnO}$ nanorods grown using the hydrothermal method [109].

The transmission electron microscopy (TEM) is used to characterize the internal structure of the material such as the lattice parameter, the miler indices and the lattice distances. A high energy electron beam used in the TEM interacts with the sample to give elastic scattering radiation and particles. These signals provide the information to characterize the sample by using energy-dispersive X-ray spectroscopy (EDS), back scattered and secondary electron beam images. TEM has two ways to provide specimen information, the diffraction method and the image method. In the diffraction method, an electron diffraction pattern is created by the electron beam. The TEM diffraction and the X-ray diffraction patterns are similar; a single crystalline structure material provides a spot pattern on the screen. However, the polycrystalline structures provide a powder or ring pattern at the illuminated area on the screen. A glassy or amorphous sample will show a chain of diffused halos. With the image method, the image of the illuminated sample area can be created by several different mechanisms; mass contrast due to the spatial separations between specific atomic constituents, thickness contract due to the non-uniform thickness of the sample and diffraction contrast which is created by the interaction of the incident 
electron beam phase contrast and the structural defects of the sample. The TEM also has several disadvantages, the preparation of the samples is a time consuming technique in order to make a sample thin enough to be transparent for electrons.

In this work, TEM images of metal oxide NSs were made using an FEI Tecnai G2 TF20 UT (Hillsboro, OR, USA) with a field emission gun operating at $200 \mathrm{kV}$ and a point resolution of $1.9 \AA$ and equipped with an EDS. Figure 3.7 shows TEM image of a metal oxide NSs.

\subsubsection{The X-ray photoelectron spectroscopy (XPS)}

X-ray photoelectron spectroscopy (XPS) is a surface-analytical tool that is used to characterize the elemental composition, chemical state and electronic state of the material by photoionization. The principle process of the XPS method can be explained by irradiating a material with the X-ray beam onto the surface of the sample; electrons of the atoms at the surface will escape from the material because of the incident X-ray energy. When the photon energy of the X-ray is enough, core electrons at the surface will escape from the atom with a specific kinetic energy ( $\left.E_{\text {kinetic }}\right)$. These are photoelectron. The kinetic energy of these photoelectrons can be experimentally determined by the equation:

$$
E_{\text {kinetic }}=h v-E_{\text {binding }}-W
$$

where the photon energy of the X-ray is $h v, E_{\text {binding }}$ is the binding energy and $W$ is the work function of the spectrometer. For atoms with a larger number of electron orbits, the electron in each orbital is related to a binding energy like a "finger print”. Due to the X-ray excitation, each element will show specific peaks on the XPS spectra that are related to the electron kinetic energies of specific radius. In the XPS spectrum, the electron kinetic energy is plotted as a function of the elements binding energy. From the XPS data, we can identify all elements other than Hydrogen and Helium by calculating the binding energy of their core electrons.

In this work, XPS measurements were performed by the ESCA200 spectrometer in an ultrahigh vacuum and a base pressure of $10^{-10}$ mbar. The chamber was fitted with a monochromatic $\mathrm{Al}(\mathrm{K} \alpha)$ x-ray source using photons with energy ( $h v=1486.6 \mathrm{eV})$ for the identification of the chemical composition of the sample. Carbon was used as a reference substance to calibrate the binding energies for all XPS measurement. Figure 3.8 shows high resolution XPS spectra of CuO NSs obtained using the x-ray photoelectron spectroscopy model ESCA 200. 

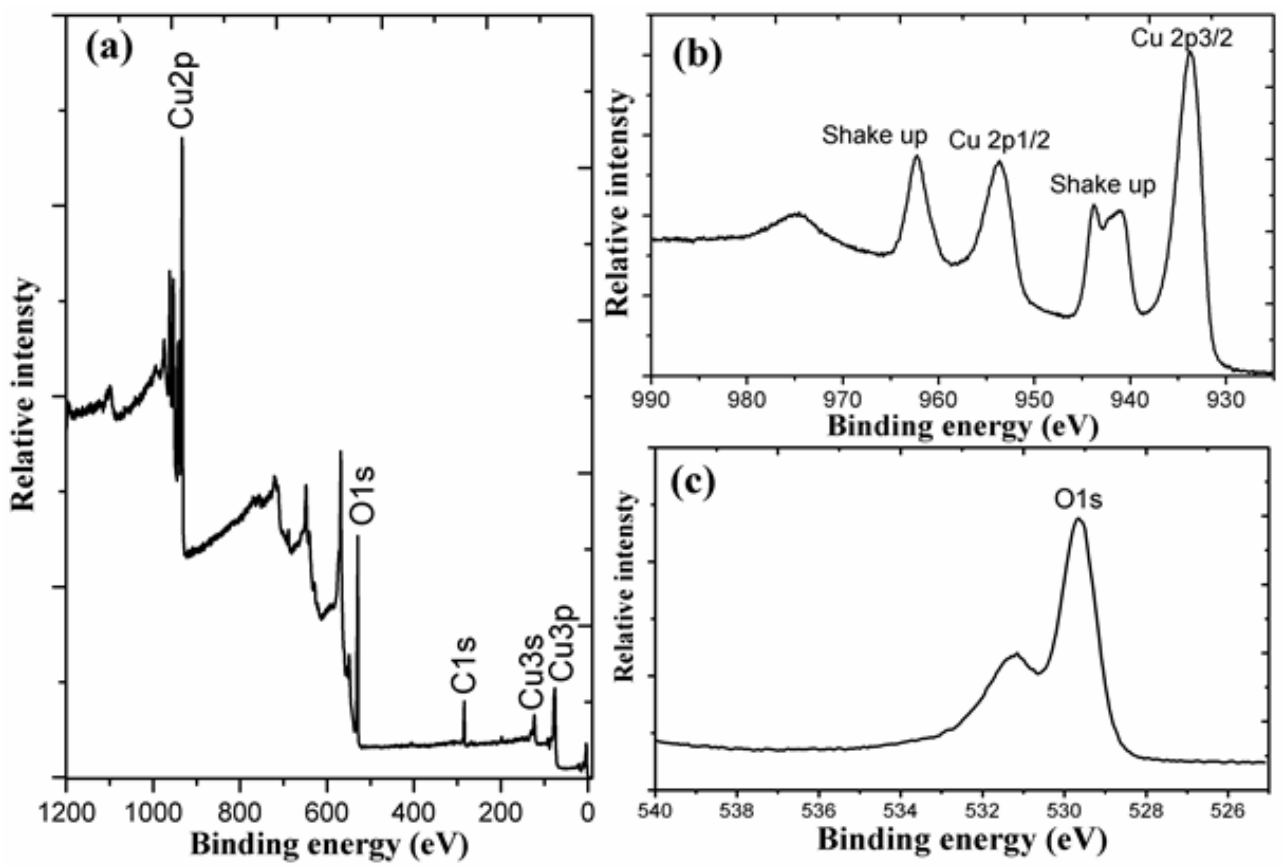

Figure 3. 8: XPS spectra of $\mathrm{CuO}$ nanosheets grown using the hydrothermal method [110].

\subsubsection{Photoluminescence spectroscopy (PL)}

Photoluminescence spectroscopy (PL) is the method used to characterize the various properties of a material such as purity, crystalline quality and the minority carrier lifetime of semiconductors. The PL is the light emission from any material after they absorb photons (electromagnetic radiation). A PL spectrum gives accurate and precise information about the nature of the surface, interface, the impurity level of the material and it also provides knowledge about an estimate of interface disorder and roughness of the sample. For a semiconductor with a low indirect band gap it is not easy to use PL because these materials have less radiation efficiency. The recognition of impurity and defect levels of materials are related to their optical activity. The tools required for the normal PL measurement are an optical light source and a spectrophotometer.

In this work, the PL was performed at room temperature with experimental third harmonics $(\lambda \mathrm{e}=266 \mathrm{~nm})$ from a Coherent $\mathrm{Ti}$; a sapphire laser used and the detection was observed with a Hamamatsu CCD camera. To measure the dispersion of the PL signal a monochromator of one 
meter focal length (model Brucker Optics Chromex 25, Bruker Corp., Billerica, MA, USA) was used with a diffraction grating of 150 lines $/ \mathrm{mm}$. A typical PL spectrum of $\mathrm{ZnO}$ NRs at room temperatures is shown in figure 3.9.

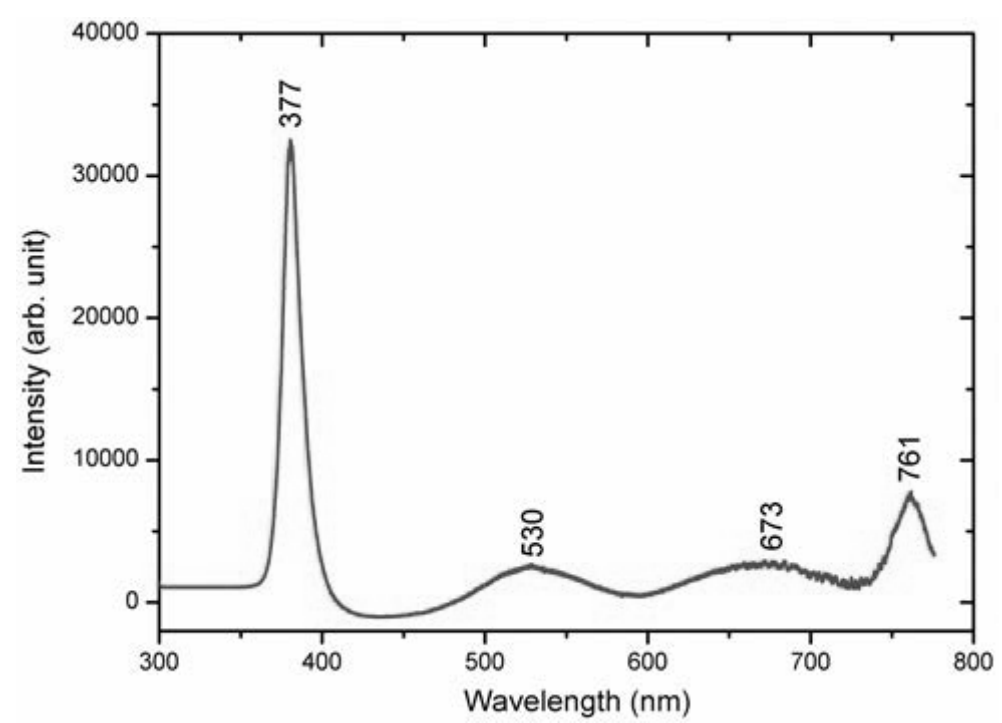

Figure 3. 9: $\mathrm{PL}$ spectrum of $\mathrm{ZnO}$ nanorods at room temperatures $\left(25^{\circ} \mathrm{C}\right)$ [109].

\subsubsection{Atomic force microscopy (AFM)}

The AFM is used for imaging, measuring and manipulating materials at nanoscale. The AFM equipment was invented in 1986 by G. Binnig, C. Quate and C. Gerber. It has a very high resolution scanning probe microscope. The AFM equipment provides an image of a surface that is 1000 times better than an optical diffraction device. The AFM has a cantilever with a sharp tip (probe) at the end that is used to scan the material surface. The cantilever is made of silicon or silicon nitride with a nanometer tip radius. During the experiment, a force is generated between the tip and the sample surface which results in the deflection of the cantilever, which follows Hooke's law [111]. The size of deflection is measured by using a laser spot which is reflected from the cantilever top surface into photodiodes. The laser deflection provides the information of the hills and valleys on the sample surface; this makes the image of the surface. In the AFM equipment there are two ways to perform the experiment with the scanning probe microscope; 
one is the contact mode where the tip touches on the sample surface, the other is the tapping mode where the tip taps across the sample surface.

In this work, the AFM measurements were performed using Veeco Dimension 3100 (Veeco Instruments, Inc., Plainview, NY, USA), operated in tapping mode with a silicon tip (resistivity 0.01-0.025 $\Omega \cdot \mathrm{cm}$; cantilever $\mathrm{T}=3.95-4.71 \mu \mathrm{m} ; \mathrm{W}=29-31 \mu \mathrm{m} ; \mathrm{L}=124 \mu \mathrm{m} ; \mathrm{C}=39-71 \mathrm{~N} / \mathrm{m}$; and $\mathrm{f}_{0}=330-399 \mathrm{kHz}$ ). A typical AFM image of $\mathrm{ZnO}$ seed nanoparticle is shown in figure 3.10.

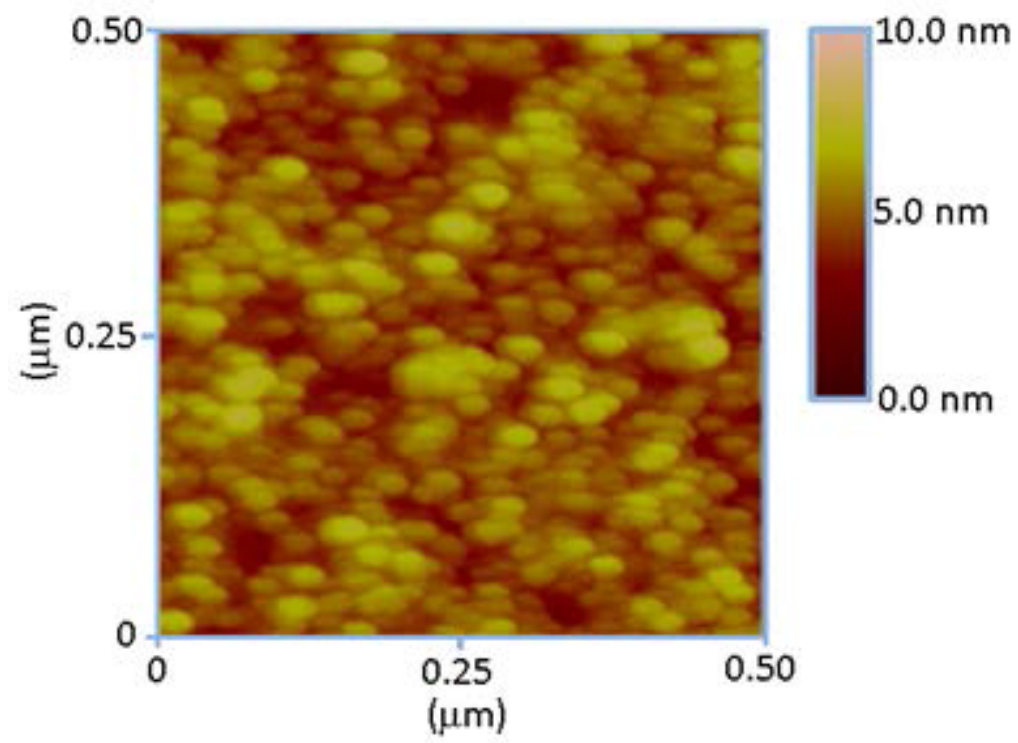

Figure 3. 10: AFM image of $\mathrm{ZnO}$ seed nanoparticle on the gold coated substrate [109].

\subsubsection{Fourier transform infrared spectroscopy (FTIR)}

The FTIR spectroscopy is a useful tools to characterize an unknown specimen and provide information about the chemical bonding and molecular structure of inorganic and organic materials. The FTIR tool is used to obtain the characteristic infrared radiation absorption, emission, photoconductivity or Raman scattering of a sample (solid, liquid or gas). The FTIR spectrum gives molecular information of the sample from the different absorption peaks which relate to the bond formation between atoms and certain frequencies. The intensity of the absorption peaks in the spectrum provides data about the amount of the material contained in the sample. In this work, FTIR was used to investigate the bonding of the enzyme, ionophore membrane and metal oxide nanostructures on the sample. 


\subsection{The electrical measurement}

The electrical and electrochemical characterizations of our devices in this research work were performed by several tools such as Auto-lab, semiconductor parameter analyses, $\mathrm{pH}$ meter and Keithley. Auto-lab with model PGSTAT 12 potentiostat/galvanostat FRA 2 Auto-lab Type (III) model that uses the general purpose electrochemical system software program (Eco Chemie, The Netherland) was used to measure the current response of the free enzyme biosensor and UV photodetector device. The semiconductor parameter analyzer is the basic equipment used to investigate the electrical properties of semiconductor devices and is used to record the I-V data of the UV photodetector devices. The potentiometric measurement was carried out using the $\mathrm{pH}$ meter and Keithley equipment to measure the voltage output response and time response of the sensing devices, respectively. 


\section{Chapter 4}

\section{Fabrication and characterization of devices}

This chapter focusses on my research results during my Ph.D. study at Linkoping University, Sweden. There are three parts of the results that are presented and discussed;

1. The investigation of the well aligned growth of ZnO NRs using composite seed layer of $\mathrm{ZnO}$ nanoparticles and chitosan polymer on a GCGS. This was done using the hydrothermal method. We completed a comparative study of ZnO NRs and thin films based on the chemical sensing application.

2. The synthesis of novel $\mathrm{CuO}$ nanosheets, nanoflowers and the composite of $\mathrm{ZnO} / \mathrm{CuO}$ NSs for developing enzyme free dopamine, glucose sensors and potentiometric $\mathrm{Cd}^{2+}$ ion sensor.

3. The synthesis of $\mathrm{NiO} \mathrm{NSs}$ and $\mathrm{ZnO}$ nanosheets was investigated using the hydrothermal growth method and applied to the development of fast sensitive UV photodetector device.

\subsection{The growth of well-aligned ZnO NRs and thin films based on strontium ion sensing application}

In this section, we discuss our research work on the growth of well-aligned ZnO NRs; using a composite seed layer on gold coated substrate by the hydrothermal method and a comparison between the $\mathrm{ZnO} \mathrm{NRs}$ and thin films based on the strontium ion sensor studied by the potentiometric method.

\subsubsection{Fabrication of well-aligned $\mathrm{ZnO}$ NRs using $\mathrm{ZnO}$ nanoparticles and chitosan polymer as a composite seed layer (paper I)}

In this paper, $\mathrm{ZnO}$ nanoparticles are combined with chitosan polymer and used as a composite seed layer to control the growth of well aligned ZnO NRs over the surface of a substrate using the hydrothermal method [112]. Some of the results of our research work are described below:

FESEM images of the fabricated ZnO NRs grown on GCGS with different composite seed layer concentrations are shown in figure 4.1 (a-d) and figure 4.2 (a-d). Figure 4.1 (a) shows the growth image of the ZnO NRs using only chitosan seed layer and that shows random growth of the $\mathrm{ZnO}$ NRs with low density on the substrate. With $10 \mathrm{mg}$ of $\mathrm{ZnO}$ nanoparticles added to the 
chitosan solution; an improved alignment of the ZnO NRs is observed, as shown in figure 4.1 (b). When the amount of $\mathrm{ZnO}$ nanoparticles is increased to $30 \mathrm{mg}$ and $50 \mathrm{mg}$, the result shows a better alignment with high density of the ZnO NRs on GCGS, as shown in figure 4.1(c, d). A similar growth trend was studied for the different concentrations of composite seed layer with 70 $\mathrm{mg}$ and $90 \mathrm{mg}$ of $\mathrm{ZnO}$ nanoparticles as shown in figure $4.2(\mathrm{a}, \mathrm{b})$. The reason behind this growth pattern might be the effect of the uniform distribution of the $\mathrm{ZnO}$ nanoparticles in the composite seed solution leading to a substrate providing better nucleation sites for controlling the aligned growth of ZnO NRs.

In addition to the top view FESEM images of well-aligned growth pattern, a cross-sectional FESEM image was provided to confirm the well-aligned growth pattern of the $\mathrm{ZnO}$ NRs on the GCGS as shown in figure 4.2 (c). It can be seen from the cross-sectional image that the ZnO NRs are perpendicular to the substrate with a length and average diameter of approximately $7 \mu \mathrm{m}$ and $100 \mathrm{~nm}$, respectively. The use of the composite seed solution of $\mathrm{ZnO}$ nanoparticle and chitosan polymer has shown two advantages: (i) the nucleation is provided by the $\mathrm{Zn}$ and $\mathrm{O}$ ions of the $\mathrm{ZnO}$ nanoparticles and (ii) the chitosan makes uniform distribution of the $\mathrm{ZnO}$ nanoparticles on the surface of substrate. Moreover, a combined bunch of the $\mathrm{ZnO}$ nanoparticle on the surface might be responsible for the well aligned and high density of the ZnO NRs growth [113]. The energy-dispersive X-ray (EDX) spectra of the well aligned ZnO NRs fabricated by the composite seed layer were shown in figure 4.2 (d). The results show that the composed nanorods have only $\mathrm{Zn}$ and $\mathrm{O}$ atoms; however, a peak of carbon atoms also appears in these spectra which may be due to the presence of carbon in the chitosan polymer. In the chitosan compound, there is also other atoms such as hydrogen, oxygen and nitrogen, but those atoms do not appear in the EDX spectra due to their low percentage in the chitosan molecule.

The HRTEM image and selected-area electron diffraction of a single crystal ZnO NRs is shown in figure 4.3 (a). This image shows that the growth of ZnO NRs leads to a single crystal with a hexagonal crystal structure (wurtzite structure), the growth direction is along the (0002) plane, as shown in figure 4.3 (b). Figure 4.3 (c) shows one nano-grain with the (0002) plane distance of approximately $0.26 \mathrm{~nm}$ which is consistent with the lattice spacing of the wurtzite crystal structure of ZnO. The diameter of the ZnO NRs was calculated by the HRTEM analysis, to be $90 \mathrm{~nm}$ approximately, which corresponds to the diameter that is observed from the FESEM data. Our results show single crystal nature of the $\mathrm{ZnO}$ NRs and good orientation of growth along 
the c-direction when using $\mathrm{ZnO}$ nanoparticles and chitosan polymer as the composite seed layer. A uniform and heterogeneous nucleation on the other surfaces has been reported [114]. However, the nucleation of well-aligned grown $\mathrm{ZnO} \mathrm{NRs}$ on substrate using the seed layer of $\mathrm{ZnO}$ nanoparticles is a simple and suitable method.
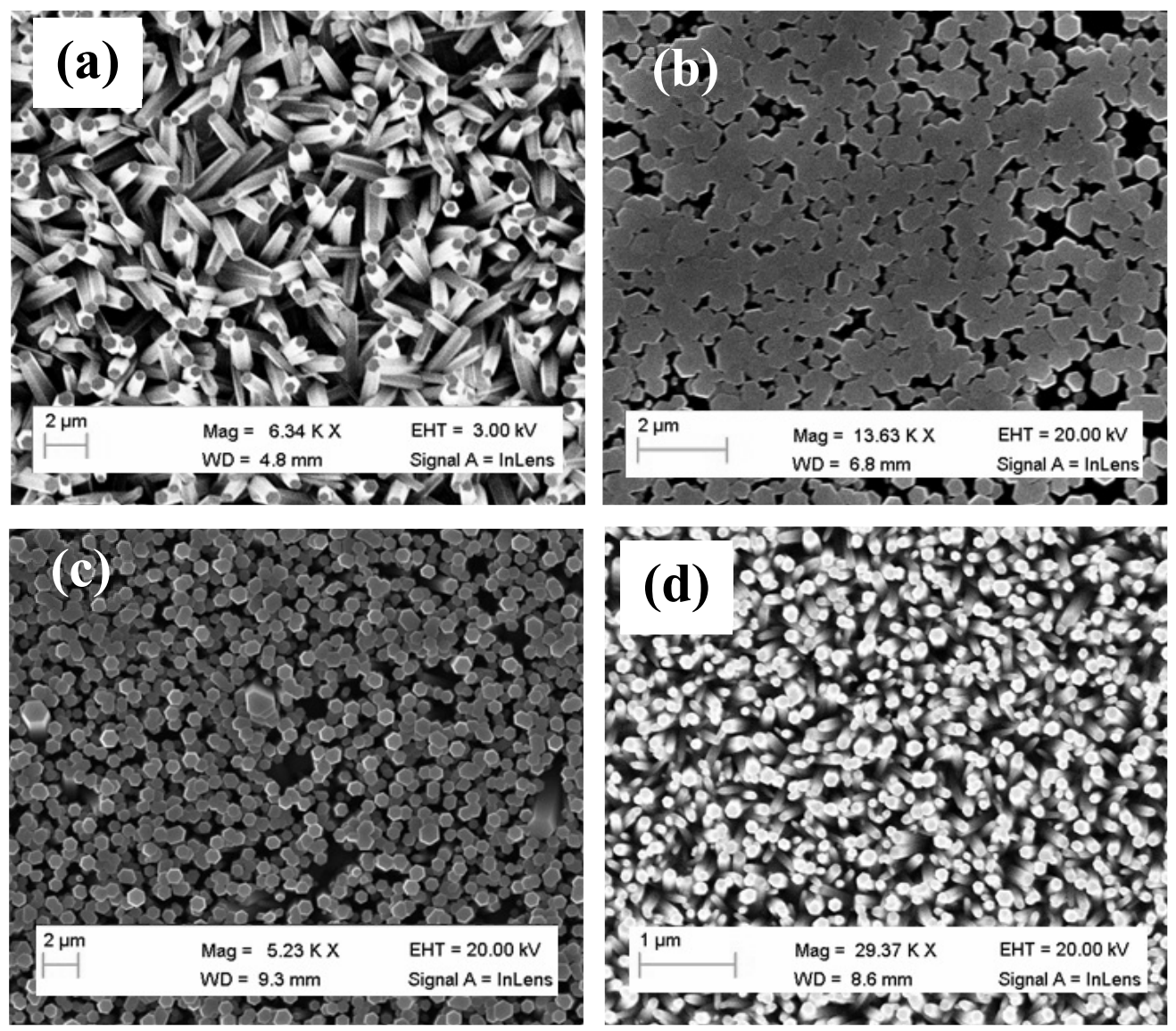

Figure 4. 1: FESEM images of the $\mathrm{ZnO}$ NRs grown with composite seed layer at different amounts of $\mathrm{ZnO}$ nanoparticles: (a) $0 \mathrm{mg}$, (b) $10 \mathrm{mg}$, (c) $30 \mathrm{mg}$ and (d) $50 \mathrm{mg}$ [112]. 

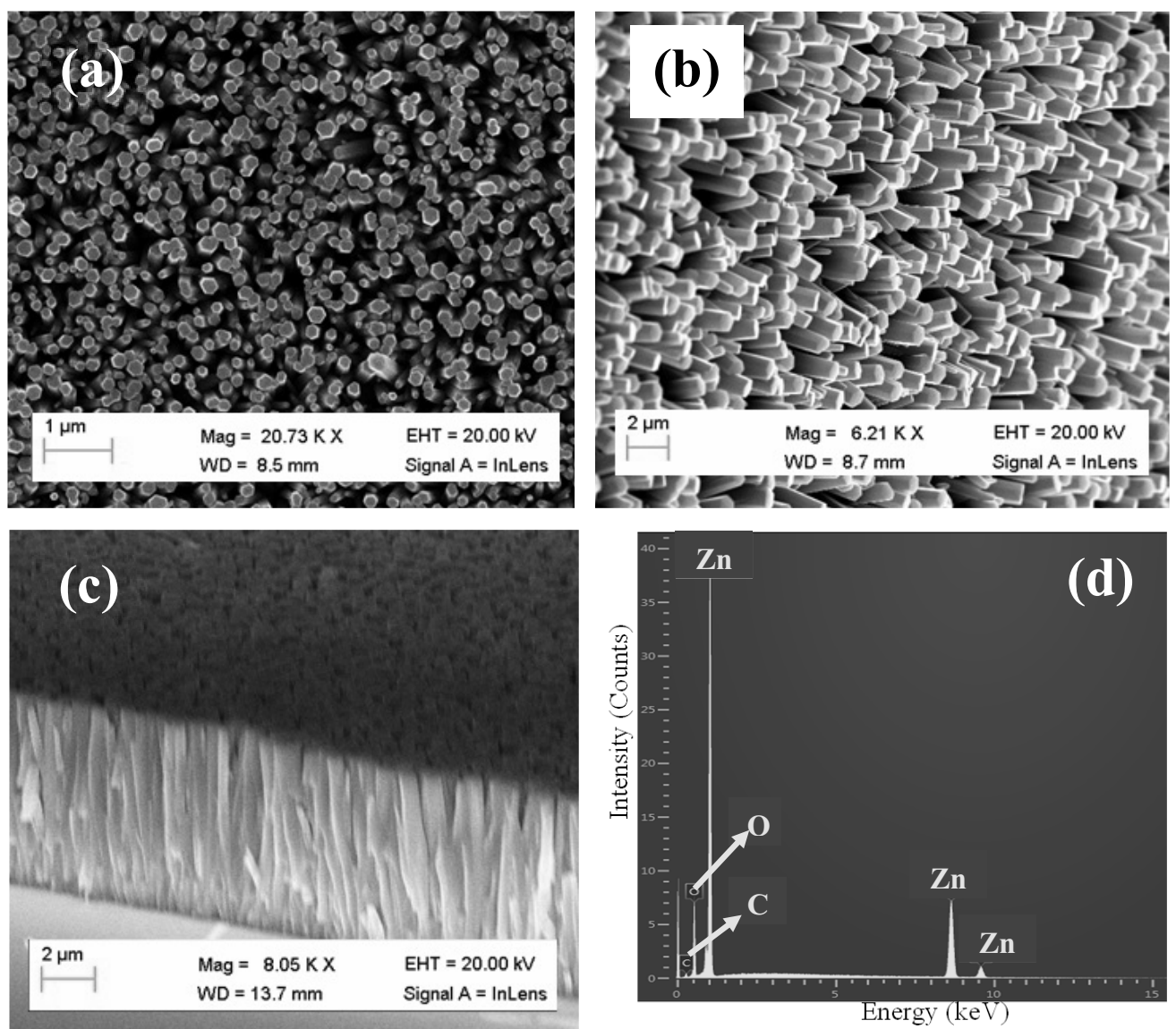

Figure 4. 2: FESEM images of the $\mathrm{ZnO}$ NRs grown with composite seed layer at different amounts of $\mathrm{ZnO}$ nanoparticles: (a) $70 \mathrm{mg}$ and (b) $90 \mathrm{mg}$; (c) the cross sectional image of the $\mathrm{ZnO}$ NRs growth using $90 \mathrm{mg}$ of $\mathrm{ZnO}$ nanoparticles and (d) The EDX spectra of the $\mathrm{ZnO}$ NRs using $70 \mathrm{mg}$ of $\mathrm{ZnO}$ nanoparticles [112]. 


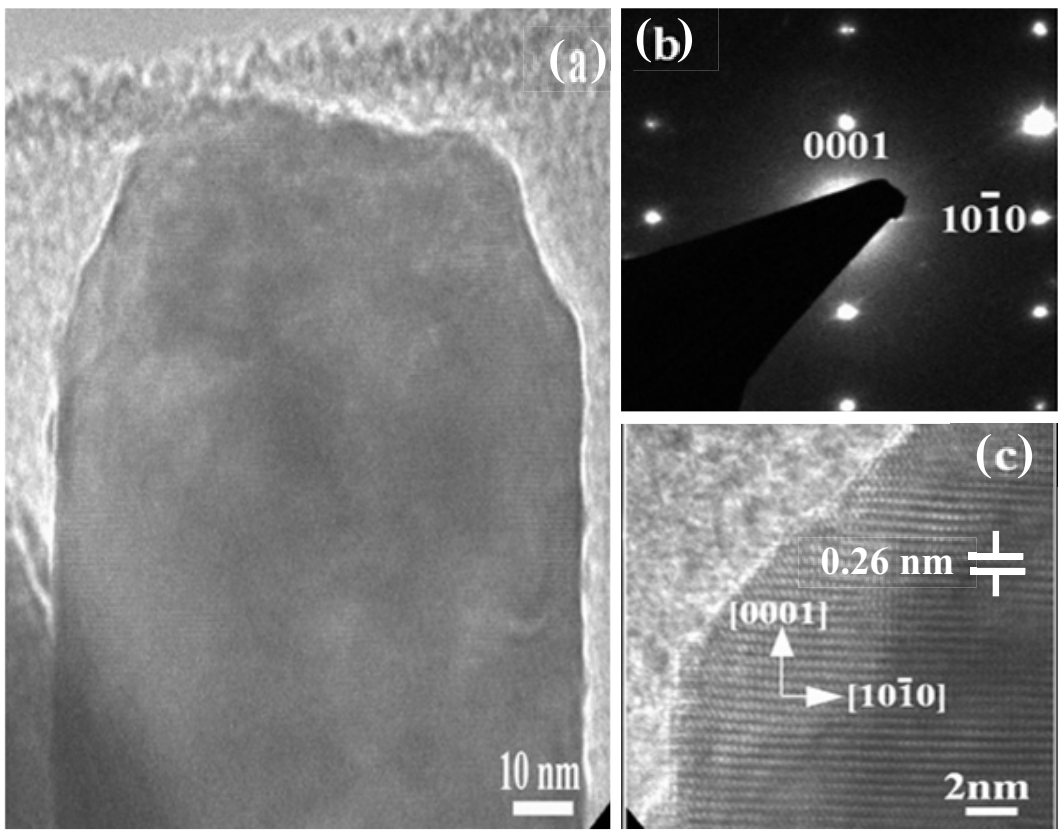

Figure 4. 3: HRTEM image of the $\mathrm{ZnO}$ nanorods grown with $70 \mathrm{mg}$ of $\mathrm{ZnO}$ nanoparticle [112].

Figure 4.4 show PL spectra at room temperature of the grown $\mathrm{ZnO} \mathrm{NRs}$ using the $\mathrm{ZnO}$ nanoparticle and chitosan polymer as composite seed layer. It can clearly be seen that a strong UV peak is observed at wavelength of $377 \mathrm{~nm}$; and wide visible peaks appear at wavelengths of $528 \mathrm{~nm}$ and $676 \mathrm{~nm}$. These represent a green emission and orange/ red emission, respectively. The broader green emission peak can be associated with the Oxygen vacancies [115], and the orange/red emission peak may be due to the interstitial atomic and defects in the $\mathrm{ZnO}$ [113]. The PL spectra of the ZnO NRs grown using the zinc acetate dihydrate seed solution is shown with dotted lines for comparison, in figure 4.4. From the PL data, the grown $\mathrm{ZnO}$ NRs with $\mathrm{ZnO}$ nanoparticles and chitosan as the composite seed layer have shown higher defect level compared to the $\mathrm{ZnO}$ NRs grown with the zinc acetate dihydrate seed layer. Therefore, the grown ZnO NRs with the composite seed layer shows intense luminescence properties in the visible region. 


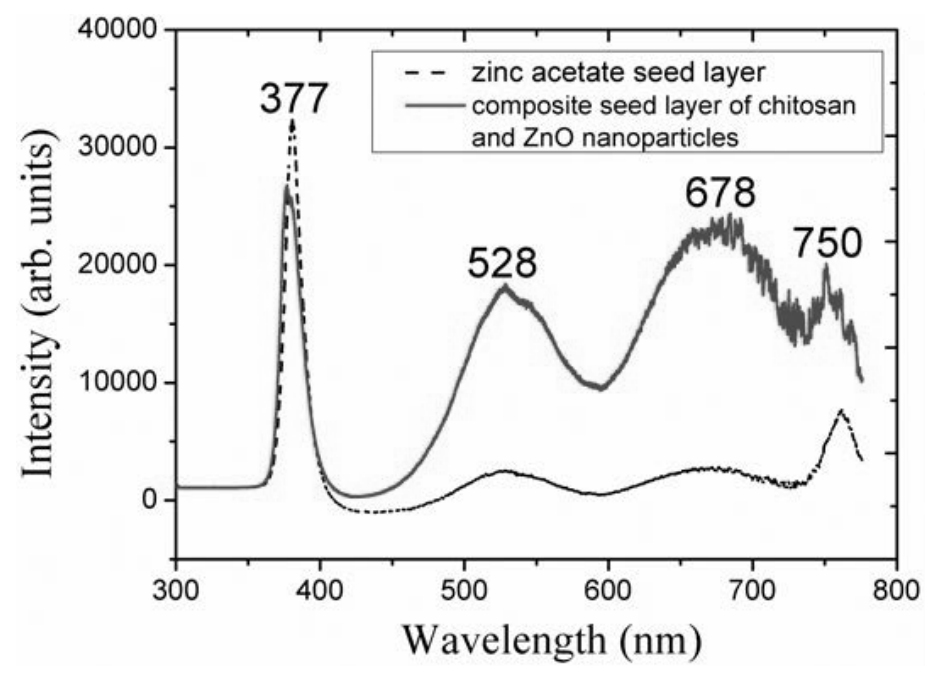

Figure 4. 4: $\mathrm{PL}$ data of the $\mathrm{ZnO}$ NRs grown with the composite seed layer using $70 \mathrm{mg}$ of $\mathrm{ZnO}$ nanoparticle and the seed layer of zinc acetate dihydrate [112].

\subsubsection{The comparative study of $\mathrm{ZnO} \mathrm{NRs}$ and thin films, for chemical and biosensing applications and the development of a $\mathrm{ZnO}$ NRs based potentiometric strontium ion sensor (paper II)}

In this study, ZnO NRs were fabricated on the GCGS by the hydrothermal method and the $\mathrm{ZnO}$ thin films grown was deposited with the electrodepositing method. The comparative study of $\mathrm{ZnO} \mathrm{NRs}$ and thin films was performed for chemical and biosensing applications [109]. The $\mathrm{ZnO}$ NRs were used to develop the strontium ion sensor based on the potentiometric method. Results of this research work are discussed below;

The morphologies of $\mathrm{ZnO} \mathrm{NRs}$ and thin films were investigated using the FESEM technique. The top view of the FESEM image shows clearly that the fabricated ZnO NRs were of high density, uniform and well-aligned on the GCGS, shown in figure 4.5 (a). The proposed $\mathrm{ZnO}$ thin films grown by the deposition method is shown in figure 4.5 (b). Figure 4.5 (b) shows that the $\mathrm{ZnO}$ thin films have been created by many nano clusters with a diameter of approximately 20 $\mathrm{nm}$. At the insertion of the sensor into the analytic solution, there is a formation of a complex between the analytic molecules and the enzyme or ionophore, on the $\mathrm{ZnO}$ nanostructures material working electrode to detect the target molecules, is shown in figure 4.6. In the schematic diagram, it is shown how the $\mathrm{ZnO}$ NRs or thin films working electrode with immobilized enzyme 
or ionophore and $\mathrm{Ag} / \mathrm{AgCl}$ reference electrode are connected to a $\mathrm{pH}$ meter. The calibration curve for the strontium ion sensor which was based on $\mathrm{ZnO} \mathrm{NRs}$ and thin films by using the potentiometric method is shown in figure $4.7(\mathrm{a}, \mathrm{b})$. It can be seen that the $\mathrm{ZnO}$ NRs have shown a better sensitive response and a wider detection range, compared to $\mathrm{ZnO}$ thin films. This result for the different morphologies of $\mathrm{ZnO}$ material could be the effect of the surface sensitiveness related to different morphologies. The electrode based on ZnO NRs provided a larger surface area to volume ratio and consisted of a greater number of surface possibilities to bind the selective strontium ionophore, resulting in higher sensitivity and wider detection range of strontium ion concentrations. The fabricated $\mathrm{ZnO}$ thin films showed a flat surface, which attached these exposed fewer surfaces to the strontium selective ionophore. The obtained results showed a less sensitive response and a lower detection range for strontium ion concentrations compared to the $\mathrm{ZnO}$ NRs. Because of this, the $\mathrm{ZnO}$ NRs showed a highly sensitive and wide detection range for chemical sensor devices. In order to clearly understand, the high chemical and biosensing sensitivity of $\mathrm{ZnO}$ NRs and thin films, two more experiments with different types of bioactive compounds were performed separately. The second experiment was performed with galactose oxidase immobilised $\mathrm{ZnO}$ NRs and thin films using the potentiometric method for the detection of D-galactose. The third experiment was with the $\mathrm{ZnO}$ NRs and thin films immobilised with the lactate oxidase and used for the detection of L-lactic acid by the potentiometric method.
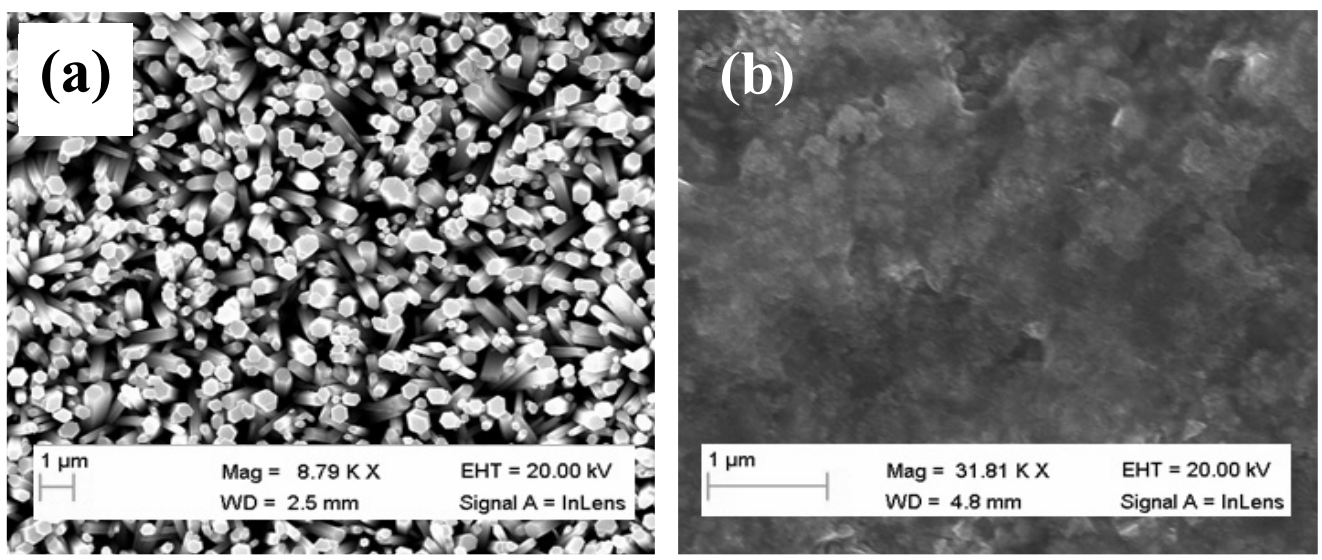

Figure 4. 5: Top view FESEM image of ZnO NSs (a) NRs and (b) thin films [109]. 


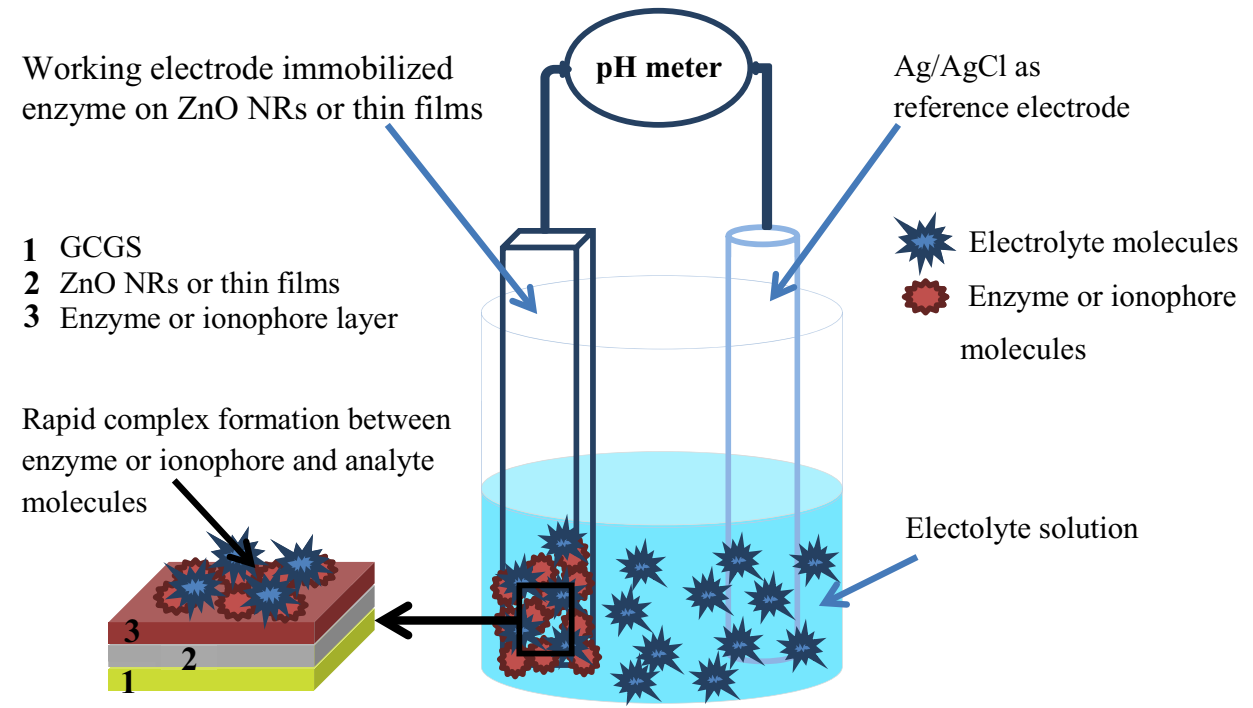

Figure 4. 6: Schematic diagram of potentiometric measurement of immobilized $\mathrm{ZnO}$ nanorods and thin films based on a chemical and biosensing application.
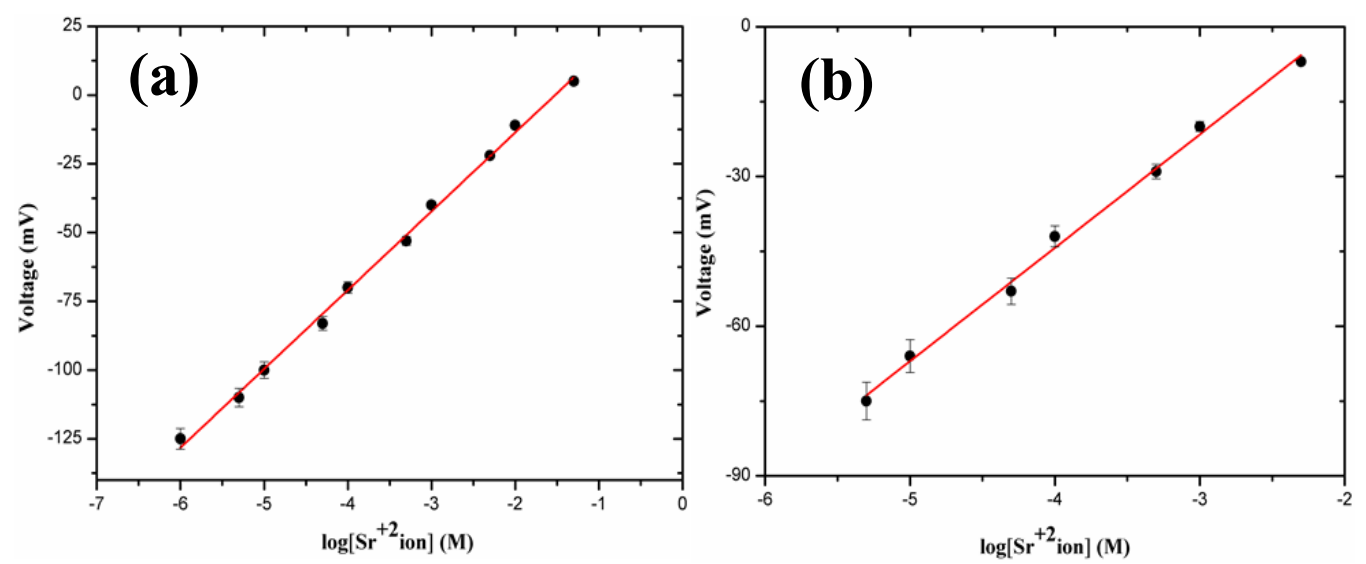

Figure 4. 7: The calibration curve of the strontium ion sensor based on immobilized $\mathrm{ZnO}$ (a) nanorods and (b) thin films [109]. 
Both experiments with bioactive compound showed that the working electrode based on immobilised ZnO NRs has a highly sensitivity response and a wider detection range for analytes compared to immobilised $\mathrm{ZnO}$ thin films electrode. The summarised results of the comparative study of the $\mathrm{ZnO}$ NRs and the $\mathrm{ZnO}$ thin films for chemical and biosensing application are shown in table 4.1 .

Table 4. 1: Summary of results for the comparative study of $\mathrm{ZnO}$ nanorods and thin films, for chemical and biosensing applications [109, 116, 117].

\begin{tabular}{lll}
\hline Sensing & Nanorods & Thin films \\
\hline Strontium & & \\
Slope (mV/decade) & $28.65 \pm 0.52$ & $22.72 \pm 0.66$ \\
Intercept (mV) & $43.69 \pm 2.03$ & $46.58 \pm 2.67$ \\
Detection range (M) & $1.00 \times 10^{-6}-1.00 \times 10^{-1}$ & $5.00 \times 10^{-6}-5.00 \times 10^{-3}$ \\
$\mathbf{R}^{2}$ & 0.99 & 0.99 \\
& & \\
D-galactose & & \\
Slope (mV/decade) & $-89.14 \pm 1.23$ & $-37.89 \pm 1.34$ \\
Intercept (mV) & $235.45 \pm 2.25$ & $97.75 \pm 2.61$ \\
Detection range (M) & $1.00 \times 10^{-2}-2.00 \times 10^{-1}$ & $3.00 \times 10^{-2}-2.00 \times 10^{-1}$ \\
$\mathbf{R}^{2}$ & 0.99 & 0.99 \\
& & \\
L-lactic acid & & $9.97 \pm 0.25$ \\
Slope (mV/decade) & $41.33 \pm 1.58$ & $44.05 \pm 0.58$ \\
Intercept (mV) & $208.24 \pm 3.66$ & $1.00 \times 10^{-7}-1.00 \times 10^{-3}$ \\
Detection range (M) & $1.00 \times 10^{-7}-1.00 \times 10^{-3}$ & 0.99 \\
$\mathbf{R}^{2}$ & 0.99 & \\
& & \\
\hline
\end{tabular}

\subsection{The synthesis of novel $\mathrm{CuO}$ nanostructures and their chemical and biosensing application}

In this section, we will summarize the results of the urea assisted $\mathrm{CuO}$ nanoflowers and the $\mathrm{CuO}$ nanosheets by the hydrothermal method. The functionalized $\mathrm{CuO}$ nanoflowers with $\mathrm{Cd}^{2+}$ ion selective ionophore were used for the $\mathrm{Cd}^{2+}$ ion detection and the $\mathrm{CuO}$ nanosheets were used as a non-enzymatic electrode for the development of glucose sensor. 


\subsubsection{Urea assisted synthesis of $\mathrm{CuO}$ NSs and their chemical sensing application for the determination of cadmium ions (paper III)}

This section describes the synthesis of novel urea assisted $\mathrm{CuO}$ nanoflowers by using hydrothermal method. The $\mathrm{CuO}$ NSs are immobilized with the tetrathia-12-crown-4 selective ionophore for the detection of $\mathrm{Cd}^{2+}$ ions [55]. The results of this work are discussed below;
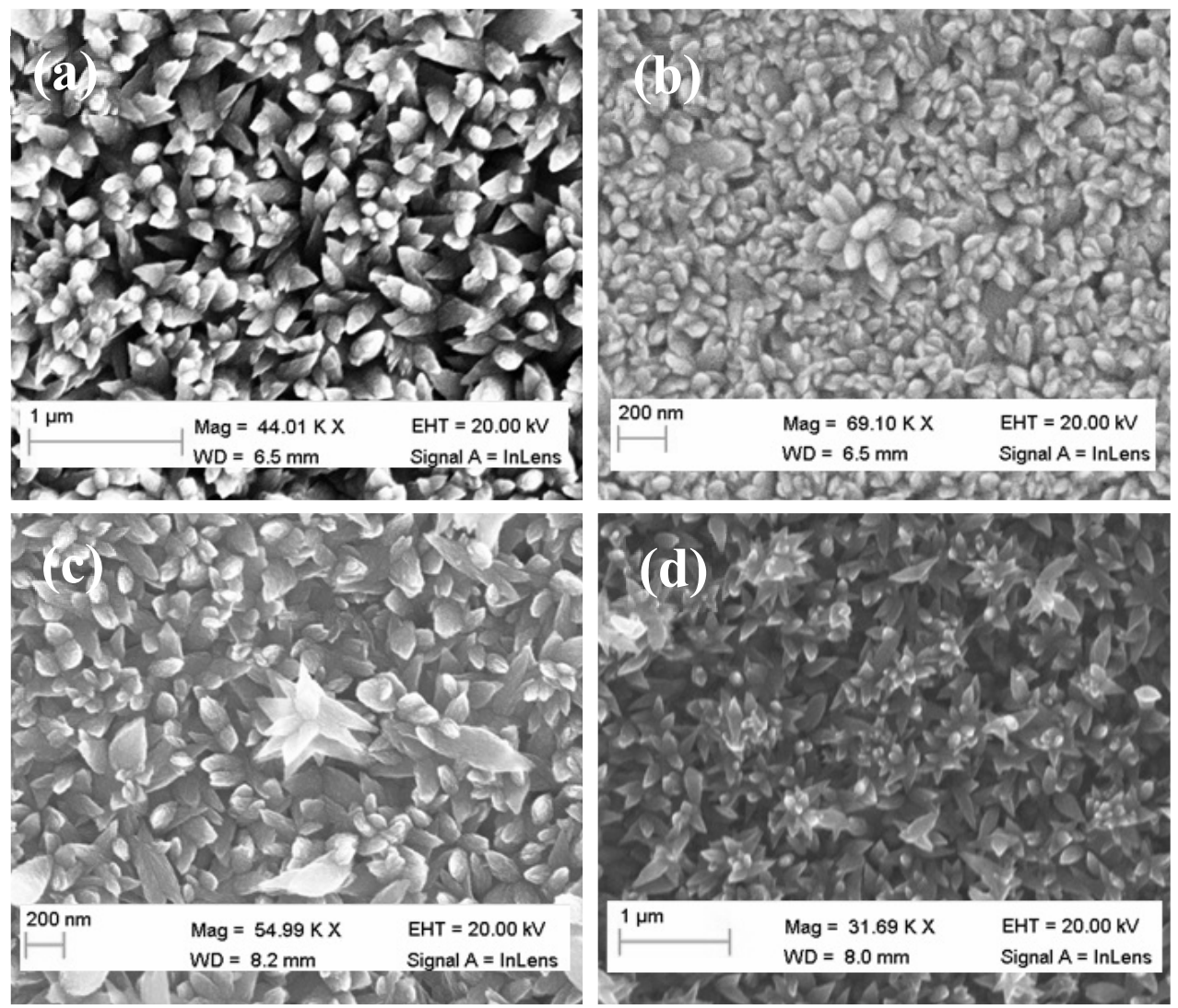

Figure 4. 8: FESEM image of $\mathrm{CuO}$ nanoflowers synthesized by adding different amounts of urea in the growth solution: (a) $0.1 \mathrm{~g}$, (b) $0.4 \mathrm{~g}$, (c) $0.8 \mathrm{~g}$ and (d) $1.0 \mathrm{~g}$ [55].

The FESEM image of the highly dense and well aligned growth of $\mathrm{CuO}$ nanostructures is shown in figure $4.8(\mathrm{a}-\mathrm{d})$. The FESEM data has provided that nanobeads like morphologies of the grown $\mathrm{CuO}$ NSs using the urea as the template for controlling the $\mathrm{CuO}$ NSs morphology has been 
achieved. Different amounts of urea: $0.1 \mathrm{~g}, 0.4 \mathrm{~g}, 0.8 \mathrm{~g}$ and $1.0 \mathrm{~g}$ were added into the growth solution ( $0.025 \mathrm{M}$ concentration of copper nitrate and HMT) to control the effect on the $\mathrm{CuO}$ NSs. FESEM image shows that the morphology is slightly changed by increasing the urea concentration in the growth solution. The size of $\mathrm{CuO}$ NSs is decreased and finally turned into the $\mathrm{CuO}$ nanoflowers. Urea plays an important role in the change of the $\mathrm{CuO}$ NSs which may be due to hydroxide ions $\left(\mathrm{OH}^{-1}\right)$ being provided in large quantities for higher concentrations of urea. In the presence of low concentrations of urea, HMT and urea both assisted the formation of $\mathrm{CuO}$ nanobeads. HMT and urea give the $\mathrm{NH}_{3}$ and $\mathrm{OH}^{-}$, respectively. $\mathrm{NH}_{3}$ also provided $\mathrm{OH}^{-1}$ ions and in doing so the $\mathrm{OH}^{-1}$ concentration is increased in the growth solution for higher amounts of urea. This increases the growth speed that produces the $\mathrm{CuO}$ nanoflowers, as shown in figure 4.8 (d). $\mathrm{CuO}$ is one of the electrochemical materials and it was used as anodic material in some fabricated electrochemical batteries. Due to these advantageous properties of $\mathrm{CuO}$ material, we have grown $\mathrm{CuO}$ nanoflowers with urea using the hydrothermal growth method. They have also been used to develop cadmium ion sensor. Tetrathia-12-crown-4 is a neutral ionophore which has been used with the Polyvinyl Chloride (PVC) membrane electrode for the determination of cadmium ions [118]. Due to the advantages of $\mathrm{CuO}$ NSs such as high surface to volume ratio, high electrocatalytic activity, fast electron transfer and strong electrical signal generation, the Tetrathia-12crown-4 ionophore is functionalized on the $\mathrm{CuO}$ nanoflowers to develop cadmium ion sensor.
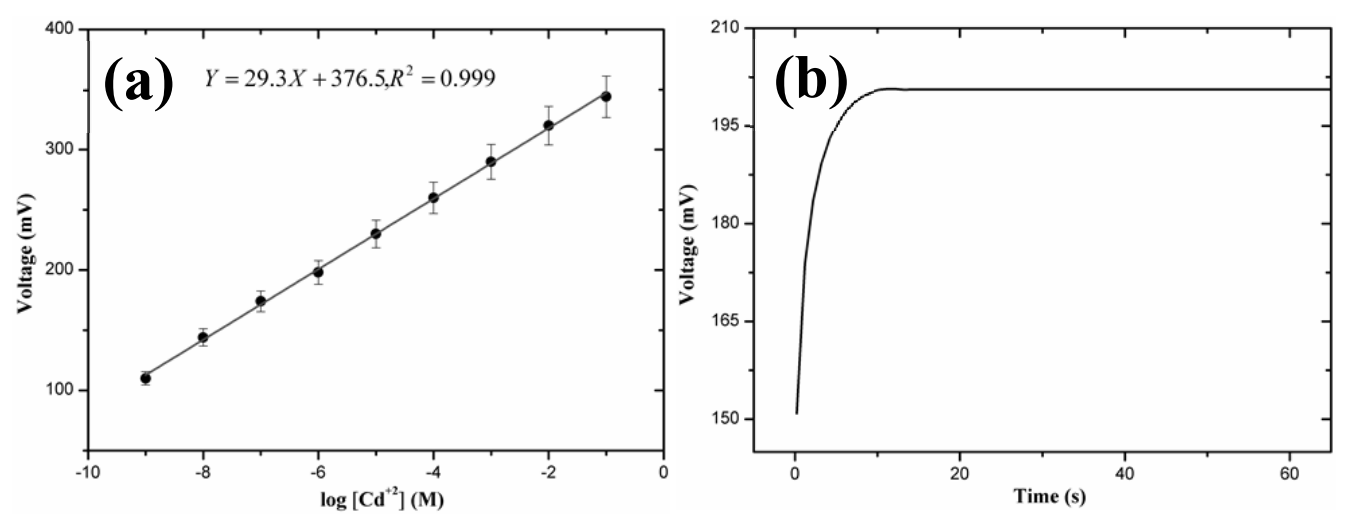

Figure 4. 9: (a) The calibration curve of the proposed $\mathrm{Cd}^{2+}$ sensor and (b) the time response curve measured at a concentration $1.0 \times 10^{-6} \mathrm{M}[55]$. 
The developed sensor has shown a wide detection range for cadmium ion concentration from $1.0 \times 10^{-9}$ to $1.0 \times 10^{-1} \mathrm{M}$ with sensitivity of $29.3 \pm 0.3 \mathrm{mV} /$ decade as shown in figure 4.9 (a). The wide detection range of the proposed $\mathrm{Cd}^{2+}$ ion sensor based on tetrathia-12-crown-4 ionophore may be assigned to the advantageous properties of $\mathrm{CuO}$ nanoflowers. The proposed cadmium ion sensor has shown a stable and highly sensitive response for the detection of cadmium ion concentration. Moreover, this sensor has shown a fast time response of less than $10.0 \mathrm{~s}$ as shown in figure 4.9 (b).

\subsubsection{The growth of $\mathrm{CuO}$ nanosheets and their non-enzymatic glucose sensor application (paper IV)}

In this part of our research work, $\mathrm{CuO}$ nanosheets were grown in a highly alkaline medium on GCGS using the hydrothermal method. The fabricated $\mathrm{CuO}$ nanosheets were used for the development of non-enzymatic glucose sensor device [110]. Results of this research work are discussed below;

The CuO nanosheets were fabricated on GCGS in a growth solution of $\mathrm{pH} 11$. The obtained $\mathrm{CuO}$ nanosheets could be due to the high concentrations of hydroxide ions which improved the speed for the formation of the nanosheets by increasing the number of growth nuclei for the $\mathrm{CuO}$ material. Initially during the growth, some $\mathrm{CuO}$ nuclei with negative or positive charge were produced. Therefore, oppositely charged species on the substrate, including $\mathrm{OH}^{-}$or $\mathrm{Cu}^{2+}$ will be attracted by those nuclei. The collection of these opposite charges provides the formation of $\mathrm{CuO}$ nanosheets. $\mathrm{H}_{2} \mathrm{O}$ also has a significant effect on the morphology and the number of nuclei in $\mathrm{CuO}$ multiple nanosheets nanomaterial. The fabricated $\mathrm{CuO}$ nanosheets have an average thickness of approximately $10-20 \mathrm{~nm}$ as shown in figure 4.10 (a, b). The XPS technique was used to determine the chemical composition of the grown $\mathrm{CuO}$ nanosheets. A full wide scan XPS spectrum of the synthesized CuO NSs is shown in figure 4.11 (a). In figure 4.11 (a) distinct peaks at 284.00 and $531.00 \mathrm{eV}$ are corresponding to the C1s and the O1s, respectively [119]. The three main peaks at $933.30 \mathrm{eV}, 121.10 \mathrm{eV}$ and $77.00 \mathrm{eV}$ are observed and belong to the $\mathrm{Cu} 2 \mathrm{p}, \mathrm{Cu} 3 \mathrm{~s}$ and $\mathrm{Cu} 3 p$, respectively [120]. The XPS spectra of the $\mathrm{Cu} 2 \mathrm{p}$ and the O1s are shown in figure 4.11 (b, c). The peak of $933.60 \mathrm{eV}$ in the $\mathrm{Cu} 2 \mathrm{p}$ spectra corresponds to the binding energy of $\mathrm{Cu}$ 2p3/2 [120] as shown in figure 4.11 (b). The two shake up peaks show the formation of the $\mathrm{CuO}$ compound on GCGS. 

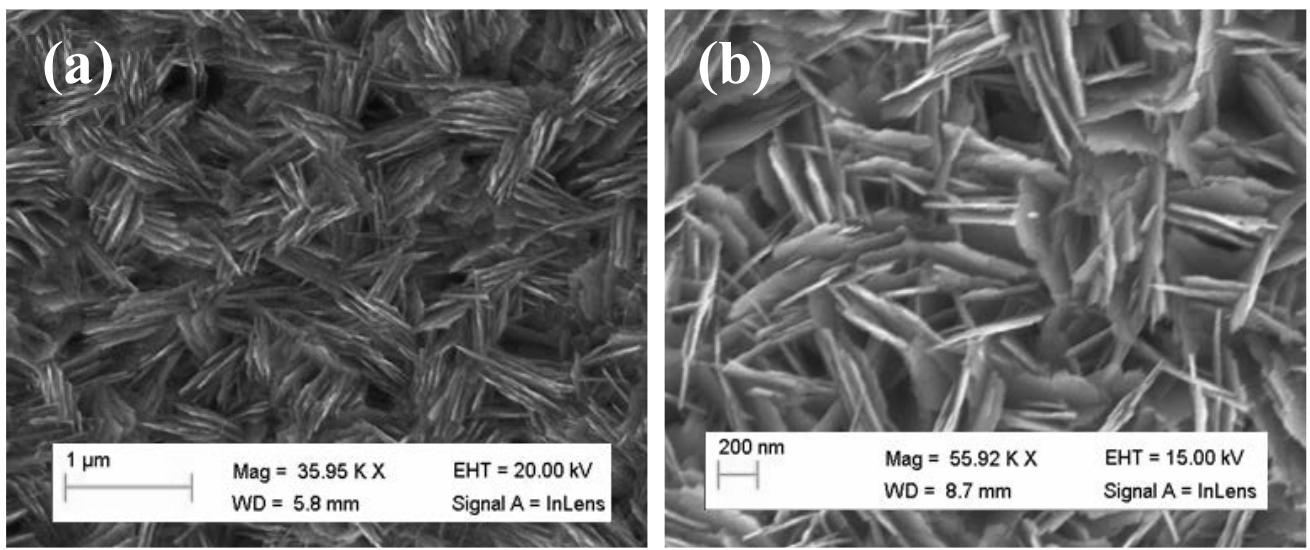

Figure 4. 10: FESEM images of $\mathrm{CuO}$ nanosheets (a) low magnification image and (b) high magnification image [110].
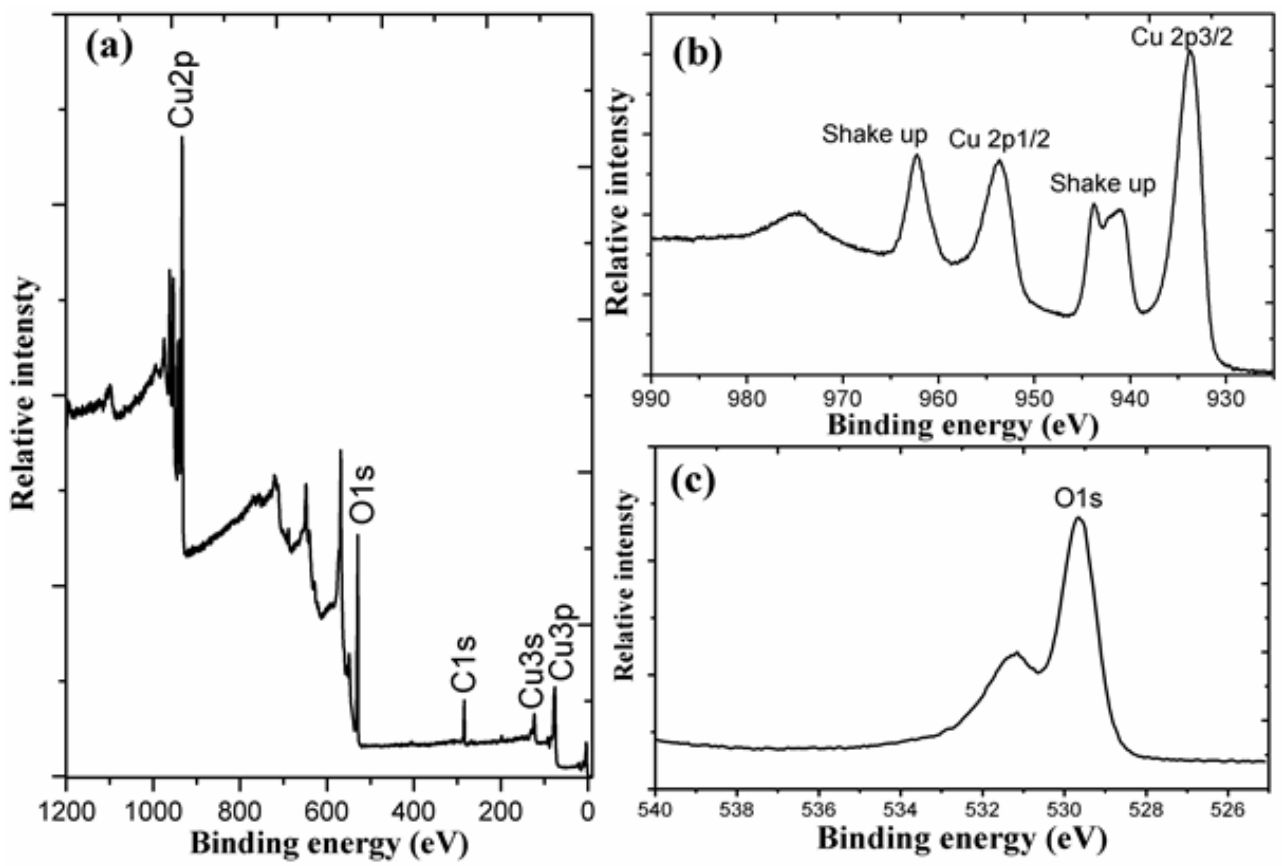

Figure 4. 11: (a) The full XPS spectra of $\mathrm{CuO}$ nanosheets grown using the hydrothermal method, (b) Cu 2p XPS spectra and (c) O 1s XPS spectra [110]. 
The O1s spectrum shows two peaks at $529.47 \mathrm{eV}$ and $531.15 \mathrm{eV}$ which correspond to the $\mathrm{O}^{2-}$ ion and adsorbed oxygen in the $\mathrm{CuO}$ nanomaterials, respectively as shown in figure 4.11 (c). The results of the XPS show that the fabricated $\mathrm{CuO}$ nanosheets are highly pure and composed of $\mathrm{CuO}$ material. In order to understand the oxidation process of the $\mathrm{CuO}$ nanosheets, the amperometric detection of glucose was studied. The amperometric measurement was performed at an applied potential of $0.50 \mathrm{~V}$ for different glucose concentrations in a $0.10 \mathrm{M} \mathrm{NaOH}$ of electrolyte solution. The relationship between the glucose concentration and the current response of the $\mathrm{CuO}$ nanosheets non-enzymatic electrode is shown in figure 4.12 (a). Figure 4.12 (a) show the linear range of glucose concentration from $5.00 \times 10^{-1}-1.00 \times 10^{1} \mathrm{mM}$ with sensitivity of $5.20 \times 10^{2} \mu \mathrm{AmM}^{-1} \mathrm{~cm}^{-2}$ and a correlation coefficient of 0.998 . The presented non- enzymatic glucose sensor exhibited good sensitivity due to the high electro catalytic properties of the $\mathrm{CuO}$ nanosheets. The proposed non-enzymatic glucose sensor based on $\mathrm{CuO}$ nanosheets has a fast response time of approximately 10 s with a steady current signal upon the addition of glucose, as shown in figure $4.12(\mathrm{~b})$.

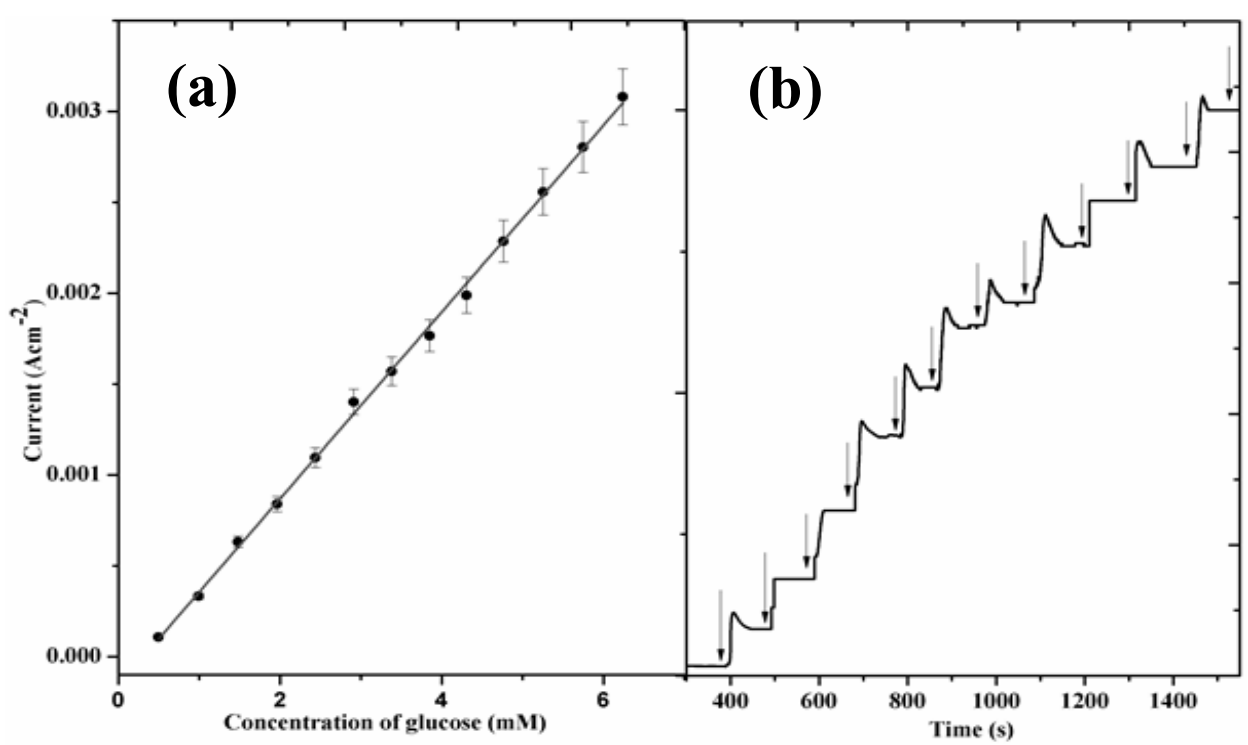

Figure 4. 12: (a) The calibration curve of the non-enzymatic electrode based on the glucose and (b) the response time curve of the proposed glucose sensor with successive addition of glucose in $0.10 \mathrm{M} \mathrm{NaOH}$ solution [110]. 


\subsection{The growth $\mathrm{CuO} / \mathrm{ZnO}$ and $\mathrm{NiO} / \mathrm{ZnO}$ nanocomposite and their sensor and $\mathrm{UV}$ photoreaction application}

In this section, we will present our results on heterostructures of $\mathrm{ZnO} / \mathrm{CuO}$ and $\mathrm{NiO} / \mathrm{ZnO}$. These heterostructures are used for the development of non-enzymatic dopamine sensing device and highly sensitive UV photodetector device, respectively.

\subsubsection{An electrochemical dopamine sensor based on the $\mathrm{ZnO} / \mathrm{CuO}$ nano-hybrid structures (paper V)}

In this part of this research work, a nanocomposite of $\mathrm{ZnO} / \mathrm{CuO}$ was grown on GCGS by the hydrothermal method. The fabricated $\mathrm{ZnO} / \mathrm{CuO}$ composite NSs were used for the detection of dopamine molecules by the amperometric method [107]. The results of this research work are discussed below;

The growth of the $\mathrm{ZnO} / \mathrm{CuO}$ composite NSs on GCGS was performed in two steps by the hydrothermal method. Firstly, the ZnO NRs were grown on GCGS. Then the CuO NSs were grown on the fabricated $\mathrm{ZnO}$ NRs. The morphologies of the $\mathrm{ZnO} / \mathrm{CuO}$ nanocomposite were studied by FESEM. Figure 4.13 (a, b) show the top and the cross section views of the $\mathrm{ZnO} / \mathrm{CuO}$ composite NSs. It can clearly be seen that the $\mathrm{CuO}$ nanoflowers are grown on the ZnO NRs with enhanced surface. The cross sectional FESEM showed that the top surface of the ZnO NRs was etched due to the acidic nature of the copper nitrate growth solution. The crystal quality of the synthesized $\mathrm{ZnO} / \mathrm{CuO}$ composited NSs was measured by XRD. The very intense (002) miler plane peak in figure 4.14 shows well aligned growth of $\mathrm{ZnO}$ NRs on the substrate. From figure 4.14, there are several peaks of ZnO NRs such as (100), (002), (101), (102), (103), (112) and (004) which are denoted by star sign in the XRD pattern. The CuO peaks in the XRD pattern are denoted by the sign of delta. These could be assigned to the monoclinic phase of $\mathrm{CuO}$; there was no any other impurity related peaks that were found in the sample; the gold peak appeared due to the gold on the substrate. The fabricated $\mathrm{ZnO} / \mathrm{CuO}$ nanocomposite was used for the development of non-enzyme dopamine sensor using the cyclic voltammetric (CV) and amperometric methods. To understand the catalytic kinetics of dopamine's oxidation with the $\mathrm{ZnO} / \mathrm{CuO}$ composite NSs, the effect of the scan rate to the current peak response in $2 \mathrm{mM}$ of dopamine was measured; the result of this measurement is shown in figure 4.15 (a). The scan rates were selected from 10 to $100 \mathrm{mVs}^{-1}$; the results show that the current response is linear to the square root of the scan rate. 
This behaviour of the $\mathrm{ZnO} / \mathrm{CuO}$ nanocomposite electrode shows that the electrochemical reaction take place at the electrode surface is diffusion controlled. $\mathrm{CV}$ characterization was investigated for the different dopamine concentrations $(0,2.0,2.9,3.9$ and $5.7 \mathrm{mM})$ in the phosphate buffer solution (PBS) as shown in figure 4. 15 (b).
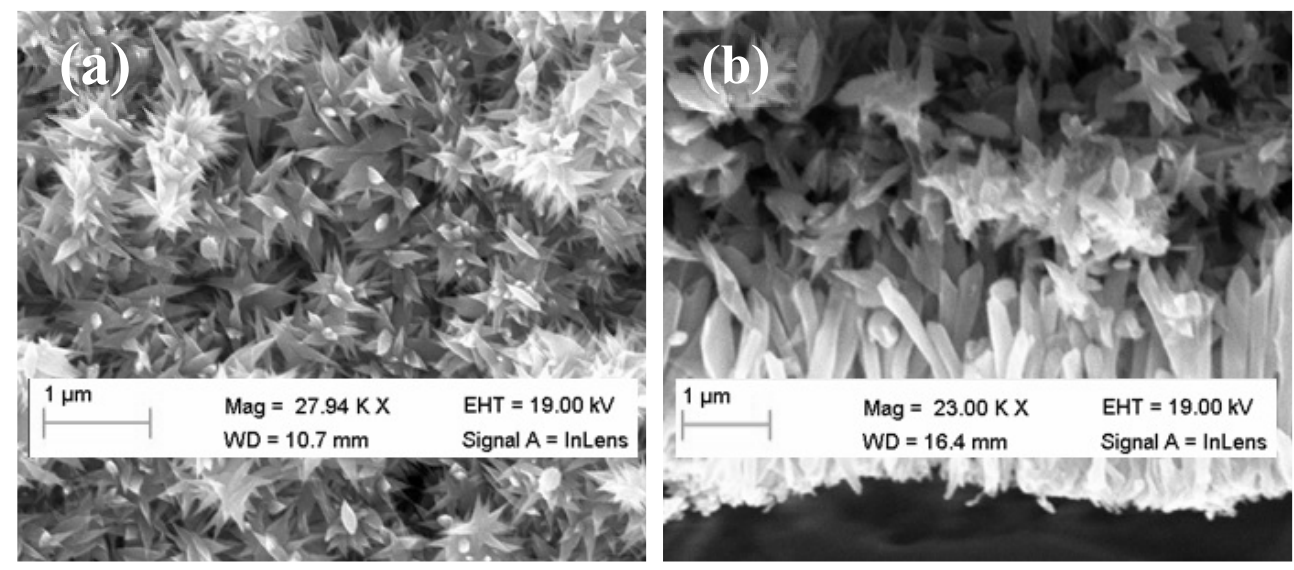

Figure 4. 13: FESEM image of $\mathrm{ZnO} / \mathrm{CuO}$ nano-hybrid structures (a) top view and (b) cross sectional view [107].

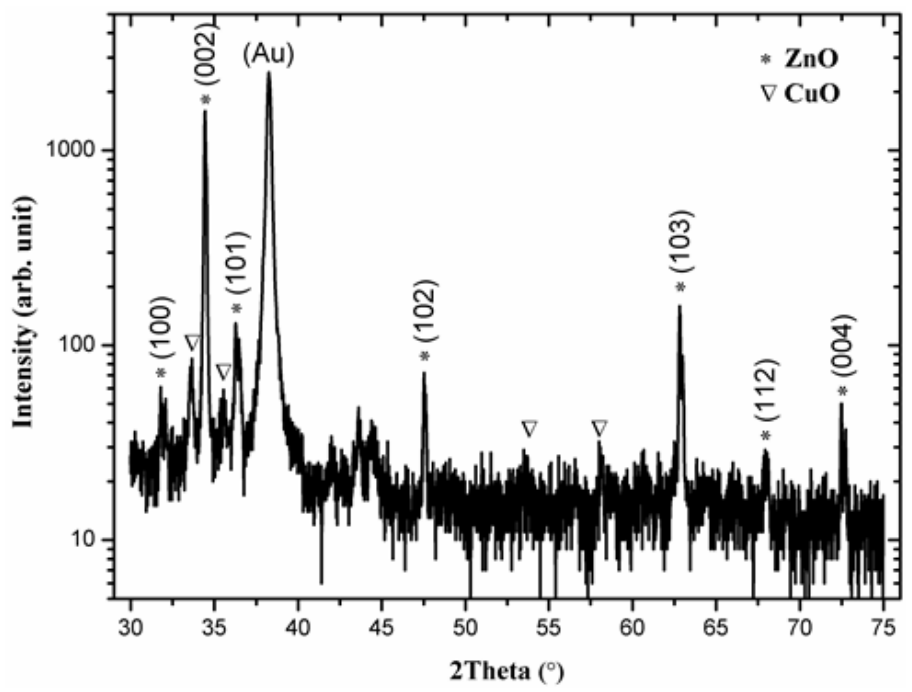

Figure 4. 14: $\mathrm{XRD}$ pattern of $\mathrm{ZnO} / \mathrm{CuO}$ composite NSs grown using the hydrothermal method [107]. 

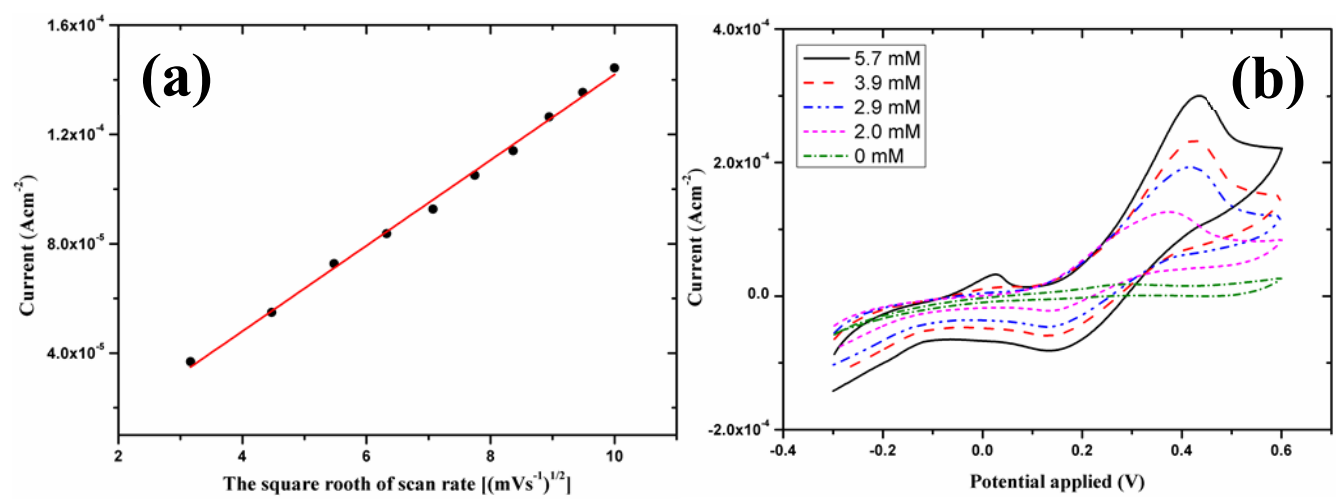

Figure 4. 15: (a) The current response for the fabricated dopamine sensor versus the square root of the scan rate in $2.0 \mathrm{mM}$ concentration of dopamine in PBS and (b) the CV curve at a scan rate of $10 \mathrm{mV}^{-1}$ of the fabricated sensor at different concentrations of dopamine [107].
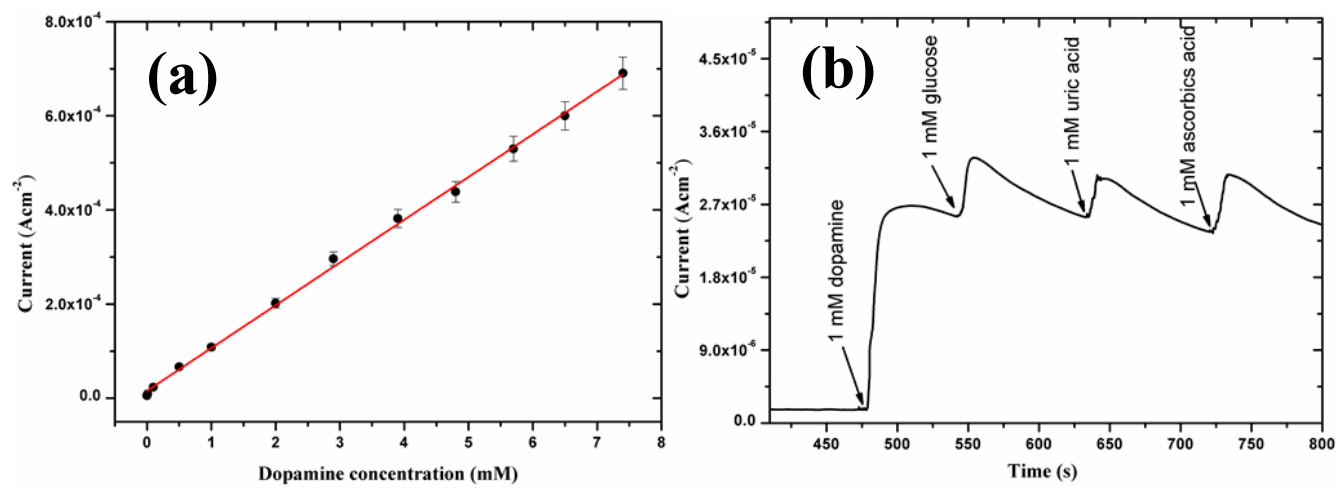

Figure 4. 16: (a) The calibration curve of the current versus dopamine concentration by amperometric measurement at an applied potential of $0.50 \mathrm{~V}$ and (b) the interference response of the fabricated dopamine sensor for $1.0 \mathrm{mM}$ of glucose, uric acid and ascorbic acid [107].

From figure 4.15 (b), it can clearly be seen that the anodic peak, related to the oxidation of the dopamine, and the cathodic peak, associated to the reduction of dopamine are increasing. Figure 4.16 (a) shows the obtained response of the anodic current at $+0.5 \mathrm{~V}$ by amperometric technique versus the dopamine concentration. The anodic current response was found to be linear from $1.0 \times 10^{-3}$ to $8.0 \mathrm{mM}$ range of dopamine concentration with a sensitivity of $90.9 \mu \mathrm{AmM}^{-1} \mathrm{~cm}^{-2}$ 
and a lower detection limit of $1.0 \times 10^{-4} \mathrm{mM}$. For the monitoring of the stability and the usability of the $\mathrm{ZnO} / \mathrm{CuO}$ nano-hybrid structures based sensor, a series of experiments were performed for a period of three weeks. This sensor has shown to retain $90 \%$ of its original activity during the period of study. The small loss in the activity can be due to the loss of $\mathrm{CuO}$ or $\mathrm{ZnO}$ material during measurement or washing steps. The selectivity is one of the most important parameters for the improvement of sensors. There are several common interferents and easily oxidative substances including glucose, uric acid and ascorbic acid, which are mixed with dopamine in the human serum. The selectivity of the fabricated dopamine sensor was measured by comparing the electrochemical response of the sensor in the presence of these interferents. The interference response of the fabricated sensor was tested by adding of $1 \mathrm{mM}$ of each interferent concentration into the dopamine solution. The results showed that the current response of the sensor for these interferents is negligible compared to the dopamine, as shown in figure 4.16 (b).

\subsubsection{Supramolecules-assisted ZnO NSs grown for the fabrication of a sensitive UV photodetector (paper VI)}

This part of the research work studies the UV absorption of ZnO nanosheets synthesized on FTO substrate in a supramolecules-assisted growth solution by the hydrothermal method. The proposed $\mathrm{ZnO}$ nanosheets were used for the development of UV photodetector based on p-NiO/n$\mathrm{ZnO}$ heterostructure. The results of this work are discussed below;

Figure 4.17 (a, b) show FESEM image of ZnO NRs and nanosheets grown on FTO by the hydrothermal method. From those figures it can clearly be seen that well-aligned ZnO NRs have been converted to nanosheets due to the effect of the supramolecules. The $\mathrm{ZnO}$ nanosheets have highly faceted grains of an average size of approximately $200 \mathrm{~nm}$, and are densely packed in a polycrystalline layer. In figure 4.17 (c), it can be seen that the $\mathrm{NiO}$ nanoflowers are in fact a network of thin sheets which cover the $\mathrm{ZnO}$ nanosheets surface. The cross section image of the $\mathrm{ZnO}$ nanosheets and $\mathrm{NiO}$ nanoflowers show that the interface of the $\mathrm{ZnO} / \mathrm{NiO}$ nanocomposite is in good connection as shown in figure 4.17 (d). Figure 4.18 (a) shows the crystal quality and the phase purity of the $\mathrm{ZnO}$ NRs, nanosheets, $\mathrm{NiO}$ nanoflowers and $\mathrm{ZnO} / \mathrm{NiO}$ nanocomposite, which were characterized by XRD pattern. The XRD pattern of the $\mathrm{ZnO} / \mathrm{NiO}$ nanocomposite has exhibited only peaks for the $\mathrm{ZnO}$ and the $\mathrm{NiO}$ NSs. However, a peak related to $\mathrm{SnO}_{2}$ was also observed, which is due to the FTO substrate. The XRD pattern of the ZnO NSs (NRs and nanosheets), $\mathrm{NiO}$ nanoflowers and $\mathrm{ZnO} / \mathrm{NiO}$ heterostructure matched the standard pattern of $\mathrm{ZnO}$ 
hexagonal crystal (JCPDS 01-1136) and cubic NiO (JCPDS 44-1159). Both XRD patterns for the $\mathrm{ZnO}$ NRs and nanosheets show a (002) peak, although for the $\mathrm{ZnO}$ nanosheets the peak intensity is relatively much lower than for the $\mathrm{ZnO}$ nanorods. This is expected since the dominant growth direction of the $\mathrm{ZnO}$ nanosheets is not along the c-axis. This result clearly exhibits that the supramolecules affected the growth direction and resulted in a new morphology. In figure 4.18 (b), the PL spectra of the obtained $\mathrm{ZnO}$ nanosheets and nanorods that were grown on the FTO by the hydrothermal method are shown. This PL spectra have the main high intensity peak at approximately $380 \mathrm{~nm}$, which is related to near band-edge transition in $\mathrm{ZnO}$ because of the recombination of free and bound donor exciton [121].
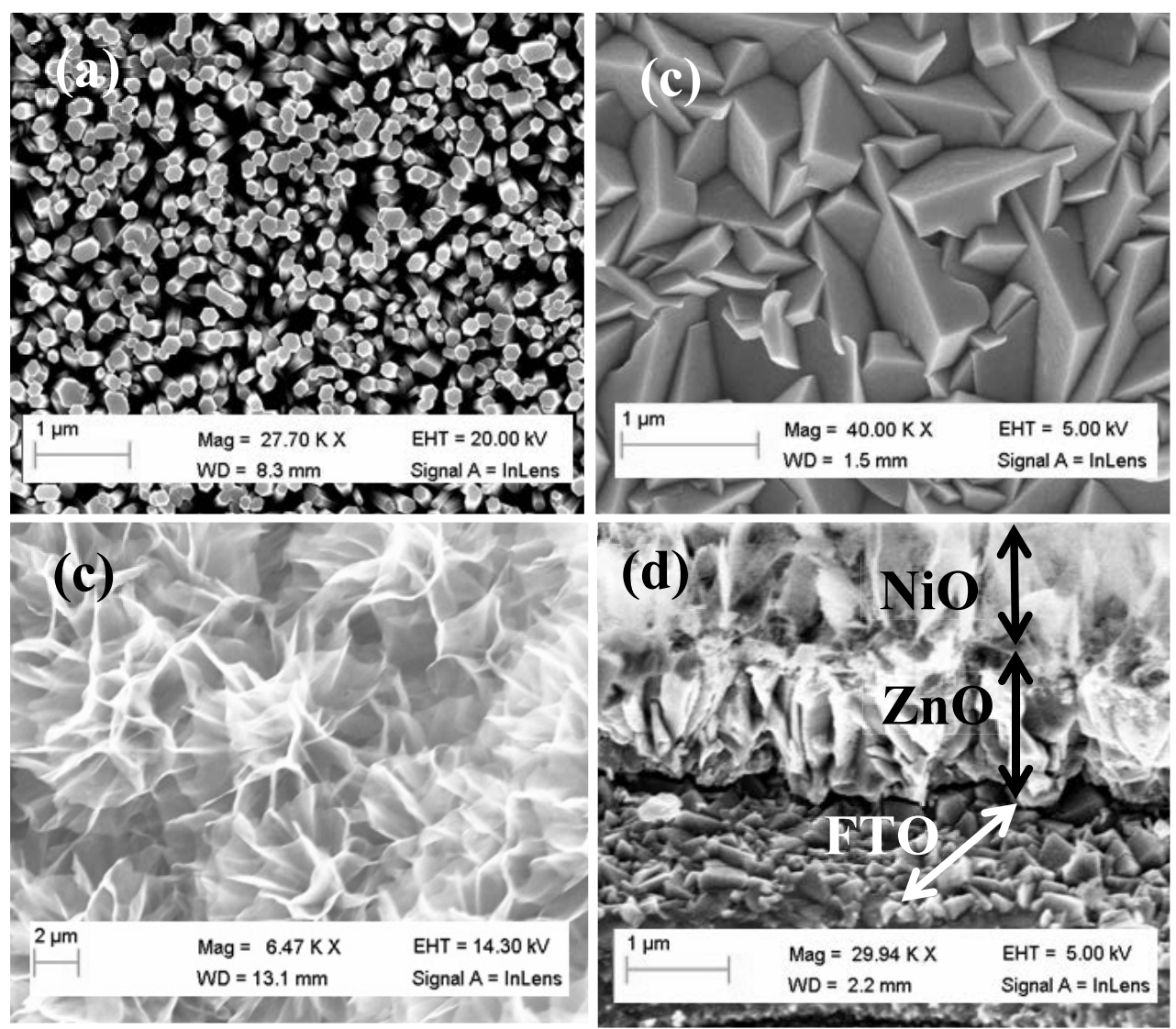

Figure 4. 17: FESEM images of metal oxide nanostructures: (a) $\mathrm{ZnO}$ nanorods, (b) $\mathrm{ZnO}$ nanosheets, (c) $\mathrm{NiO}$ nanoflowers and (d) cross section of $\mathrm{ZnO} / \mathrm{NiO}$ nanocomposite. 

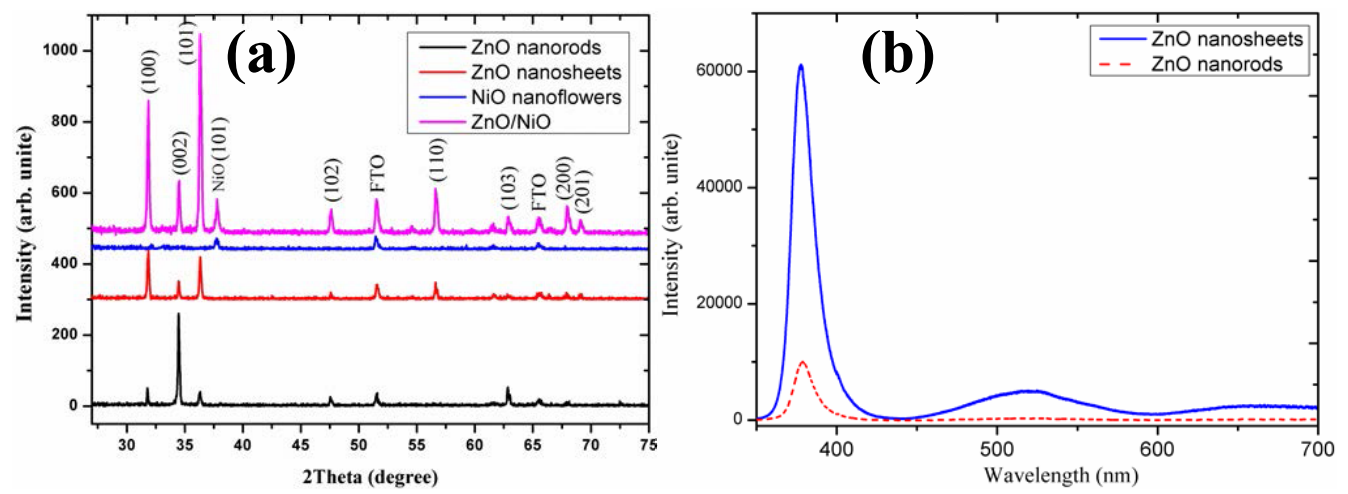

Figure 4. 18: (a) $\mathrm{XRD}$ pattern of $\mathrm{ZnO} / \mathrm{NiO}$ nanocomposite growth on $\mathrm{FTO}$ and (b) the $\mathrm{PL}$ spectra of $\mathrm{ZnO}$ nanosheets (blue solid line) and $\mathrm{ZnO}$ NRs (red dotted line).

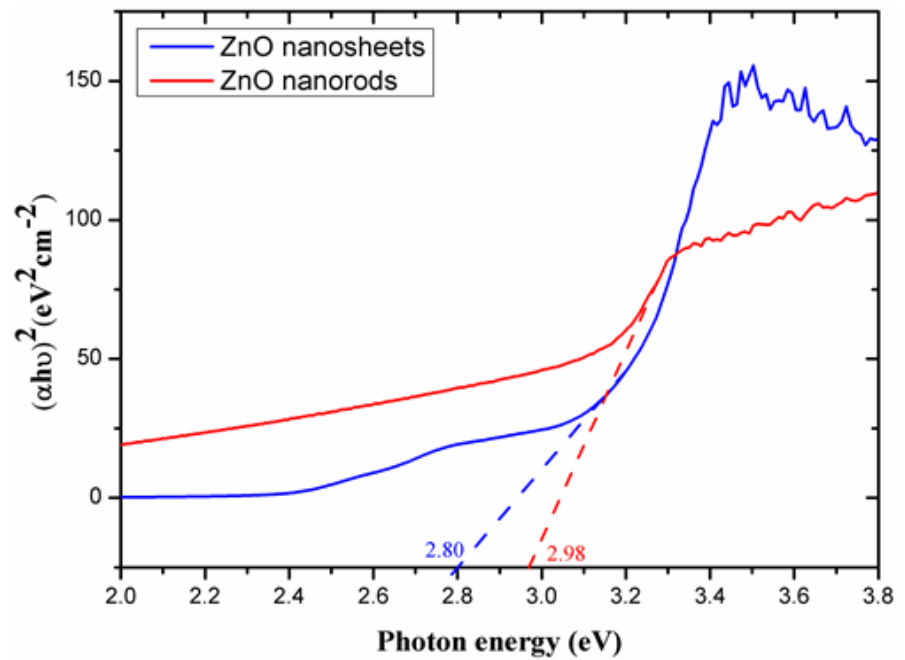

Figure 4. 19: Plot of $(\alpha h v)^{2}$ versus the photon energy for the $\mathrm{ZnO}$ NRs and nanosheets.

The PL spectra also shows two other lower intensity peaks that are related to visible emissions. Those two peaks appeared due to a recombination from deep level defects in the $\mathrm{ZnO}$ materials, like e.g. Oxygen vacancies and other interstitial defects. The $\mathrm{ZnO}$ nanosheets have a stronger intensity of the UV emission than the ZnO NRs because of the effect of the supramolecular to the hydrogen bonding with $\mathrm{ZnO}$ [122]. The other reason for the stronger UV absorption of the $\mathrm{ZnO}$ nanosheets may be due to the presence of many thin leaves leading to relatively larger surface area to volume ratio than the $\mathrm{ZnO}$ nanorods. Beside the modified 
morphology, growth direction and PL spectrum of the $\mathrm{ZnO} \mathrm{NSs}$, the optical band of the $\mathrm{ZnO}$ nanosheets and NRs were investigated using UV-visible absorption tool for comparison. In figure 4.19 , the relationship between the $(\alpha h v)^{2}$ and the photon energy (hv) is plotted. The optical bandgap value of the $\mathrm{ZnO}$ nanosheets was smaller " $2.80 \mathrm{eV}$ " than $\mathrm{ZnO} \mathrm{NRs}$ " $2.98 \mathrm{eV}$ ". Furthermore, for the $\mathrm{ZnO}$ nanosheets, two new bands with a non-pronounced intensity have been observed at around "2.56 eV and $2.79 \mathrm{eV",} \mathrm{respectively.} \mathrm{Simply,} \mathrm{all} \mathrm{these} \mathrm{modulation} \mathrm{in} \mathrm{the} \mathrm{UV/visible}$ spectra could be due to impurities as a direct influence of the added supramolecular species. They can result in electronic energy states within the band gap of the $\mathrm{ZnO}$ nanosheets [123].
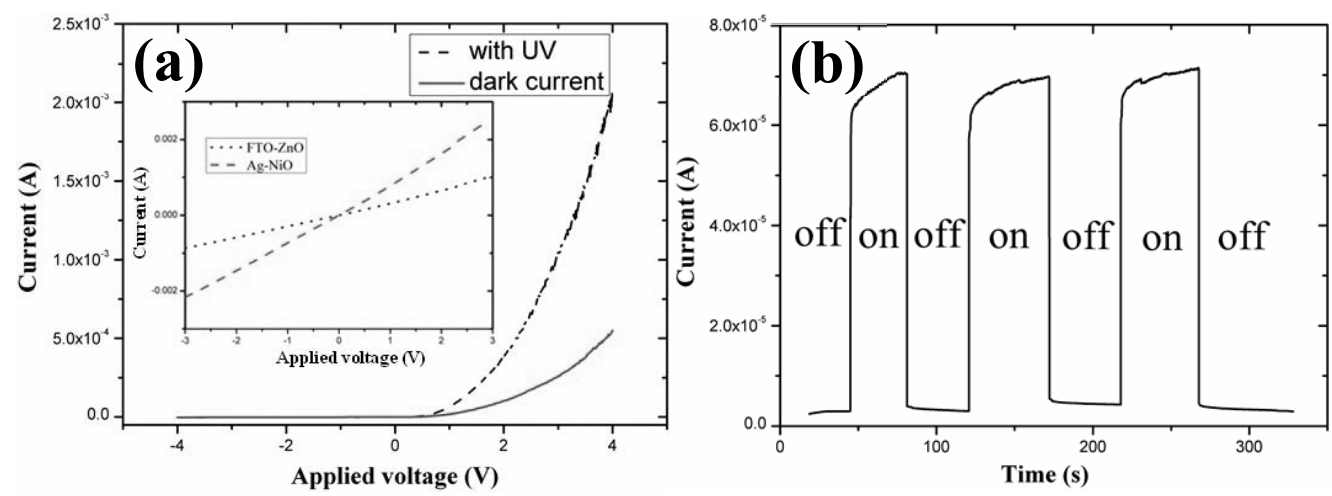

Figure 4. 20: (a) The I-V data obtained in the dark current (solid red line) and under UV light (dotted black line), (b) The time response of $\mathrm{ZnO} / \mathrm{NiO} \mathrm{UV}$ photodetector in conditions of on/off UV light.

Figure 4.20 (a) show the rectifying $\mathrm{I}-\mathrm{V}$ characteristics of the $\mathrm{NiO} / \mathrm{ZnO}$ heterojunction devices performed in the dark and under UV light. The I-V response of the proposed device shows that it is highly rectifying, nonlinear and with a forward threshold voltage of $\sim 0.5 \mathrm{~V}$. The proposed UV photodetector device become highly sensitive to UV light by increasing the photocurrent response in the forward region due to the increased generation of electron-hole pairs in the device, when UV light is applied. The I-V response of the Ag-NiO and FTO-ZnO is shown in the inset in figure 4.20 (a). It can be seen that both I-V response are liner, which shows that the contacts are good ohmic conductors. Hence, the rectifying and nonlinear behavior of the proposed device is due to the $\mathrm{ZnO} / \mathrm{NiO}$ heterojunction. The time response of the proposed $\mathrm{UV}$ photodetector device was measured in two conditions continuously: dark (UV off) and light (UV 
on) as shown in figure 4.20 (b). We have repeated a number of cycles of the UV response during the on/off of the UV light. The results show that the proposed UV photodetector response is repeatable and stable. The free carrier electrons generated from the $\mathrm{ZnO} / \mathrm{NiO} \mathrm{UV}$ photodetector device corresponded to the adsorption/desportion of oxygen molecules. The oxygen molecules are absorbed onto the nanostructures surface and then they capture free electrons from the $\mathrm{ZnO}$ materials. When the UV light is illuminated onto the UV photodetector device, an electron-hole pair is generated. The holes move toward the $\mathrm{ZnO}$ surface for desorbing the oxygen ions, and due to this phenomenon, the thickness of the depletion layer at the surface is decreased. This result in the free carrier electron concentration is increased. The free electrons are collected with the passage of time at desorption and reabsorption of oxygen ions, producing an increasing photocurrent. 


\section{Chapter 5}

\section{Summary}

The main objective of the presented work focused on the synthesis of metal oxide NSs ( $\mathrm{ZnO}, \mathrm{CuO}$ and $\mathrm{NiO}$ ), some of their composites, their characterization and their chemical and optical sensing applications. All metal oxide NSs were grown using the low temperature growth method. This research work is divided into: (i) the growth of the well aligned ZnO NRs using a composite seed layer of nanoparticles and conducting polymer, and the synthesis of novel $\mathrm{CuO}$ nanoflowers and nanosheets using urea and the alkaline medium of $\mathrm{pH} 11$ assisted growth solution, respectively. (ii) $\mathrm{ZnO}$ material, $\mathrm{CuO}$ material and their composite nanostructures were used for chemical and biosensing applications and (iii) $\mathrm{NiO} / \mathrm{ZnO}$ composite NSs were used for UV photodetector application.

Well-aligned ZnO NRs were prepared by the hydrothermal growth method using a composite seed layer of $\mathrm{ZnO}$ nanoparticles and chitosan-polymer in paper I. This research work showed that different concentrations of $\mathrm{ZnO}$ nanoparticles in composite seed layer controlled the size, density, alignment and optical properties of ZnO NRs. In paper II, a comparative study of $\mathrm{ZnO} \mathrm{NRs}$ and thin films have been carried out by investigating chemical and biosensing applications. The result showed that both fabricated sensor devices of ZnO NRs and thin films worked very well, but the sensor device based on ZnO NRs has shown better performance in terms of higher sensitivity and lower detection limit.

$\mathrm{CuO}$ nanoflowers have been prepared by different urea concentrations assisted growth solution in the hydrothermal method. This work showed that the obtained CuO NSs are highly dense, uniform and compromise pure $\mathrm{CuO}$ crystal phase. Moreover, $\mathrm{Cd}^{2+}$ ions has been detected with the obtained $\mathrm{CuO}$ nanoflowers (paper III). The fabricated sensor showed a wide detection range of $\mathrm{Cd}^{2+}$ ions concentration from $1.0 \times 10^{-9}$ to $1.0 \times 10^{-1} \mathrm{M}$ with a high sensitivity of $29.3 \pm 0.3$ $\mathrm{mV} /$ decade and fast response time of approximately 10.0 seconds. In addition, the proposed sensors have also shown a good repeatability, reproducibility, stability and selectivity. Nonenzymatic glucose sensors have been carried out with the growth of $\mathrm{CuO}$ nanosheets in paper IV. The proposed sensor showed wide advantages of compatible size, cheap and simple fabrication. 
Further, the fabricated sensor have a high sensitivity of $5.20 \times 10^{2} \mu \mathrm{A} \cdot \mathrm{mM}^{-1} \cdot \mathrm{cm}^{-2}$, a wide detection range, good selectivity and reproducibility.

In paper $\mathrm{V}$, electrochemical dopamine sensors have been fabricated with the $\mathrm{ZnO} / \mathrm{CuO}$ nano-hybrid structures. The presented devices exhibited a good sensitivity over a wide concentration range of dopamine from $1.0 \times 10^{-3}$ to $8 \mathrm{mM}$ with a lower detection limit of $1.0 \times 10^{-4}$ $\mathrm{mM}$. In addition, the proposed sensor showed good selectivity to ascorbic acid, glucose and uric acid; it has also been observed that good stability and reproducibility after using seven different electrodes. Further, supramolecules-assisted ZnO NSs were synthesized on FTO using the hydrothermal method (paper VI). The research work has exhibited that the supramolecular effected to the morphology, growth direction, crystal quality and improved the UV absorption of ZnO NSs. Furthermore, the obtained $\mathrm{ZnO}$ nanosheets and NiO nanoflowers have been used to fabricate UV photodetector devices. The proposed UV photodetector devices have shown a nonlinear and rectifying I-V characterization, high sensitivity, fast rising and decaying time response $\sim 100$ ms and relatively low leakage current.

Due to the bio-safe properties in many cases and the low cost for fabrication of the metal oxide semiconductors, especially $\mathrm{ZnO}$ nanomaterial, these will be of relevance in my future work. Such work will focus on the intracellular measurement of bio-molecules in blood cells, such as cholesterol and dopamine. This will require the development of $\mathrm{ZnO}$ nanomaterials. These nanomaterials will also be evaluated in my future work on the development of highly efficient and low cost solar cells and energy harvesting nanodevices. 


\section{References}

[1] C. Buzea, I. Pacheco, K. Robbie, Biointerphases, 2 (2007) MR17.

[2] K.E. Drexler (1986) Engines of Creation: The Coming Era of Nanotechnology. Doubleday. ISBN 0-385-19973-2.

[3] K.E. Drexler (1992). Nanosystems: Molecular Machinery, Manufacturing, and Computatin. New York: John Wiley \& Sons. ISBN 0-471-57547-X.

[4] J. Gribbin, M. Gribbin (1997) Richard Feynman: A Life in Science. Dutton. p. 170. ISBN 0-452-27631-4.

[5] M.A. Kazlev (2003) Histry of Nanotechnology. Retrieved 12 May 2011.

[6] N. Taniguchi (1974) On the Basic Concept of Nano-Technology. Proceedings of the International Conference on Production Engineering, Tokyo, 1974, Part II (Japan Society of Precision Engineering).

[7] G. Binnig, H. Rohrer, IBM Journal of Research and Development 30 (1986) 4.

[8] Press release for the 1986 Nobel Prize in Physics.

[9] H.W. Kroto, J.R. Heath, S.C. Brien, R.F. Curl, R.E. Smalley, Nature 318 (1985) 162.

[10] W.W Adams, R.H. Baughman, Science 310 (2005) 1916.

[11] L. V. Radushkevich and V. M. Lukyanovich, J. Phys. Chem. 26 (1952) 88 (in Russain).

[12] A. Turner, G. Wilson, I. Kaube, (1987) Biosensors: Fundamentals and Applications. Oxford, UK: Oxford University Press. p. 770. ISBN 0-198-54724-2.

[13] A. Cavalcanti, B. Shirinzadeh, M. Zhang, L.C. Kretly, Sensors 8 (2008) 2932.

[14] L.C. Clark Jr, Transactions American Society for Artificial Internal Organs 2 (1956) 41.

[15] L.C. Clark Jr, C. Lyons, Annals of the New York Academy of Sciences 102 (1962) 29.

[16] S.J. Updike, J.P. Hicks, Nature 214 (1967) 986.

[17] G.G. Guilbault, J. Montalvo, Journal of the American Chemical Society 91 (1969) 2164.

[18] W.R. Heineman, W.B. Jensen, Biosensors and Bioelectronics 21 (2006) 1403.

[19] P. Bergveld, IEEE Transactions on Biomedical Engineering 17 (1970) 70.

[20] Y. Zhang, M. Yang, N.G. Portney, D. Cui, G. Budak, E. Ozbay, M. Ozkan, C.S. Ozkan, Biomed. Microdev 10 (2008) 321.

[21] D. Cui, J. Nanosci, Nanotechnol 7 (2007) 1298. 
[22] B. Pan, D. Cui, C.S. Ozkan, M. Ozkan, P. Xu, T. Huang, F. Liu, H. Chen, Q. Li, R. He, F. Gao, J. Phys. Chem. C 112 (2008) 939.

[23] B. Pan, D. Cui, P. Xu, Q. Li, T. Huang, R. He, F. Gao, Colloids Surface A 295 (2007) 217.

[24] Z.H. Ibupoto, S.M.U. Ali, C.O. Chey, K. Khun, O. Nur, M. Willander, J. Appl. Phys. 110 (2011) 104702.

[25] B. Pan, D. Cui, Y. Sheng, C. Ozkan, F. Gao, R. He, Q. Li, P. Xu, T. Huang, Cancer Res. 67 (2007) 8156.

[26] D. Cui, F. Tian, S.R. Coyer, J. Wang, B. Pan, F. Gao, R. He, Y. Zhang, J. Nanosci. Nanotechnol. 7 (2007) 1639.

[27] X. You, R. He, F. Gao, J. Shao, B. Pan, D. Cui, Nanotechnology 18 (2007) 035701.

[28] J. Wang, Analyst. 130 (2005) 421.

[29] X. Luo, A. Morrin, A.J. Killard, M.R. Smyth, Electroanalysis 18 (2006) 319.

[30] F. Valentini, G. Palleschi, Anal. Lett. 41 (2008) 479.

[31] N. Chopra, V.G. Gavalas, L.G. Bachas, B.J. Hinds, L.G. Bachas, Anal. Lett. 40 (2007) 2067.

[32] K. Kerman, M. Saito, S. Yamamura, Y. Takamura, E. Tamiya, Trends Anal. Chem. 27 (2008) 585.

[33] D.C. Chow, M.S. Johannes, W.K. Lee, R.L. Clark, S. Zauscher, A. Chilkoti, Materials Today, 8 (2005) 30.

[34] M.H. Huang, S. Mao, H. Feick, H. Yan, Y. Wu, H. Kind, E. Weber, R. Russo, P. Yang, Science 292 (2001)1897.

[35] J.J. Wu, S.C. Liu, Adv. Mater. 14 (2002) 215.

[36] J.J. Wu, S.C. Liu, J. Phys. Chem. B 106 (2002) 9546.

[37] R. Liu, A.A. Vertegel, E.W. Bohannan, T.A. Sorenson, J.A. Switzer, Chem. Mater. 13 (2001) 508.

[38] L. Vayssieres, Adv. Mater.15 (2003) 464.

[39] M. Guoa, P. Diao, S. Cai, J. Solid State Chem. 178 (2005) 1864.

[40] S. Xu, Z.L. Wang, Nano Research, 4 (2011) 1013.

[41] S. Kishwar, M.H. Asif, O. Nur, M. Willander, P.O. Larsson, Nanoscale Research Letters, 5 (2010) 1669. 
[42] A. Manekkathodi, M.Y. Lu, C.W. Wang, L.J. Chen, Advanced Materials 22 (2010) 4059.

[43] B. Postels, M. Kreye, H.H. Wehmann, A. Bakin, N. Boukos, A. Travlos, A. Waag, Superlattice Microst 42 (2007) 425.

[44] Q. Zhang, Z. Yang, B. Ding, Mater. Sci. Forum. 610-613 (2009) 233.

[45] L. Schmidt-Mende, J.L. MacManus-Driscoll, Materials Today 10 (2007) 40.

[46] X. Wang, C.G. Hua, H. Liu, G.J. Du, X. S. He, Y. Xi, Sens. Actuators B 144 (2010) 22.

[47] L.P. Xu, S. Sithambaram, Y.S. Zhang, C.H. Chen, L. Jin, R. Joesten, S.L. Suib, Chem. Mater. 21 (2009)1253.

[48] J.Y. Kim, J.C. Park, H. Kang, H. Song, K.H. Park, Chem. Commun. 46 (2010) 439.

[49] P. Poizot, S. Laruelle, S. Grugeon, L. Dupont, J.M. Tarascon, Nature 407 (2000) 496.

[50] H. Li, Z.X. Wang, L.Q. Chen, X.J. Huang, Adv. Mater. 21 (2009) 4593.

[51] J.Y. Xiang, J.P. Tu, L. Zhang, Y. Zhou, X.L. Wang, S.J. Shi, J. Power Sources 195 (2010) 313.

[52] H.M. Xiao, L.P. Zhu, X.M. Liu, S.Y. Fu, Solid State Commun. 141 (2007) 431.

[53] Z.H. Ibupoto, K. Khun, V. Beni, X. Liu, M. Willander, Sensors, 13 (2013) 7926.

[54] K. Khun, Z.H. Ibupoto, M. Willander, Electroanalysis 25 (2013) 1425.

[55] M.H. Cao, C.W. Hu, Y.H. Wang, Y.H. Guo, C.X. Guo, E.B. Wang, Chem. Commun. 15 (2003) 1884.

[56] H. Sato, T. Minami, S. Takata, T. Yamada, Thin Solid Films 236 (1993) 27.

[57] Z. Xuping, C. Guoping, Thin Solid Films 298 (1997) 53.

[58] Y. Wu, Y. He, T. Wu, W. Weng, H. Wan, Mater. Lett. 61 (2007) 2679.

[59] U. Ozgur, Y.I. Alivov, C. Liu, A. Liu, M.A. Reshchikov, S. Dogan, V. Avrutin, S.J. Cho, H. Morkoc, J. Appl. Phys. 98 (2005) 041301.

[60] C. Jagadish, S.J. Pearton, Zinc oxide bulk, thin films and nanostructures processing, properties and applications, Elsevier, Amsterdam, London, 2006.

[61] A.B. Djurisic, A.M.C. Ng, X.Y. Chen, Prog. Quant. Electron. 34 (2010) 191.

[62] N.H. Alvi, K. Ul Hasan, O. Nur, M. Willander, Nanosc. Res. Lett., 6 (2011) 130.

[63] A.B. Djurisic, Y.H. Leung, K.H. Tam, L. Ding, W.K. Ge, H.Y. Chen, S. Gwo, Appl. Phys. Lett. 88 (2006) 103107.

[64] M. Willander, O. Nur, Q.X. Zhao, L.L. Yang, M. Lorenz, B.Q. Cao, J.Z. Perez, C. Czekalla, G. Zimmermann, M. Grundmann, A. Bakin, A. Behrends, M. Al-Suleiman, A. 
El-Shaer, A.C. Mofor, B. Postels, A. Waag, N. Boukos, A. Travlos, H.S. Kwack, J. Guinard, D.L.S. Dang, Nanotechnology, 20 (2009) 332001.

[65] A. Ashrafi, C. Jagadish, J. Appl. Phys. 102 (2007) 071101.

[66] F. Tuomisto, K. Saarinen, D.C. Look, G.C. Farlow, Phys. Rev. B 72 (2005) 085206.

[67] D. Li, Y.H. Leung, A.B. Djurisic, Z.T. Liu, M.H. Xie, S.L. Shi, S.J. Xu, W.K. Chan, Appl. Phys. Lett. 85 (2004) 1601.

[68] M. Gomi, N. Oohira, K.Ozaki, M. Koyano, J. Appl. Phys. 42 (2003) 481.

[69] A. Janotti, C.G. Van de Walle, Phys. Rew. B 76 (2007) 165202.

[70] C.G. van de Walle, Phys. Rev. Lett. 85 (2000) 1012.

[71] M.H. Asif, S.M.U. Ali, O. Nur, M. Willander, U.H. Englund, F. Elinder, Biosen. Bioelectro. 26 (2010) 1118.

[72] S.M. Usman Ali, N.H. Alvi, Z. Ibupoto, O. Nur, M. Willander, B. Danielsson, Sens. Actu. B 152 (2011) 241.

[73] C.H. Ahn, Y.Y. Kim, D.C. Kim, S.K. Mohanta, H.K. Cho, J. Appl. Phys. 105 (2009) 013502.

[74] D.C. Look, Mater. Sci. Eng. 80 (2001) 383.

[75] T. Olorunyolemi, A. Birnoim, Y. Carmel, O. Wilson, I. Lioyd, S. Smith, R. Campbell, J. Am. Cera. Socie. 85 (2002) 1249.

[76] A.P. Moura, L.S. Cavalcante, J.C. Sczancoski, D.G. Stroppa, E.C. Paris, A.J. Ramirez, J.A. Varela, E. Longo, Adv. Pow. Techno. 21 (2010) 197.

[77] Z.H. Ibupoto, K. Khun, J. Lu, M. Willander, Appl. Phys. Lett. 102 (2013)103701.

[78] K.K. Dey, A. Kumar, R. Shanker, A. Dhawan, M. Wan, R.R. Yadav, A.K. Srivastava, RSC Adv. 2 (2012) 1387.

[79] S.D. Seo, Y.H. Jin, S.H. Lee, H.W. Shim, D.W. Kim, Nanosc. Resea. Lett. 6 (2011) 397.

[80] A. Punnoose, H. Magnone, M.S. Seehra, J. Bonevich, Phys. Rev. B, 64 (2001) 174420.

[81] X. Zhang, Y.G. Guo, W.M. Liu, J.C. Hao, J. Appl. Phys. 103 (2008) 114304.

[82] J.B. Forsyth, S. Hull, J. Phys.: Condensed Matter 3 (1991) 5257.

[83] J. Ghijsen, L.H. Tjeng, J. van Elp, H. Eskes, J. Westerink, G.A. Sawatzky, M.T. Czyzyk, Phys. Rev. B, 38 (1988) 11322.

[84] O. Madelung, Semiconductors: data handbook, Springer, Berlin, 2004. 
[85] K.K. Dey, A.K. Srivastava (2013) Metal oxide nanomaterials: An overview (oxide nanostructures: growth, microstructures and properties) (Boca Raton, FL: Pan Stanford) at press.

[86] S. Chakrabarty, K. Chatterjee, J. Phys. Sci. 13 (2009) 245.

[87] I. Hotovy, J. Huran, J. Janik, A.P. Kobzev, Vacuum 51 (1998) 157.

[88] A. Azens, L. Kullman, G. Vaivars, H. Nordborg, C.G. Granqvist, Solid State Ionics 113115 (1998) 449.

[89] W. Shin, N. Murayama Materials Letters 45 (2000) 302.

[90] S. Shang, K. Xue, D. Chen, X. Jiao, Cryst. Eng. Commun. 13 (2011) 5094.

[91] B. Varghese, M.V. Reddy, Z. Yanwu, C.S. Lit, T.C. Hoong, G.V.S. Rao, B.V.R. Chowdari, A.T.S. Wee, C. T. Lim, C.H. Sow, Chem. Mater. 20 (2008) 3360.

[92] A. Salimi, A. Noorbakhash, E. Sharifi, A. Semnani, Biosens. Bioelectron. 24 (2008) 792.

[93] A.M. Soleimanpour, S.V. Khare, A.H. Jayatissa, ACS Appl. Mater. Interfaces 4 (2012) 4651.

[94] K. Arshak, O. Korostynska, F. Fahim, Sensors 3 (2003)176.

[95] W. Estrada, A.M. Andersson, C.G. Granqvist, J. Appl. Phys. 64 (1988) 3678.

[96] N.N. Khoi, W.W. Smeltzer, J.D. Embury, J. Electrochem. Soc. 122 (1975) 1495.

[97] Q.X. Xia, K.S. Hui, K.N. Hui, D.H. Hwang, S.K. Lee, W. Zhou, Y.R. Cho, S.H. Kwon, Q.M. Wang, Y.G. Son, Mater. Lett. 69 (2012) 69.

[98] I.T.E.O. Zayim, F.Z. Tepehan, N. Ozer, Sol. Energy Mater. Sol. Cells 92 (2008) 164.

[99] G.F. Cai, C.D. Gu, J. Zhang, P.C. Liu, X.L. Wang, Y.H. You, J.P. Tu, Electrochim. Acta, 87 (2013) 341.

[100] T. Maruyama, S. Arai, Sol. Energy Mater. Sol. Cells 30 (1993) 257.

[101] M.A. Abbasi, Z.H. Ibupoto, M. Hussain, Y. Khan,O. Nur, M. Willander, Sensors 12 (2012) 15424.

[102] N.N. Greenwood, A. Earnshaw (1984) Chemistry of the Elements. Oxford: Pergamon Press, 1336-37, ISBN 0-08-022057-6.

[103] T. Manisha, T. Monika, G. Vinay, Analytica Chimica Acta 726 (2012) 93.

[104] A. Zainelabdin, S. Zaman, G. Amin, O. Nur, M. Willander, Cryst Growth Des, 10 (2010) 3250.

[105] C. Pacholski, A. Kornowski, H. Weller, Ange. Chem. Inter. Edit. 41 (2002) 1188. 
[106] K. Khun, Z.H. Ibupoto, S.M. Usman Ali, C.O. Chey, O. Nur, M. Willander, Electroanalysis 24 (2012) 521.

[107] K. Khun, Z.H. Ibupoto, X. Liu, N.A. Mansor, A.P.F. Turner, V. Beni, M. Willander, J. Nanosci. Nanotech. 14 (2014) 6646.

[108] K. Khun, Z.K Ibupoto, M. Willander, Phys. Status Solidi 210 (2013) 2720.

[109] K. Khun, Z.H. Ibupoto, C.O. Chey, Jun. Lu, O. Nur, M. Willander, Applied Surface Science 268 (2013) 37.

[110] Z.H. Ibupoto, K. Khun, V. Beni, X. Liu, M. Willander, Sensor 13 (2012) 7926.

[111] B. Cappella, G. Dietler, Surf. Sci. Repo. 34 (1999) 1.

[112] K. Khun, Z.H. Ibupoto, M.S. AlSalhi, M. Atif, A.A. Ansari, M. Willander, Materials 6 (2013) 4361.

[113] L.E. Greene, M. Law, J. Goldberger, F. Kim, J.C. Johnson, Y. Zhang, R.J. Saykally, P. Yang, Angew. Chem. Int. Ed. 42 (2003) 3031.

[114] L. Vayssieres, K. Keis, A. Hagfeldt, S.E. Lindquist, Chem. Mater. 13 (2001) 4395.

[115] K. Vanheusden, W.L. Warren, C.H. Seager, D.R. Tallant, J.A. Voigt, B.E. Gnade, J. Appl. Phys. 79 (1996) 7983.

[116] K. Khun, Z. H. Ibupoto, O. Nur, M. Willander, J. Sens. 2012 (2012) 696247.

[117] Z.H. Ibupoto, S.M.U. Ali Shah, K. Khun, M. Willander, Sensors 12 (2012) 2456.

[118] M. Shamsipur, M. H. Mashhadizadeh, Talanta 53 (2001) 1065.

[119] M.A. Dar, Q. Ahsanulhaq, Y.S. Kim, J.M. Sohn, W.B. Kim, H.S. Shin, Appl. Surface Sci. 255 (2009) 6279.

[120] Y. Zhang, F. Xu, Y. Sun, Y. Shi, Z. Wen, Z.J. Li, Mater. Chem. 21 (2011) 16949.

[121] X.L. Zhang, K.S. Hui, K.N. Hui, Mater. Resea. Bull. 48 (2013) 305.

[122] S. Manna, A. Saha, A.K. Nandi, Chem. Commun. 45 (2006) 4285.

[123] V.E. Henrich metal-oxide surface, Progress in Surface Science 50 (1995) 77. 


\section{Papers}

The articles associated with this thesis have been removed for copyright reasons. For more details about these see:

http://urn.kb.se/resolve?urn=urn:nbn:se:liu:diva-112865 